\title{
Regimes of Social Cohesion
}

Andy Green, Jan Germen Janmaat and Christine Han

LLAKES Research Paper 1
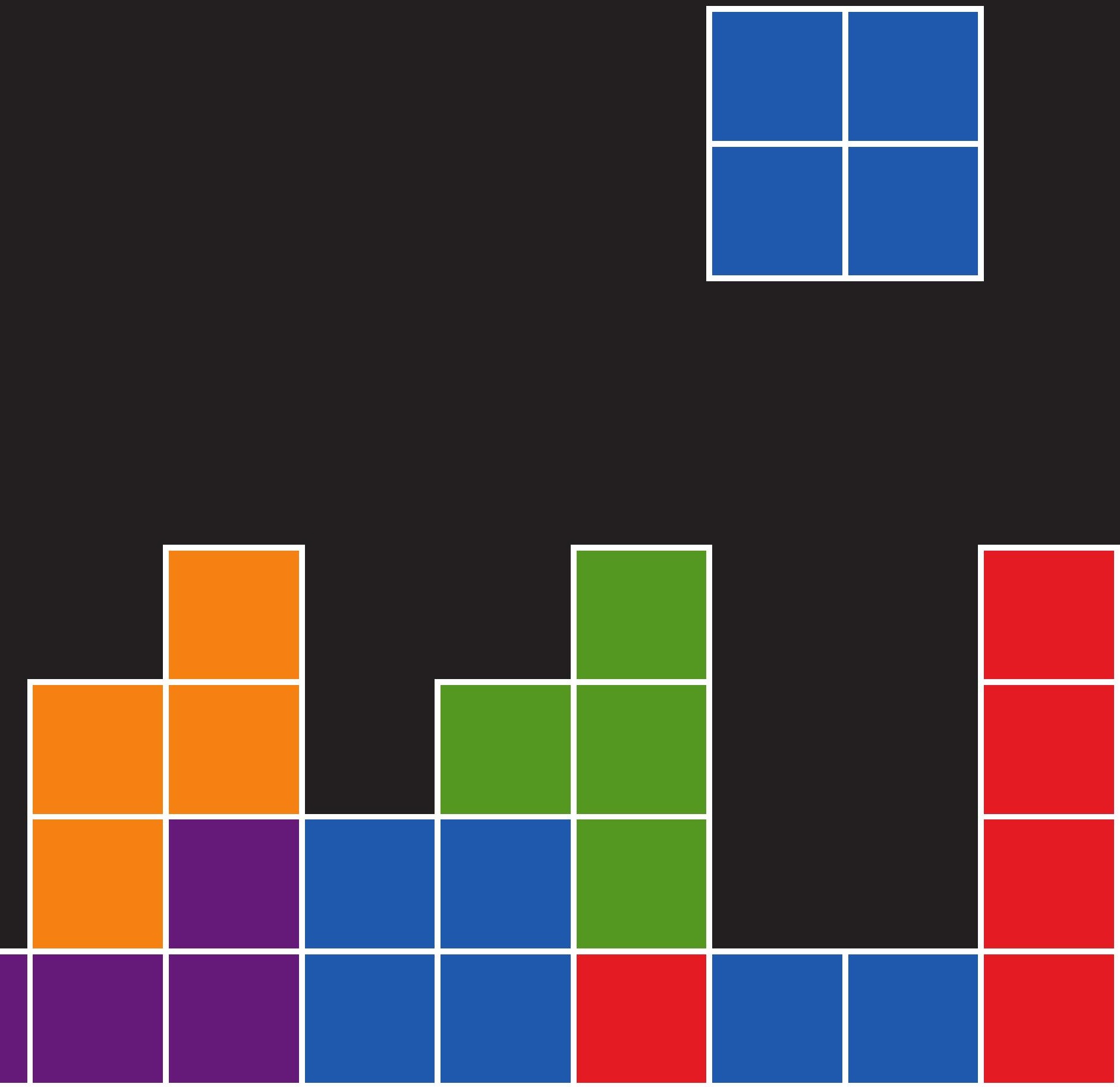


\section{Centre for Learning and Life Chances in Knowledge Economies and Societies}

LLAKES is an ESRC-funded Research Centre.

To request printed copies of this paper or other LLAKES Research Papers, please contact Jeremy Tayler, LLAKES Centre Administrator: j.tayler@ioe.ac.uk.

To view this and other LLAKES Research Papers online, please visit www.llakes.org.uk.

\section{LLAKES Research Papers - Copyright}

This paper may be cited or briefly quoted in line with the usual academic conventions, and for personal use. However, this paper must not be published elsewhere (such as mailing lists, bulletin boards etc.) without the author's explicit permission.

If you copy this paper, you must:

- include this copyright note.

- $\quad$ not use the paper for commercial purposes or gain in any way.

- observe the conventions of academic citation in a version of the following:

Green, A., Janmaat, J. G. and Han, C. (2009) Regimes of Social Cohesion, published by the Centre for Learning and Life Chances in Knowledge Economies and Societies at: http://www.llakes.org.uk. 


\title{
Regimes of Social Cohesion
}

\author{
Andy Green, Jan Germen Janmaat \\ and Christine Han
}

\begin{abstract}
This paper explores the different meanings of social cohesion in historical and contemporary societies and identifies some different 'regimes of social cohesion', and their characteristics, that can be found in western and east Asian societies. It adopts a mixed-method and interdisciplinary approach, drawing on the literatures in comparative historical sociology and comparative political economy, and using both qualitative, logical comparative methods, and quantitative statistical analysis.
\end{abstract}

In the first section of the paper we analyse the constituents of social cohesion which are specified in different definitions-in-use in policy and contemporary academic writing. This leads to a definition of social cohesion which is non-normative and non-exclusive and which can be used in empirical analysis.

The second section seeks to identify the major historical traditions of writings about social cohesion and the social order in western sociology and political philosophy and the logics they imply as to the forces which bind society together.

Sections three and four review some historical evidence for social origins of different traditions of social cohesion in the West, and their subsequent patterns of evolution, based on 'longue durée' accounts of historical development and on 'non-absolute' notions of path dependency.

Section five uses the literature on 'varieties of capitalism' and 'welfare state regimes' to develop some provisional theories about different contemporary forms of social cohesion which may be found in particular regions - or clusters of countries - in the West and east Asia. We call these 'regimes of social cohesion', in the same way that Esping-Andersen (1990) refers to 'welfare regimes' and Michael Walzer (1997) to 'regimes of toleration'. The last section of the paper uses international data on social attitudes and institutional characteristics to test empirically whether such regimes can be identified in terms of regions or country clusters which display particular sets of institutional characteristics and aggregate social attitudes. 


\section{Contents}

$\begin{array}{lr}\text { Introduction } & 4\end{array}$

$\begin{array}{lr}\text { Section One: Definitions of Social Cohesion } & 8\end{array}$

$\begin{array}{ll}\text { Pressure Points } & 11\end{array}$

$\begin{array}{ll}\text { Defining Social Cohesion and Identifying its Regimes } & 19\end{array}$

Section Two: Western Intellectual Traditions of Social Cohesion 22

$\begin{array}{ll}\text { Liberalism } & 24\end{array}$

$\begin{array}{ll}\text { Republicanism } & 28\end{array}$

The Romantic Conservative Tradition 36

Section Three: The Social Origins of Social Cohesion Traditions 41

Section Four: Lineages and Mutations of Social Cohesion Traditions

in the Twentieth Century

$\begin{array}{ll}\text { Liberalism } & 50\end{array}$

Republicanism and Romantic Conservatism $\quad 57$

$\begin{array}{ll}\text { Social Democracy } & 61\end{array}$

Section Five: Contemporary Regimes of Social Cohesion and their

$\begin{array}{lc}\text { Institutional Foundations } & 63\end{array}$

$\begin{array}{ll}\text { The Liberal Regime of Social Cohesion } & 67\end{array}$

$\begin{array}{ll}\text { The Social Market Regime of Social Cohesion } & 74\end{array}$

The Social Democratic Regime of Social Cohesion $\quad 77$

$\begin{array}{ll}\text { A Note on East Asia } & 80\end{array}$

Section Six: Quantitative Analysis of Regimes of Social Cohesion 92

$\begin{array}{ll}\text { Data and methods } & 92\end{array}$

$\begin{array}{ll}\text { Findings } & 102\end{array}$

$\begin{array}{ll}\text { Discussion } & 129\end{array}$

$\begin{array}{ll}\text { Section Seven: Conclusions } & 130\end{array}$

$\begin{array}{ll}\text { Appendix 1: Sources and Survey Items } & 136\end{array}$

$\begin{array}{ll}\text { Appendix 2: Dataset used for Statistical Analyses } & 142\end{array}$

$\begin{array}{ll}\text { References } & 144\end{array}$ 


\section{Figures}

$\begin{array}{lll}1 & \text { Income inequality by country group } & 72\end{array}$

$\begin{array}{lll}2 & \text { Skills equality and general trust } & \mathbf{8 0}\end{array}$

$3 \quad$ Passive civic participation (WVS wave 4) 97

$4 \quad$ Active civic participation (WVS wave 4) 99

$5 \quad$ Cultural versus political conceptions of identity $\quad 99$

$6 \quad$ Xenophobia (ISSP 1995) $\quad 100$

$\begin{array}{llr}7 & \text { Inequality and crime } & 103\end{array}$

8 Wage regulation: union coverage and centralization of wage bargaining 106

$9 \quad$ Income inequality by centralization of wage bargaining 106

$\begin{array}{llr}10 & \text { State involvement and employment protection } & 108\end{array}$

$\begin{array}{llr}11 & \text { Ethno-racial diversity and welfare state } & 108\end{array}$

12 Ethno-racial diversity and value diversity 110

13 Passive and active civic participation $\quad 111$

$14 \quad$ Freedom versus equality and merit versus equality 112

15 Conceptions of nationhood and xenophobia 113

16 Ethnic tolerance: xenophobia and acceptance of immigrants as neighbours 114

17 Social hierarchy and gender equality 116

18 Output hierarchical cluster analysis on all indicators 117

19 Cluster analysis based on administrative indicators only 119

20 Cluster analysis on all administrative indicators including union coverage and $\begin{array}{ll}\text { centralization of wage bargains } & 120\end{array}$

$21 \quad$ Cluster analysis on indicators drawn from opinion surveys 121

$22 \quad$ Social democracy and liberalism $\quad 127$

$\begin{array}{lll}23 & \text { Diversity, tolerance and liberalism } & 128\end{array}$

\section{Tables}

1 Components of social cohesion regimes $\quad 94$

2 Countries associated with hypothesised social cohesion regimes 101

$\begin{array}{lll}3 & \text { Indexes reflecting social cohesion traditions } & 123\end{array}$

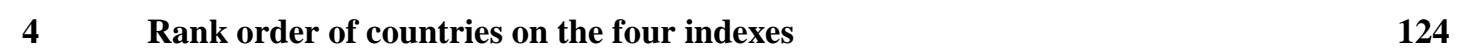

$\begin{array}{llr}5 & \text { Results of factor analysis } & 126\end{array}$ 


\section{Introduction}

The term social cohesion has been increasingly invoked amongst policy-makers, both nationally and internationally, since the late 1980s. Its frequent usage reflects widespread and diverse concerns about the effects of social change on the social fabric - not least those that may arise from the increasing inequality and social diversity that accompanies globalisation. With the 2008 financial crisis and subsequent global recession comes mounting unemployment, and such concerns are now necessarily intensified. At the same time the concept of social cohesion has seen a revival in social theory (Chan, To and Chan, 2006; Dubet (forthcoming); Green, Preston and Janmaat, 2006; Gough and Olafsson, 1999; Osberg, 2003). As Jane Jenson (1998) has rightly noted, questions of social order and cohesion tend to surface at times of rapid social change. The major efflorescence of writings on social cohesion in the nineteenth century - by Comte, Durkheim, Tőnnies and others - coincided with the transition to industrial capitalism in Europe, and was a response to the social dislocations that this entailed. In our own time, it has been rapid globalisation, and its attendant effects, which have acted as the spur (Green, Preston and Janmaat, 2006).

Politicians and social commentators of different stripes have identified threats, or potential threats, to social cohesion, from: rising income inequality (Wilkinson and Pickett, 2009; OECD, 1997) unemployment and crime (Jenson, 1998; OECD, 1997); the decline of the traditional family (Fukuyama, 1999) and religious observance (CPGNIS, 2007); increased immigration (Council of Europe, 2004; CPGNIS, 2007) and the segregation of migrant communities (Cantle, 2001); the proliferation of identity politics and prevailing mores of individualism and self-interest (Reich, 2000; Touraine, 2000); and political extremism and terrorism (CPGNIS, 2007). Many have claimed that social cohesion is in decline - a view supported by Robert Putnam's (2000) research on the attenuation of social capital in the USA (which he equates with declining social cohesion). To Putnam associational life has atrophied with the passing of the socially-concerned 'New Deal' generation and the advent of more individualistic younger generations. For the cohorts of Xers and Yers coming to adulthood post 1960, according to Putnam, watching TV and other individualised pursuits have substantially replaced the more convivial associational activities which are the lifeblood of social capital - hence leading to the overall decline in the vitality of civic life.

Overarching these specific - and empirically debateable - trends, has been the allegedly centrifugal effect of globalisation which, at the same time as it increases global 
interconnectedness, has dislocated communities and eroded many of the traditional sources of social cohesion (Green, Preston and Janmaat, 2006). To Manuel Castells, the major theorist of global change, globalisation has diminished the effective power of nation states and thus reduced the hold of national identity (Castells, 1997). In its place has emerged a multiplicity of group identities - based on ethnicity, religion, region and lifestyle - whose fragmentation narrows the ambit of trust, reciprocity and collective identification. For Castells, as for other social theorists, such as Delanty (2000) and Touraine (2000), identity and citizenship have parted company. This 'dissolution of shared identities, which is tantamount to the dissolution of society as a meaningful social system,' writes Castells, 'may well be the state of affairs of our time.' (Castells, 1997, 355). Such pessimistic views are by no means universal, and the evidence for each of the trends cited is contested. However, concern about the sustainability of social cohesion is certainly widespread. The term is thus in constant use in both policy and research publications and is likely to remain so, not least with the increasing unemployment and related social problems that will accompany the current global recession.

Social cohesion, however, is a term which is both widely used and widely abused. It has considerable emotive power but, like many ideologically- and symbolically- freighted terms, lacks precise definition. Those who have mapped its current usage (Beauvais and Jenson, 2002; Bernard, 1999) acknowledge this, but describe it as a 'multi-facetted' 'quasi-concept' which, despite its unscientific nature, has policy utility as a 'framing concept.' (Beauvais and Jenson, 2002). Precisely how it is defined will vary from context to context, they say, depending on the issues it is being used to frame. This is no doubt the case in terms of its policy usage, and may be inevitable despite the rather long tradition of more rigorous theoretical writing on the subject in both political philosophy and sociology. However, this does not obviate the problems of using the term in social scientific analysis.

There are at least four major difficulties with the way the term is currently deployed. Firstly, it is almost always used in a normative fashion - that is to say as a signifier for a positive condition for which we ought to strive. This, as with all normative terminology in social science, creates problems for objective analysis, even within a critical realist epistemology that recognises that subjective beliefs and ideological forces are constitutive of the reality which we seek to understand and which exists independently of our perceptions of it (Bhaskar, 2009). On the one hand, where social cohesion is defined in a particular normative fashion, according to the political preferences of the researcher or policy analyst, this pre- 
empts analysis of the whole phenomenon, including the different forms of social cohesion which may exist in the real world. On the other hand, it assumes that social cohesion is always 'a good thing' which may not invariably be the case. Too much cohesion can, arguably, lead to social insularity and backwardness (Banfield, 1958), economic sclerosis (Olson, 1971) or to a failure to address substantive injustices in society (cf Marx on religion as the 'opium of the people' in his 'Critique of Hegel's Philosophy of Rights', 1973). Secondly, the term is often defined through the mere aggregation of socially 'desirable' attributes, such as trust, tolerance, active citizenship and so on. These may have no necessary relation to each other and their aggregation thus fails to provide a coherent definition. Thirdly, social cohesion is often defined in terms of its supposed causes (eg equality or welfare states) or effects (eg. greater well-being or faster economic growth). This is problematic not only, again, because it narrows the range of phenomena that may be analysed as possible incidents of social cohesion, but also because it then prevents any analysis of the causes and effects which are already endogenous to the definition. Including causes and effects in the definition amounts to arguing by definition - a logical fallacy which philosophers call 'petitio principii.' (Durkheim, 1982).

Fourthly, definitions of social cohesion are often confused as to their intended level of analysis and thus their units of analysis. Most people use the term to refer to whole societies (usually states); but others, like Putnam (2000), conflate it with 'community cohesion’ or even with 'social capital', the latter normally deemed to refer to characteristics of individuals or to relationships amongst individuals in bounded groups and communities (Coleman, 1988). The European Commission sometimes uses the term 'social cohesion' to refer to structural cohesion at the supra-national regional level, as well as to societal bonding. This multiple usage not only causes conceptual confusion; it may also lead quantitative researchers into 'ecological' or 'cross-level' fallacies whereby statistical effects at one level are falsely imputed from data gathered at a different level (Smelser, 1976). An example would be the frequent assumption that because more educated individuals tend to more tolerant in some developed modern societies, more educated societies are always more tolerant - which is, historically, clearly not true (see discussion in Green et al, 2006, chapter 3). ${ }^{1}$ All of these usages create barriers to rigorous analysis and have deprived the term social cohesion of

\footnotetext{
${ }^{1}$ Wilkinson (1996) also shows the fallacy in the assumption that because richer people tend to be healthier richer societies are healthier can poorer ones. Above a certain level of national prosperity prosperity (at middle income levels) this does not hold true.
} 
much of the explanatory power that former generations of sociologists and political philosophers discovered in the concept.

This paper aims to do some necessary conceptual ground clearing. The analysis seeks to establish how the term social cohesion can be used in a more scientific way which advances theory and, at the same time, provides a basis for empirical analysis. The paper seeks to provide a usable, non-normative and non-exclusive definition of social cohesion, which can then be operationalised in research to analyse the difference forms of social cohesion which may be identified in actual societies - the non-normative social types which Durkheim analysed in The Division of Labour in Society (1964).

In the first section of the paper we analyse the constituents of social cohesion which are specified in different definitions-in-use in policy and contemporary academic writing. The fault lines between different definitions are identified and some empirical evidence is presented on the relationships - or lack of such - between the constituent components of different definitions. This leads to a definition of social cohesion which is non-normative and non-exclusive and which can be used in empirical analysis. The second section seeks to identify the major historical traditions of writings about social cohesion and the social order in western sociology and political philosophy and the logics they imply as to the forces which bind society together. Sections three and four review some historical evidence for social origins of different traditions of social cohesion in the West, and their subsequent patterns of evolution, based on 'longue durée' accounts of historical development and on 'non-absolute' notions of path dependency. Section five uses the literature on 'varieties of capitalism' and 'welfare state regimes' to develop some provisional theories about different contemporary forms of social cohesion which may be found in particular regions - or clusters of countries in the West and in east Asia. We call these 'regimes of social cohesion', in the same way that Esping-Andersen refers to 'welfare regimes' (1990) and Michael Walzer to 'regimes of toleration' (Walzer, 1997). The last section of the paper uses international data on social attitudes and institutional characteristics to test empirically whether such regimes can be identified in terms of regions or country clusters which display particular sets of institutional characteristics and aggregate social attitudes. It should be emphasised that, despite the order of presentation, the theoretical and statistical analyses of post-war regimes have been developed concurrently, and have informed each other. 


\section{Section One: Definitions of Social Cohesion}

As suggested above, definitions of social cohesion in current research and policy literature are frequently additive in nature. That is to say they invoke a number of societal characteristics which are taken to be constitutive of a cohesive society. These generally include characteristics which relate to social attitudes and behaviours, but they can also include institutional features of societies which are taken to be necessary for cohesion to exist. The social attitudes and behaviours commonly invoked include:

- Shared values and goals (such as liberty, democracy, meritocracy, equality etc)

- A sense of belonging and common identity (including national and other forms of identity)

- Tolerance and respect for other individuals and cultures

- Interpersonal and institutional trust

- Civic cooperation

- Active civic participation

- Law-abiding behaviour (low crime rates)

The societal institutions deemed to be pre-requisite for social cohesion are often cited as:

- Institution for the sharing of risk and providing social protection (the welfare state)

- Redistributive mechanisms (such as taxes) to foster equality or equality of opportunity

- Conflict resolution mechanisms.

However, not all definitions-in-use of social cohesion include all of these characteristics or emphasise them in equal measure. Mappings of policy perspectives on social cohesion by Jenson (1998), Beauvais and Jenson (2002) and Bernard (1999) suggest different typologies for distinguishing concepts of social cohesion. Beauvais and Jenson (2002), following Berger -Schmitt (2000), suggest that we can distinguish broadly between definitions of social cohesion which emphasise social bonds and associational activity (social capital type attributes) and those which emphasise 'solidarity and equality'. Bernard distinguishes 
between definitions which emphasise: 1) liberty and equality (labelled 'inclusive democracy' - ie welfare States; 2) equality and solidarity (participatory democracy - ie social democracy) and 3) liberty and solidarity (pluralist democracy). The tensions suggested here between liberty and equality will be familiar to all students of philosophical liberalism and can be clearly identified in the policy discourses. The exact meaning of solidarity in Bernard's tripodic typology is harder to decipher, but it is clear in Jenson (1998) that the term is being used in the French 'republican' sense, familiar to social scientists from the work of Durkheim, which involves a sense of social interdependency and common identity and values.

Jenson's distinction does indeed provide a good point of departure for distinguishing between different discourses. Some definitions of social cohesion place much greater emphasis on common values and common identities than others. Jenson cites a definition from the French Commissariat Général du Plan which refers to common values and identities and links these with a sense of belonging. According to this 'social cohesion is a set of social processes that help instil in individuals the sense of belonging to the same community and the feeling that they are recognized as members of that community.' (quoted in Jenson, 1988, 4). The Council of Europe, starting from a human rights-based perspective, defines a cohesive society as 'a mutually supportive community of free individuals pursuing common goals by democratic means.' (Council of Europe, 2004, 3). They also note the importance of equality and respect for the individual in fostering social cohesion, but a strong emphasis is again placed on belonging and shared values, though with the latter conceived at various different levels. 'Social Cohesion,' according to their background study, 'comprises a sense of belonging to a family, a social group, a neighbourhood, a workplace, a country...' (Heydt, 2003, 12). They are careful to stress that this must not be exclusive and may involve multiple identities, but the main report nevertheless reiterates the importance of shared values, emphasising the need for 'rebuilding a sense of society, of belonging, of commitment to shared gaols.' (Heydt, 2003, 12). Judith Maxwell’s (1996) definition fulsomely combines both the egalitarian and solidaristic dimensions: 'social cohesion involves building shared values and communities of interpretation, reducing disparities in wealth and income, and generally enabling people to have a sense that they are engaged in a common enterprise, facing shared challenges, and that they are members of the same community.' (quoted in Jenson, 1998, 3). 
Definitions which invoke equality, shared values and common identities are certainly common in debates about social cohesion. However, they are not ones that everyone would accept. Increasing social diversity, as both Jenson (1998) and Bernard (1999) point out, makes shared values and common identities difficult to achieve, and would not in any case be desirable to many people. As Jenson notes, too much value conformity may be socially stultifying and can contradict other principles of freedom and respect for other cultures. Jenson's own (1998) definition of social cohesion avoids making either equality or 'shared values' a constitutive condition. The term social cohesion, she writes, 'is used to describe a process more than a condition or end state, while it is seen as involving a sense of commitment, and a desire to live together in some harmony.' (op cit, 1) The emphasis on process and 'getting on together', as opposed to more 'demanding' criteria of shared values and identities, can also be found in the British report on 'Our Shared Future' from the Commission on Integration and Cohesion (2007; chaired by Darra Singh). This report makes much of what might be considered old-fashioned procedural protocols of social interaction, including 'courtesy' and 'hospitality', but does not appeal to more expansive notions of shared values and identities. 'Integration and cohesion,' the report states 'is no longer a special programme or project. It is also not about race, faith, or other forms of group status or identity. It is simply about how we all get on and secure benefits that are mutually desirable for our communities and ourselves.' (ibid, 5). The report does not require allegiance to a dominant identity or value system. Rather it envisages a diversity of communities with different identities and values which adapt to each other in a spirit of mutual respect, guided by norms of hospitality and courtesy. Social cohesion and integration are conceptually differentiated but act in mutually reinforcing ways. 'Cohesion is principally the process that must happen in all communities to ensure different groups of people get on together; while integration is principally the process that ensures new residents and existing residents adapt to one another.' (ibid, 36)

Common identities and shared values (beyond perhaps the minimum of 'core values' advocated in the Denham (2001) Report in Britain- Denham) are clearly not a precondition for social cohesion in much of the policy writing within the liberal tradition, even though they are more strongly asserted within what may be called the 'republican tradition' (about which distinction more later). Likewise equality only appears in some versions of social cohesion, and only features strongly in the more social democratic traditions. Within liberal discourses 
on social cohesion there tends to be a stress on equality of opportunity at the most, and on meritocracy as a necessary legitimating principle of society (Parsons, 1968).

It should also be noted that combinations other than those represented by 'liberalism' and 'republicanism' are possible. Some conceptions of social cohesion place a strong emphasis on shared values and identities without subscribing strongly to principles of economic equality (although they may subscribe to equal civic and political rights). The communitarian tradition in the USA (Etzioni, 1993; Taylor, 2005) sets great store in the socially binding effects of shared community values and identities, without stressing equality as a condition of community cohesion. Likewise social capital theorists, such as Robert Putnam, see shared norms and values at the community level, as well as a lively civic association, as being crucial to a strong civic culture but rarely discuss the impact of economic equality on these (Putnam, 2000). A recent report from the British Conservative Party 'Long Term Policy Group on National and International Security' in Britain exemplifies another variety of this combination (CPGNIS, 2007). This report, which is largely about the threats of terrorism, notes a number of social trends which it says may undermine social cohesion, including increased social mobility, social liberalisation, the decline in religious observance, continuing immigration and the growth of multiple identities. Interestingly income inequality is not mentioned amongst these 'centrifugal forces' and the promotion of 'equality' does not feature in the report as a means of reinforcing social cohesion. However, the report does stress the need for 'a united society based on a shared ethos', lamenting the fact that 'compared to other countries, the UK does little consciously to inculcate a sense of national identity and shared values.' (CPGNIS, 2007, 23). Amongst these shared values which it claims are at the heart of British identity, are those of individualism and the 'rights of the individual against the state.'

\section{Pressure Points}

Policy documents are not necessarily the best source for analysis of sensitive topics like social cohesion because they tend to be somewhat vague and gestural - often providing appropriate nods towards all politically correct notions rather than coherent statements of position. However, even from a cursory reading one can begin to observe certain differences in emphasis between discourses. Their sometimes subtle rhetorical variations often mask what are, in fact, quite marked fault lines or 'pressure points' in the more explicit academic writings about social cohesion. A pressure point may be defined as a crux issue in policy 
debate, where contradictions are evident and where ideological choices or policy trade-offs have to be made. Two such pressure points are already visible from the policy discourses on social cohesion. One relates to the question of diversity and the other to the question of equality.

\section{Diversity and Shared Values}

Much of the debate on social cohesion revolves around issues of cultural diversity and the appropriate responses to it. The latter may be couched in terms of adjustment policies, such as integration, assimilation, multiculturalism and mutual adaption, or social attitudes, such as tolerance and respect for other people and cultures and so on. The fundamental dilemma is how far cultural diversity, which is a reality in most countries, is compatible with social cohesion, and particularly forms of social cohesion which depend strongly on shared values. Both academic research and policy responses vary considerably in their approach to this question.

Nationalists, including liberal nationalists (Canovan, 1996; Miller, 1995), have always argued that a degree of cultural homogeneity is a necessary precondition for a cohesive society with a well-functioning democratic system and expansive welfare state. Democracies require a certain degree of value consensus, at least in core areas, they say, to function smoothly. In order for citizens to consent willingly to their taxes being used to pay for redistributive welfare policies they must believe that others are also willing to pay taxes which will support them when they are in need and that recipients of welfare are not abusing the system. According to such theories consent to democratic and government and the re-distributive welfare state requires a degree of trust on behalf of citizens and this is more likely to occur where there is a degree of cultural homogeneity. This can occur where (unusually today) societies are fairly homogenous in ethnic and religious terms, or where policies effectively assimilate immigrants into the dominant culture. The claims find some support in research (Alesina et al, 1997) which shows that more ethnically diverse societies tend to spend a lower percentage of their GDP on welfare and public services. Liberal multiculturalists and political pluralists, on the other hand, have tended to argue that cultural diversity is not a problem for democracies, providing that their political institutions are robust enough to mediate conflicting interests and providing that societies are based on a widespread belief in the values of tolerance or, more actively, on respect for other cultures and traditions. Examples 
can be found of diverse societies which are reasonably cohesive, such as Canada, as well as more homogenous societies which are quite divided, such as Italy.

Research on diversity and cohesion is contradictory and inconclusive. Samuel Huntington, the controversial American political scientist, has argued recently (Huntington, 2004) that national identity and social cohesion in the US are being undermined by increasing ethnic and linguistic diversity. From its foundation the US has been a country of immigration and ethnic diversity; according to its own myth, a cosmopolitan melting pot where diverse groups have been bound together by a shared idea of the 'American Way of Life' and the civic values of the Constitution. However, Huntingdon argues that as a 'settler society', the country always had a dominant set of (ethno-cultural) values which were those of the WASP (White AngloSaxon Protestant) pioneers and that it is those dominant values that have underpinned and given potency to the binding civic values of the American Creed. With increasing ethnic diversity, linguistic pluralism and adoption of multiple and so-called hyphenated identities (ie Polish-American etc), he argues, the core culture and identity, in which he claims the American Creed is rooted, is being eroded. The American Creed is all that is left to bind society together but the deracinated Creed cannot fulfil its function. His answer to the question posed by his book: 'Can a nation be defined only by its political ideology?' (ibid, 337) is: probably not. The reason he gives, which can be found in many writings on nationalism (eg Smith, 1995), has to do with the deeper affective attachments that a robust sense of nationhood allegedly requires: people, he says, 'are not likely to find in political principles the deep emotional content and meaning provided by kith and kin, blood and belonging, culture and nationality.' (Huntington, 2004, 339.) Hence, he claims, comes the flight of contemporary Americans into religious identity.

From a different, and more liberal, perspective, and focussing on communities rather than the national state, Putnam (2007) has also argued that increasing diversity is a problem for social capital, which he defines here as 'social networks and the associated norms of reciprocity and trustworthiness.' (137). Using data for a large sample of neighbourhoods in the US on what he takes to be key indicators of social capital, including inter-racial trust, and intra-racial trust, Putnam claims to show that ethnic diversity is inversely related to levels of social capital, both across ethnic communities and within them. Even controlling for levels of poverty and crime, his statistical analysis suggests that 'greater ethnic diversity is associated 
with less trust in neighbours.' (153) Putnam acknowledges that the effects of diversity may vary according to the longevity of ethnic mixing in an area, and that areas which have become ethnically diverse through rapid inward migration may become more trusting over time. However, his overall message is that diversity is a problem for community cohesion.

Putnam is not alone amongst quantitative sociologists in arguing that ethnic diversity erodes trust, or other key aspects of social cohesion. Other studies across states in the US find the same inverse relationship (Alesina and Ferrara, 2002) and there are several cross-national studies which also purport to show a negative relation between diversity and key measures of social cohesion, such as trust (Delhey and Newton, 2004; Knack and Keefer, 2005), although in the case of the Delhey and Newton study the ethnic fractionalisation variable loses much of its strength in models which include good governance.

However, the thesis has also been much contested. Putnam's research cited here relates only to the US. In other countries where the relationship has been examined across areas no such clear correlations are found. The British Commission on Integration and Cohesion report, Our Shared Future, examines evidence from the 2005 Citizenship Survey and finds no correlation between the proportion of ethnic minority households in an area and perceptions of area respondents on cohesion or respect for differences. The report concludes that only in certain cases - typically where areas have experienced rapid new immigration in a context of existing social problems or overstretched services - did there seem to be a problem with diversity and cohesion. Lekti (2006) uses area data from an earlier 2001 Citizenship Survey in Britain and likewise finds no correlation between diversity and cohesion at the neighbourhood level when other factors, including socio-economic status, are taken into account. Johnson and Soroka (1999) analyse the impact of ethnic diversity on social capital in different regions in Canada and find no link. There are also cross - national analyses which find no relationship between diversity and cohesion. Using a measure of ethno-linguistic diversity for a large sample of countries, Green et al (2006) found no relationship across countries between diversity and various aggregate measures of social cohesion. Likewise in Ulsaner's (2003) multivariate cross-national analysis there is no relationship between diversity and levels of interpersonal trust.

Lastly, Putnam's methodology can also be contested. His measure of diversity is a somewhat crude and limited one based on a fourfold categorization of his sample into Hispanic, non- 
Hispanic White, non-Hispanic black and Asian. This procedure does not capture ethnic diversity within white populations, or, come to that, within any of the other categories. Putnam is essentially measuring diversity in terms of 'racial groups.' Given the rapid growth and migrations of the Hispanic population much of the diversity he is measuring is in neighbourhoods with relatively recent experiences of ethnic diversity. Had the non-Hispanic white category been disaggregated to include German-Americans, Italian-Americans, IrishAmericans, Jewish Americans, in a city like New York, for instance, arguably much more long term ethnic diversity would have been captured in his measure and this would no doubt change the relationships he finds with social capital.

Policy positions on the diversity and cohesion issues vary considerably, not only according to whether cultural diversity is seen as an asset or problem, but also in how to respond to it if it is a problem. For racists and ethno-nationalists diversity is by definition a problem for society, and the answer will be to reduce it by various means, including through reducing immigration or, at an extreme, through repatriation. Within the mainstream of politics in liberal democracies the official policy in recent years has normally been to celebrate the benefits of diversity (in terms of what it bring to creative and cultural life and its economic benefits) but at the same time to acknowledge that it can under certain conditions create social tensions which have to be 'managed'. As the British Commission on Integration and Cohesion puts it '[d]iversity can have a negative impact on cohesion, but only in particular local circumstances,' (op. cit., 20) Controlling immigration is of course one such management strategy employed by most states, to a greater or lesser degree, but given that in a globalised world all states are likely to be increasingly culturally diverse, the more germane issue here is how policy-makers respond to managing diversity as it exists. Here responses differ within different traditions.

Within liberal traditions the underlying assumption is that while diversity may cause social tensions in newly diverse communities mutual contact between groups will lead to reduced tensions over time. This was the optimistic hypothesis of Gordon Allport's classic 1950s study, The Nature of Prejudice (1954). Modern social capital theorists, such as Putnam, start from a similar assumption. Cohesive communities are based on trust and reciprocal relations. Trust is developed through repeated interactions between individuals within and across social groups. Thus the key to cohesive communities, whether they be diverse or otherwise, is a high level of association and civic involvement. To Putnam, who is less optimistic than 
Allport about such activities occurring spontaneously, at least in present day America and particularly in diverse communities, civic activism needs to be encouraged, particularly through education. Liberal mutliculturalists, who are perhaps more prone to celebrate the benefits of diversity than Putnam, would also advocate activist responses, often but not only through education. These tend to include laws and institutional policies to discourage racist behaviour and institutional racism as well as educational initiatives to promote tolerance and, more positively, respect for other cultures. Beyond the core values, such as tolerance and respect for others, liberal policy is often reluctant to put too much stress on shared values. The recent Diversity and Citizenship Curriculum Review report in Britain, for instance, calls, on the contrary, for a greater focus in the Citizenship Curriculum in schools on diversities and different identities, noting that 'issues of identity and diversity do not tend to be linked explicitly enough to political understanding (of legal and political systems) and active participation.' (Ajegbo, 2007, 7 ).

Within what may be broadly called the republican tradition policy responses to diversity have been somewhat different. Generally less emphasis has been placed on local civic activism and associational activity and more on active political engagement and a sense of belonging to the political community understood in national terms. More emphasis has been placed on a broad set of shared values and identities, albeit conceived of more in political than cultural terms. Republican policies have tended historically to favour the assimilation of immigrants to the national political culture, which can easily shade into policies of cultural assimilation which can be hostile to cultural diversity (Brubaker, 1992). As Michael Walzer has argued: 'republicanism...requires a strong cultural base to sustain high levels of participation amongst the citizens; liberalism, which is less demanding, can allow more room for private life and cultural diversity.' (Walzer, 1997, 74). The state is concerned with political and economic integration. Culture and religion are seen as a private matter for families and communities. Hence the resolute emphasis in French schools, which is only gradually attenuating, on promoting a secular and culture-blind notion of national citizenship (Corbett and Moon, 1996).

\section{Equality, Welfare and the State}

Attitudes toward equality and the state provide the other major fault line - or pressure-point in discourses on social cohesion. Liberalism, and in particular US liberalism, has historically 
maintained a pronounced aversion to a centralised state, which is why the wealthiest liberal democracy in the world still does not have a full welfare state, including a public health service. Since markets in civil society naturally produce inequalities it is the state that is required to adopt redistributive policies to mitigate these and to provide the welfare provision and social protection to which individuals would not otherwise have equal access. Liberalism has tended to have some difficulty with this since increasing the redistributive role of the state implies enhancing the power of the state which is seen as contrary to liberty and freedom, its most scared principle. Equality tends to receive less emphasis in liberal discourses of social cohesion for this reason. Much is made of the importance of meritocracy which is seen to legitimate the system of unequal rewards for unequal contributions in the market (Parsons, 1968). For this to work, of course, people have got to believe that the system is equitable - you get what you deserve - and that there is opportunity for all. Equality is not the goal but equality of opportunity sometimes has to be stressed, and even enhanced, say through schooling, to lend credibility to the claims of meritocracy and to promote faith in the possibility of social mobility (Bowles and Gintis, 1976). Opportunity and meritocracy, not equality, then are the core values that undergird the liberal notion of social cohesion.

In the republican tradition, on the contrary, the state and liberty are not held to be enemies, and it is taken for granted that the state has to act as one of the principal guarantors of social cohesion. It does this through fostering common national values, but also through its institutions of social protection and welfare which are seen to underpin social solidarity. The French Revolutionary legacy, on which the republican notion of solidarity is based, included in its trinity of values, égalité, as well as liberté and fraternité. This has been interpreted variously in practise in right and left versions of republicanism, as either meritocracy, following the Napoleonic ideas of the 'career open to talents', or, in more socialist variants, equality in the fuller meaning of the word. Whatever the emphasis in actual policies, equality still features strongly in the rhetoric of social solidarity in republican discourses on social cohesion. However, it is in social democratic discourses and practises where equality holds the most central place and where the word implies most clearly equalising both opportunities and outcomes. It is no coincidence that the Nordic countries, which score highest on most indicators of social cohesion, have the lowest rates on income inequality (on Gini Coefficient measures) of any countries in the developed world (Green et al, 2006). 
In terms of the academic research there is no shortage of social theory which attempts to show how welfare and re-distributive policy underpin social cohesion (Esping-Andersen, 1990; Rothstein, 2001) - just as there is a plethora of writings from liberal social capital theorists which largely ignores the issue, and point to other foundations for social cohesion. Unfortunately there seems to be little cross-national statistical analysis that tests how far welfare institutions do actually improve social cohesion. However, on the question of income equality and social cohesion there is a wealth of evidence from both cross-area and crossnational statistical studies, and it all runs in one direction. Both within countries and across countries, income equality is strongly correlated with several key measures of social cohesion, and most significantly with interpersonal trust. In his famous study, Bowling Alone (2001), even Putnam presented evidence that income equality correlated strongly across US states with levels of trust, and as well as other key measures of social capital. He did not follow up the insight in the rest of his analysis but others have done so. Interpersonal trust and income equality are highly correlated in a large number of cross-national studies (Green et al, 2006; Knack and Keefer, 2005; Ulsaner, 2002; Wilkinson and Pickett, 2009). As Ulsaner argues:

Equality promotes trust in two ways. First a more equitable distribution of income makes people with less more optimistic that they too can share in society's bounty. And optimism is the basis of trust. Second a more equitable distribution of income creates stronger bonds between different groups in society. When some people have far more than others, neither those at the top nor those at the bottom are likely to consider the other as part of their 'moral community'. They do not perceive a shared fate with others in society. Hence, they are less likely to trust people who may be different from themselves (Ulsaner, 2005, 28).

These associations do not, of course, prove causality, and they do not show which way any causality might be running. It is quite likely that trust drives equality because it requires a trusting electorate to forge a political consensus around policies which may enhance equality. However, whichever way we construe the relationships, it seems highly likely that trust is more likely to be present, other things being equal, in reasonably egalitarian societies.

This evidence leads many researchers to say categorically that equality is a necessary constituent of social cohesion (Bernard, 1999). However, we would argue that this is mistake 
methodologically in that it pre-empts rigorous analysis of the relationship between equality and cohesion and, at the same time, rules out of consideration any definitions and forms of cohesion which do not rely on this element.

\section{Defining Social Cohesion and Identifying its Regimes}

The brief survey above of research and policy definitions of social cohesion demonstrates considerable variety in the way the concept is used. Definitions vary both in terms of the level of analysis which is implied and in terms of the various elements which are taken to constitute the phenomenon. To some degree at least, the definitions may be mutually contradictory. Any attempt to aggregate the various elements in the different definitions will simply yield a wish-list of items without internal coherence and with such over-specification that the definition will exclude most real-life forms of the phenomenon. A better way forward, as we suggested in the introduction, is to use a minimal definition that captures the essence of the phenomenon and which, at the same time, is broad enough to allow analysis of a wide range of real-life manifestations of it. To avoid argument by definition, the definition must include neither potential causes nor effects of the phenomenon.

Chan et al (2006) have also adopted this approach but their own definition is probably still over specified. 'Social cohesion,' they write 'is a state of affairs concerning both the vertical and horizontal interactions of society as characterised by a set of attitudes and norms that includes trust, a sense of belonging and the willingness to participate and help, as well as their behavioural manifestations.' (290). We prefer a yet simpler definition:

Social cohesion refers to the property by which whole societies, and the individuals within them, are bound together through the action of specific attitudes, behaviours, rules and institutions which rely on consensus rather than pure coercion.

We add the qualification in the final phrase to exclude societies which achieve social order (and thus some of the manifestations of cohesion) through coercion alone, since these would normally be seen as coerced societies rather than cohesive societies. ${ }^{2}$ We take the level of analysis implied in the term to be whole states, as in the most prevalent usage, rather than smaller communities or groups. Social cohesion is thus distinct from social capital, a term best reserved to refer to either, as in Bourdieu (1986), the social resources of individuals and

\footnotetext{
${ }^{2}$ We acknowledge, however, that the boundary between 'coerced' and cohesive societies is far from clear cut, since all societies maintain some degree of coercion.
} 
families, or to the bonding of individuals in bounded communities and groups, as in Coleman's (1988) usage. Although quantitative analysis of social cohesion and social capital may sometimes use similar indicators (like trust), the phenomena have no necessary relation to each other. As we argue elsewhere (Green et al, 2006), a country may well be rich in social capital, in terms of the social capital that resides in different groups, but this will not necessarily make it socially cohesive. Intra-group bonding does not necessarily translate into inter-group harmony. Northern Ireland in recent years would represent a case in point (Schuller, Baron and Field, 2000). Specific types of social capital, such as the 'bridging' and 'linking' social capital identified by Putnam and others as forging ties between groups and between individuals at different levels in a power hierarchy, may contribute to social cohesion. Some social capital theorists, like Halpern (2005), do in fact refer to 'macro-level social capital' in a way that could proxy for social cohesion. However, given the conceptual confusion arising already from the conflation of levels in social capital theory, it is advisable to keep the terms separate and use social cohesion as the concept applying to national level society.

Having thus defined social cohesion, we should ideally be able to measure it. However, this is clearly not a simple matter, even though various organisations have developed extensive lists of indicators to capture different aspects of the phenomenon (Berger-Schmitt, 2000). The problem is that social cohesion takes various different forms, each of which consisting of a different configurations of social characteristics. Putnam (2000) argues that there is a set of characteristics of social capital (trust, tolerance, association and so on) which tend to go together at the individual level, at least in the US. People who trust others and institutions tend also to be tolerant, to give to charities and to join associations and so on. However, at the country level this neat coincidence of characteristics is not at all evident. If we take the whole set of characteristics imputed to all the forms of social cohesion, adopt proxy indicators for them, and analyse statistically their patterns of variation across countries, we find few overarching patterns. Many of the social capital indicators, aggregated to the national level, simply do not co-vary across countries. Association and interpersonal trust, for instance, which are the key characteristics of social capital for Putnam, do not co-vary across countries (Green et al, 2006; Norris, 2001; Newton and Norris, 2000).

Are there then any core indicators of social cohesion? The approach adopted in Green et al (2006) was to develop a composite indicator at the aggregate level based on three indicators 
which do actually co-vary across countries. These were interpersonal trust, civic co-operation and violent crime (inversely). So in the statistical analysis socially cohesive states were taken to be those with high levels of trust and civic cooperation and low levels of violent crime. This appeared to be a commonsensical approach which might be thought to accord with a popular understanding of the term social cohesion. However, it still fails to capture all the different meanings given to social cohesion in different societies. Here we adopt a different approach as our initial way into the research.

From the analysis of western academic and policy texts in the first section of this paper we can see three distinctive types of discourse around social cohesion emerging. These can be broadly designated as: a) liberal, b) republican and c) social democratic. In each case we may say that they emphasise a different set of constituent elements.

\section{Box 1: The Liberal Discourse}

The liberal discourse places most emphasis on an active civil society, particularly at the local level. The role of the central state is played down, along with its institutional roles for providing welfare and social protection and for promoting equality through re-distribution. A vibrant civil society with high levels of civic association is believed to incubate trust spontaneously through repeated interactions between individuals and groups. Where this fails attitudes of tolerance and respect are encouraged to mitigate tensions between diverse groups. The core values which help to bind society in the liberal paradigm are, in addition to tolerance, meritocracy and opportunity. A wider set of shared values and a common identity are thought to be incompatible with individual freedom and cultural diversity. 
Box 2: The Republican Discourse

The republican discourse emphasises the state rather than civil society. The state promotes social cohesion through its institutions for welfare, social protection and re-distribution. It also plays a role in disseminating (through public education) a common (national) identity and a broad set of shared values which emphasise belonging to, and active participation in, a political community at the national rather than local level. The state also plays a supervisory role in relation to key institutions in civil society which are seen to intermediate conflicts, such as professional and employer institutions. Different currents in republican thought variously stress equality of opportunity or equality of outcomes as important preconditions for social cohesion, but their role in social cohesion is often largely symbolic.

\section{Box 3: The Social Democratic Discourse}

The social democratic discourse follows the republican discourse in most of its essentials, except that here the stress on equality is more profound. Like republican theory social democratic theory emphasises both the role of the state and that of autonomous but statesanctioned national civil society organisations, like the peak bodies of employer and employee organisations, in providing the institutional underpinning of social cohesion. Social partnership is a key concept in both contemporary traditions pointing to importance of conflict intermediation through representative civil society organisations.

\section{Section Two: Western Intellectual Traditions of Social Cohesion}

Contemporary writing on social cohesion - both from policy-makers and academics - suffers from a considerable intellectual amnesia. Mention is rarely made of the historical precursors of modern concepts of social cohesion, except in the occasional passing reference to the works of Durkheim, and it would be easy to conclude from reading these accounts that social cohesion is essentially a contemporary issue. Of course, nothing could be further from the truth. The problem of social order has deep roots in political philosophy, going back to the ancients. It was also the central concern of the new discipline of sociology which grew up in the nineteenth-century Europe, in writings stretching from August Comte and Henri Saint- 
Simon through to Durkheim, Herbert Spencer, and Ferdinand Tőnnies. Social cohesion, or in French terminology, social solidarité, were the key concepts in endless theoretical debates throughout the century, as social thinkers sought to understand what social forces and institutions might hold newly industrialised societies together in the absence of the traditional sources of moral authority which had been weakened by industrial and political revolutions. It was the sociologists, and particularly those in the French positivist tradition stemming from Comte, who most explicitly addressed the issue, and gave us the terms we now use to conceptualise the phenomenon.

However, theirs was not the only tradition where the question loomed large. In fact French positivist writing on solidarity was in large measure a reaction against the way that British liberal philosophy and political economy thought about society and the place of the individual within it. And although it was less explicit here, this liberal tradition in fact contained within it an implicit theory of social cohesion. By the same token, the third main strand of nineteenth-century writings on the social order - that within the German romantic conservative tradition - was an explicit reaction against French rationalism and positivism, and provided a quite different account of what it was that held societies together (Greenfeld, 2003a). These three traditions - and the social democratic tradition which evolved later out of republican and socialist thought - each provide a highly elaborated theoretical account of the nature of social cohesion, its preconditions and the forces which can undermine it. It is worth revisiting these traditions not only because they contain all the key elements and debates found in the modern discourses, but also because their elaborated accounts, which were refined through constant argument between the traditions, show very clearly the distinctive sets of interlocking propositions which still underpin the less theorised discourses which exist today. We may start with liberal thought because it was this that started the chain of intellectual reactions which led from John Locke in the late seventeenth century to Tönnies at the end of the nineteenth. 


\section{Liberalism}

All liberal thought, from John Locke down to Herbert Spencer, can be said to derive from a set of fundamental and interconnected propositions about the nature of the individual and of individual freedoms; the relations of the individual to the state; and the ordering of civil society, the layer of social life between the individual and the state. In the first two areas we find the propositions which define what social cohesion cannot be. In the last we find the arguments about where social cohesion can reside. In liberal thought the individual is taken to precede society and to be endowed with certain natural freedoms or rights and it is the role of the state to protect these freedoms and rights. But individual liberty is held to be in constant danger from the state, which has a natural tendency towards tyranny, and the state must therefore be contained to a minimal role, as far as is consistent with protecting these individual freedoms. To put the case at its crudest, beyond the defence of the realm and maintenance of law and order, the state is not required to vouchsafe social cohesion, since that issues spontaneously from the natural harmony of interests in civil society which must remain as free from state interference as possible.

The main tenets of modern liberal thought derive from the British philosopher John Locke whose major works appeared after the 1688 so-called Glorious Revolution which he supported. Locke believed that individuals are born into a state of nature which he called a 'state of perfect freedom.' (Locke, 1963). They are endowed with reason and enjoy natural rights as human beings, not least to own property and to enjoy the fruits of their labour. As he famously argues, it is labour which gives the right to property:

Though the earth, and all inferior creatures be common to all men, yet every man has property in his own person. This no body has any right to but himself. The labor of his body, and the work of his hands, we may say are properly his. Whatsoever then he removes out of a state that nature hath provided, and left it in, he hath mixed his labour with, and joyned to it something of his own, and thereby makes it his property. (Locke, 1963, 305).

It was the right to property which underpinned Locke's theory of government, which argued for constitutional monarchy and governments elected through a limited franchise based on property ownership. The role of the state was to protect property, uphold law and order, defend the realm and safeguard the rights and liberties of citizens. Beyond this the 
prerogatives of the state should be kept to a minimum. Unlike his philosophical predecessor, Hobbes, Locke was an optimist and saw no need for a mighty Leviathan state because men had a natural identity of interests born of their desire to exchange goods in the marketplace, where he assumed there was natural equality in exchange relations. Although he does not use the term, it is this argument about civil society which lays the foundation for later liberal thinking about social cohesion. It was also the basis for his famous defence of religious and political toleration without which man could not enjoy his natural freedoms.

The liberal tradition of British Political Economy continues from where Locke left off, extending his philosophical principles into the sphere of market economics. Its fundamental argument about the natural harmony of interests in civil society remains the basis of its conception of social cohesion. Adam Smith, writing a century later, was, like Locke, an advocate of individual freedoms and minimum state intervention. Arguing for free trade against the prevailing mercantilist notions of state intervention in the economy, Smith proclaimed the fundamental beneficence of the 'natural' market order. According to the theory of the 'free market' it was the pursuit of individual self interest, unfettered by government restriction, which would lead to the mutual benefit of all and the maximum public good. The market order had multiple advantages. It allowed the greatest degree of individual liberty; it provided incentives to enterprise, a competitive spur to efficiency and guaranteed success to the most meretricious; and by encouraging the pursuit of individual self-interest it inadvertently promoted the good of the whole community. By pursuing his self interest, Smith famously wrote, a man is 'led by an invisible hand to promote an end which was not part of his intention' - the common weal. The necessary corollary of the free market was limitation of government power. Smith supported certain limited state interventions where incentives for individuals in the market were not sufficient to ensure the achievement of certain key public goods, such as education. The latter was, he believed, particularly important to offset the deleterious effects of routinised factory labour on the intelligence and morals of the growing army of factory workers. Nevertheless, there was, according to Smith, 'a strong presumption against government activity beyond the fundamental duties of protection against foreign foes and the maintenance of justice’. (Ssmith, 1904, 611).

While Locke had made the original a priori liberal case for the defence of the individual against the state, it was Adam Smith who provided the blueprint for the liberal theory of social order through his detailed anatomisation of the workings of the market. The subsequent 
giants of nineteenth-century liberal thought, Jeremy Bentham and John Stuart Mill, adapted the ideas for the somewhat more democratic times in which they lived, but added little in essence to case for the natural harmony of interests which was the basis of the theory of social order. Both placed the individual before the state as Locke and Smith had done. Like Smith, but going somewhat further, they found increasing causes why the state should intervene in specific areas of social life, such as education and urban sanitation. However, they remained fundamentally laissez-faire in their attitudes on the optimum relations between state and civil society. 'Nothing ought to be done,' wrote Bentham, 'or attempted by Government for the purpose of causing any augmentation in the national mass of wealth...without some special reason. Be quiet ought to be the motto or watchword of Government.' (Bentham quoted in Taylor, 1972, 34). John Stuart Mill had growing reservations about pure laissez-faire towards the end of his life, but was still publicly opposed to any but the most cautious state interventions and only then for exceptional reasons. In 1848 he still thought 'letting alone...should be the general practise.' (Mill quoted in Perkin, 1985, 322). He came to support the provision of public schooling, provided competition remained between private and public schools, but opposed compulsory attendance in favour legislation to require qualifications for entry into skilled occupations. But in most other matters he remained resolutely for the liberties of the individual against the state. The only justification for state restraints on liberty was the protection of individual freedoms which he defined, in the famous negative manner, as the right for the individual to do as he pleases so long as he does not infringe the freedoms of others. As he wrote: 'every departure from the laissez-faire principal, unless required by some great good, is a certain evil.' (Mill quoted in Fraser, 1985, 47).

The clearest hallmark of liberal thought, from John Locke, down to John Stuart Mill, has been the absolute priority accorded to the individual over the state and society. In principle the individual is seen to precede society and society is often portrayed as little more than the multiple interactions between individuals freely pursuing their interests in the market. Society, in its collective sense, is regarded with some suspicion. For Adam Smith even the clubbing together of individuals in associations could be an offense to liberty. 'People of the same trade,' he wrote, 'seldom meet together, even for merriment and diversion, but the conversation ends in a conspiracy against the public, or in some contrivance to raise prices.' (Smith, 1904, 1, X, 82). Nor is the individual seen as constituted by society or by culture. 
Bentham famously said that the community was a 'fictitious body', just as the Conservative Prime Minister, Margaret Thatcher, was later to declare that 'there is no such thing as society - only individuals and their families. ${ }^{3}$ In his utilitarian system the starting point is the universal propensity of individuals to pursue pleasure and avoid pain. The role of government in this 'felicific calculus' was to ensure the 'greatest happiness to the greatest number.' But Bentham has no interest in defining happiness other than on the pleasure principle. Individual wants are a private matter and, so far as Bentham was concerned, are formulated privately. There is no sense in Bentham that individual preferences might be shaped by culture and society. Mill referred to the utilitarian system, which came to provide what many would consider to be the somewhat simplistic socio-psychological basis of some modern classical economics, as cold and mechanical, based on a naive psychology and suited only to 'regulating the merely business part of social arrangements' (Mill, 1986, 105). But the criticism could be extended to much of the liberal thought of the period. It is largely culturefree, or 'philistine’ as Matthew Arnold was later to lament (Arnold, 1932).

Given the very atomised notion of society prevailing in British nineteenth-century liberal thought, it is easy to see why the theory of the natural harmony of interests became so important. There was no other argument permissible within the liberal schema that could explain how societies might hold together. Using the state as an instrument for moral and political socialisation, or for promoting levels of equality that might be more conducive to social cohesion, was intolerable to liberal principles. Nor did democracy itself hold much prospect for making societies more cohesive. Both Bentham and Mill were, to use Held's phrase, 'reluctant democrats' (Held, 1983, 11): they believed in representative government, but were wary of universal and equal voting rights, fearing that the enfranchised masses might seek to use their political power to redistribute wealth, thus infringing the freedoms of property-owners. Thus everything had to rest on the optimistic belief that social harmony could be maintained through free exchange in the market. It was Herbert Spencer, the most influential social thinker of his day, who took this argument to its apogee, denying that the state had any need to regulate at all (Lukes, 1973). Free exchange and contract, which could be enforced by law, were the only necessary preconditions of social harmony. As he wrote: 'the sole link which remains between men is absolutely free exchange.' (quoted in Lukes, 1973, 142). The problem was that the existence of free exchange did not necessarily mean

\footnotetext{
${ }^{3}$ Margaret Thatcher's famous comment was made in her appearance on BBC Radio’s Woman’s Hour.
} 
that there was a natural equality in exchange relations, and where there wasn't there would be conflict. Despite Marx's detailed dissection of this problem, and its effects, this rarely occurred to thinkers of the British liberal school (Marx and Engels, 1973).

In the end it was a Frenchman, the remarkable Alexis de Tocqueville, who provided liberal thought with a more credible vision of society in his book Democracy in America (Tocqueville, 1956). He, like British liberals, believed civil society was the key to social harmony but he did not rest his case on the abstract and culture-free doctrine of the natural harmony of interests, and was a clear opponent of individualism. Liberal individualism to him was a:

mature and calm feeling, which disposes each member of the community to sever himself from the mass of his fellows, and to draw apart with his family and his friends.......at first it only saps the virtues of public life; but in the long run, it attacks and destroys all others, and is at length absorbed into downright selfishness. (de Tocqueville, 1956, 193.).

But he found in the vibrant emergent democracy of Jacksonian America, which he observed during a study visit during the 1830s, more than pure individualism. He demonstrated, through a highly insightful analysis of the mores of American community life, how civil society in a democracy could be more than a mere market for exchange. It could also develop a civic culture where active associational life in communities could forge bonds between individuals which went beyond the thin attachments represented by contracts and exchanges. De Tocqueville certainly had his blind spots and there is little appreciation in his writings on America of the depth of racial and class divisions in that society. Nevertheless, he provided a more credible account of the foundations of social cohesion in liberal state than his British liberal contemporaries and one that has, consequently, been endlessly recouped in modern writings on social capital.

\section{Republicanism}

French republican thought, from Rousseau down to Durkheim and beyond, often explicitly repudiated laissez-faire liberalism and differed in crucial ways in the three principal areas of disputation: ie vis-a-vis the relation of the individual to the society and the state; the proper role of the state; and on the importance of collective values. In republican thought the 
individual is not antecedent to society and the state, as in liberal discourse, but is constituted by them. Man, to Rousseau, may be born a 'noble savage' but 'we begin,' he says, 'to become men only when we have become citizens.' (quoted in Williams, 1961, 94). Liberty and the state power are not fundamentally opposed, but rather true liberty is seen to lie in the embodiment of the individual interest in the collective interest, the latter which the state enacts and protects. For Rousseau the state is the guarantor not the enemy of liberty (Kohn, 2008). Social cohesion - or social solidarité in French - arises not so much spontaneously out of civil society and free market exchange, although these may provide a foundation of mutual functional interdependencies. It is primarily something which is cultivated collectively through the formation of the political (Rousseau) or moral (Durkheim) community. For Rousseau the ideal community was the democratic nation state and, indeed, Rousseau is often seen as the father of modern nationalism, although in fact democracy was more important to him than nationalism (Kohn, 2008). Durkheim could be fervently patriotic in his private life (Lukes, 1973), like Rousseau, but national identity is less central in his writings. However, for both him and Rousseau collective beliefs and culture, in Raymond Williams' anthropological use of the term (1961), were essential for social solidarity. Thus, shared values and collective political action play a larger role in the republican notion of social solidarity than in liberal notions of social cohesion.

Rousseau's Social Contract (1762), often considered the foundation stone of republican political philosophy, argued for a 'direct' or 'participative' democracy where, unlike in liberal representative democracy, sovereignty not only derived from the people but also, as David Held puts it, 'stayed there' (Held, 1983). For Rousseau the people had to exercise their sovereignty actively by creating the 'common will' which, being more than an aggregate of individual wills, could only be forged by common deliberation and action. According to Rousseau's polemical statement: 'sovereignty cannot be represented ...the people's deputies are merely agents...Any law which the people has not ratified in person is void; it is not law at all.' Representative democracies should thus not therefore be confused with free democracies, says Rousseau. 'The English people believe itself to be free; it is gravely mistaken; it is free only during the election of Members of Parliament; as soon as the Members are elected, the people is enslaved; it is nothing.' (Rousseau, 1983, 141)

The viability of Rousseau 'pure' form of democracy has been endlessly debated, not least for its practical implications of endless plebiscites, and it is certainly true that Rousseau himself 
thought it most feasible in relatively small states with close communities, and where the state was territorially secure. However, what is most relevant here is what Rousseau's political philosophy implied for his conception of social cohesion. Clearly for Rousseau the social contract depended to a high degree on a common set of beliefs, which he articulated mostly in political terms, but which he also saw as necessarily manifested in national cultural rituals and ceremonies and so on. Common beliefs arose not spontaneously out of civil society but rather out of collective deliberation and collective political action. Liberty meant not freedom from constraint by society or state, as in liberal thought, since liberty and independence were 'two things so essentially different, that they reciprocally exclude one another'. Rather it consisted of 'not subjecting the will of other people to our own' since 'whoever is the master of others is not himself free, and even to reign is to obey.' (quoted in Held, 1993, 22). Liberty and equality are thus intimately linked in Rousseau's thought, as they would be in the 1789 principles of the French Revolution. The liberal philosophical contradiction between freedom and equality, and therefore - since only the state can vouchsafe equality - between liberty and the state, does not exist in Rousseau's thought. This is because for Rousseau the basis of liberty is not the sanctity of individual property rights, as in Locke, but the freedom of the individual citizen to co-author, as it were, the democratic political community. In its celebrated legend of the Republic, 'Liberté, Égalité et Fraternité,' the Revolution yoked fraternity to liberty and equality. Rousseau had done the same. Fraternity was forged through collective political action which formed the common will, since 'every authentic act of the general will binds and favours all the citizens equally.' (p.188). This, for Rousseau, was the basis of social solidarity.

Durkheim, writing more than a century after Rousseau, also speaks from the heart of the republican tradition on social solidarity and, in fact, became its preeminent analyst and exponent during France's Third Republic. From his powerful position as Chair of Education (and later Chair of Education and Sociology) at the Sorbonne (1902-1917), Durkheim developed a theory of social solidarity which formed the core of the new discipline of sociology of which he was the leading champion, and this theory influenced generations of French school teachers whom he had trained at the Sorbonne and through his lectures at the École Normale Supérieur. Durkheim was close to the leading socialist, Jean Jaurès, and loosely associated with the political movement, Solidarité, led by Léon Bourgois. This formed a ‘third way' between laissez-faire liberalism and revolutionary socialism, arguing for 
labour and welfare legislation, social insurance and public education, and became almost the official ideology of the Third Republic in the two decades before the First World War (Lukes, 1973). Durkheim was a tireless advocate of secular state education, and came out publically for the Dreyfusards in the notorious 1898 Dreyfus Affair. ${ }^{4}$ But, although his intellectual position was broadly that of a liberal reformist socialist, he was no political activist and avoided unambiguous commitments to the socialist cause. Durkheim was essentially a social moralist. Unlike Rousseau, who saw social solidarity in terms of the political community, Durkheim talked more often about the 'moral community.'

Durkheim's theoretical position within the heated contemporary debates about sociology was a complex one and this manifested itself nowhere more than in his theory of social solidarity which he first elaborated systematically in The Division of Labour in Society and later continued to develop through his life. He was a clear opponent of laissez-faire liberalism and Spencerian individualism, eschewing the dualistic apposition of the individual and society and freedom and the state, and denying the notion that solidarity could subsist in free market exchange and contract alone (Parsons, 1968). On the other hand, although a one-time of disciple August Comte, he went beyond Comte's dogmatic utopian positivism and explicitly rejected Comte's stress on absolute moral consensus and the strong state, just as he rejected the view of his contemporary, Ferdinand Tönnies, and of the German socialists, that social solidarity within capitalism could be guaranteed by state action alone (Lukes, 1973). Although his first major work on social solidarity - The Division of Labour in Society argued that the functional interdependences created by the division of labour in industrial societies could largely compensate for the decline of the common belief - what he called the collective conscience - in subsequent writings he tended increasingly to stress the need for a new 'moral community' and for the important role of the state, and particularly state education, in cultivating this. Finally his position was that both the state and active civil society were necessary to underpin social solidarity. Prefiguring the post-Second World War movement for social partnership, he called for the development of legally authorized professional organisations to regulate market exchanges and foster mutuality within the labour market.

\footnotetext{
${ }^{4}$ Dreyfus, a Jewish captain in the French army, was falsely accused of treason by anti-semites and became a cause celébre amongst French left intellectuals.
} 
Durkheim's interest in social solidarity started early in his career. His first lecture course at the Sorbonne was entitled 'Social Solidarity' and the question he posed was 'What are the bonds which unite people together?' (Lukes, 1973, 137). It was here that he first set out the argument, later to become The Division of Labour, which sought to explain the different forms of solidarity that obtained in pre-industrial and industrialised societies. In the works that followed, including Suicide and The Elementary Forms of Religious Life, Durkheim continuously returned to this theme, on each occasion slightly modifying his views. Throughout his writing, however, there is a common approach to the subject, which is to understand the nature of different 'social types' of solidarity which could be found historically at different times and places, and to ascertain what were the social foundations of these types. To Durkheim 'social solidarity' is a completely moral phenomenon which, taken by itself, does not lend itself to exact observation nor indeed measurement,' (Durkheim, 1964, p.64) but his life work was nevertheless to analyse it empirically as well as theoretically.

His book, The Division of Labour, begins and ends with reference to liberal theories which Durkheim seeks to contest. In the Preface to the Second Edition he made clear his opposition to the dualistic liberal theory which dichotomises individual liberty and the state. 'Nothing is falser,' he writes, 'than this antagonism too often presented between legal authority and liberty.' (1993, p.5) The introduction to the study notes that Adam Smith was the first to theorise the division of labour but he goes on to criticise both Smithian and Utilitarian explanations of the causes of the phenomenon. It cannot have arisen, he says, as liberals claim, because it was the most efficient way of meeting human wants and of spreading happiness. Progress, he says, has not generally led to greater happiness. Since 'our capacity for happiness is limited' (Durkheim, 1964) it would have been met long before labour had been differentiated to its current level. Furthermore, he argues, if, as the Utilitarians claimed, the desire for happiness was universal, then the pursuit of it alone cannot explain the differential development of the division of labour across societies. Rather, Durkheim claims, there must be a social explanation, which is more likely to lie in the increasing density of human populations and consequent intensity of social interactions in industrialised societies.

Durkheim also notes early on his disagreement with the Spencerian individualist view that social solidarity arises spontaneously out of the division of labour through the exercise of free exchange in the market. Societies based solely on contract, he says, could not hold together 
'[f]or if interest relates men, it is never than for a few moments.' $(1964,204)$ Expanding on the theme Durkheim continues:

If we look further into the matter, we shall see that this total harmony of interests conceals a latent or deferred conflict. For where interest is the only ruling force each individual finds himself in a state of war with every other since nothing comes to nullify the egos, and any truce in this eternal antagonism would not be of long duration. There is nothing less constant than interest. Today, it unites me to you; tomorrow, it will make you an enemy. Such a cause can only give rise to transient relations and passing associations. (Durkheim, 1964, 204).

Durkheim maintains throughout The Division of Labour that his is not a theory of the natural harmony of interests. As if to stress the point against doubters, in the Preface to the Second Edition, he asserts that '[w]e repeatedly insist in the course of this book upon the state of juridical and moral anomy in which economic life actually is found.' (1964, 1-2). However, Durkheim's analysis in The Division of Labour is, in fact, deeply contradictory and it is only in his later works that he fully clarifies his differences with the liberals.

The core argument of The Division of Labour is that as societies change from pre-industrial communities to industrial societies the place left by the decline of 'collective conscience' is filled by the mutual functional inter-dependencies created by the division of labour. Preindustrial societies are typically divided into dispersed but relatively homogenous segments which are held together by a powerful collective conscience backed by penal sanctions. In this form of 'mechanical solidarity' the strength of social solidarity is proportionate to the intensity of collective values, which Durkheim sees as proxied in the prevalence of penal law. This exists to uphold the collective conscience, rather than to deter or reform the criminal. With the transition to industrialism, society becomes more differentiated and, at the same time, more interconnected across space. Increasing differentiation through occupational specialisation, and the moral individuation which attends it, weaken the hold of the collective conscience over the individual conscience, and collective beliefs thus reduce both in 'volume' and 'intensity'. To accommodate this increasing differentiation moral beliefs in society have to become more universalised and abstract and, as such, have less power over the individual in particular circumstances. However, as mechanical solidarity is weakened through the decline of collective conscience, a new form of 'organic solidarity' arises, based 
on the functional interdependences created by the division of labour. Durkheim sees this manifested (erroneously according to critics) in the increasing prevalence now of 'restitutive' (civil) law over repressive or penal law. This new form of functional interdependence, says Durkheim, provides the foundation of solidarity in the industrial age.

Thus far Durkheim's theory seems like a more sociological version of the liberal natural harmony of interests theory which he has previously derided. But Durkheim does, as the work proceeds, catalogue a number of ways in which modern society fails to exhibit the level of solidarity predicted by the theory of the division of labour. He notes, inter alia, the widespread manifestations of class conflict, the anarchic tendencies in the labour market, and the dehumanisation of working life for many people. Much of the conflict he attributes to high levels of inequality in wealth and in exchange relations which he considers to be a consequence of a lack of meritocracy. This lack is manifested in the continuation of inherited wealth, in the unequal rewards for work and in the misallocation of people to jobs in the labour market. As he explains: the 'hereditary transmission of wealth is enough to make the external conditions under which conflict takes place unequal, for it gives advantages to some which are not necessarily in keeping with their personal worth.' (Durkheim, 1964, 378).

So Durkheim acknowledges that social solidarity in existing industrial societies is not all that it might be despite the beneficial effects of the division of labour. However, the problem in the account in The Division of Labour is that he considers these manifestations of conflict only 'abnormal forms' which have arisen because of a lack of regulation and because social behaviour has not had time to 'mature' and 'catch up' with the changes in social relations. As he writes:

Profound changes have occurred in the structure of our societies in a very short period of time. They have become free of the segmented type with a rapidity and in proportions which are without historical parallel. As a result, the morality which corresponds to that social type has regressed, but without the other developing enough to fill the ground the first left vacant in our consciences...But, on the other hand, the functions that have been disassociated in the course of the upheaval have not had the time to adjust to one another, the new life that has emerged as if suddenly has not been able to be completely organised, and above all it has not been organised in such 
a way as to satisfy the need for justice that has never become more intense in our hearts.' (quoted in Lukes, 1973, 165).

Unlike Marx, who saw such conflicts as part of the inevitable contradictions of capitalism, Durkheim remains optimistic that such abnormalities will disappear in time.

Durkheim's account of social solidarity in The Division of Labour often seems quite contradictory because he, on the one hand, acknowledges the deep divisions within industrial society which undermine social solidarity, yet, on the other, asserts that in time organic solidarity will prevail through a full adjustment to the new division of labour. In his later writings, however, a more consistent and distinctive account of social solidarity emerges. Increasingly, Durkheim accepts that division of labour in itself is not sufficient for social solidarity to be produced and maintained and that there still needs to be a collective morality. Rather than stressing the decline of the collective conscience per se he notes in later works the formation of new forms of collective conscience which are more secular, humanist and rational and thus more attuned to an age of individualism (Lukes, 1973). His later masterpiece, Suicide, after all, argues that high rates of suicide occur either as the result of the individual being subject to too much social solidarity (Altruistic Suicide) or, more frequently, from the individual becoming disassociated from society's norms, and therefore prone to anomie (Anomic Suicide). In either event, Durkheim is implying the continuing existence and social force of strong social norms. But even these he regards, in his later work, as insufficient. Increasingly he argues that the state must act as a 'moral force' to supplement the collective values thrown up by society. As societies advance the functions of the state 'become more numerous and increasingly permeate all other social functions which it therefore concentrates and unifies.' (quoted in Lukes, 1973, 324) Most significantly, public education becomes the major institution through which the state works to promote solidarity. 'Society,' Durkheim writes, 'can only survive if there is a sufficient degree of homogeneity.' (1956, 81). Education 'perpetuates and reinforces this homogeneity by fixing in the child, from the beginning, the essential similarities that collective life demands.' (ibid, 70).

But for Durkheim it is not the state alone that must actively promote social solidarity and, in fact, the state in isolation is not able to do it. To rely too much on the state for Durkheim is to enter into the trap of the neo-Hegelians and German socialists and to fall prey to authoritarianism that this may promote (Lukes, 1973). 'Neither political society, in its 
entirety, nor the state' says Durkheim, 'can take over [the] function' of mitigating the anarchy and anomie of industrial and other conflicts (Durkheim, 1964, 5). On the contrary, this may best be achieved through the formation of occupational groups or professional associations. These should be legally sanctioned by the state, and national in organisation, but should act in an autonomous way. As Durkheim argues in his Preface to the Second Edition of The Division of Labour: 'What we see in the occupational group is a moral power capable of containing individual egos, of maintaining a spirited sentiment of solidarity in the consciousness of all workers, of preventing the law of the strongest from being brutally applied to industrial and commercial relations.’ (Durkheim, 1964,10).

It is probably fair to say that Durkheim failed in the end to resolve the question of how far the conflicts and divisions in contemporary capitalism were endemic contradictions, as Marxists and contemporary socialists claimed, or mere abnormalities which could be rectified over time or by reformist state policies. But through his later writings he did articulate a coherent republican theory of social solidarity which has remained the benchmark for all subsequent debates. His legacy, as one might expect with such a complex and sometimes contradictory thinker, has been distinctly divided, with one line of influence running through the conservative liberal American tradition of structural functionalism (of Robert Merton and Talcott Parsons) and another through the more socialist tradition of French structuralist anthropology (from Marcel Mauss down to Levi Strauss) which centred around the Anné Sociologique journal which Durkheim co-founded. However, indirectly, and not least through his advocacy of professional association which prefigures the modern discourse of social partnership, his legacy has also strongly influenced the middle path of social democracy which today encapsulates his notion of social solidarity perhaps more than any other political tradition.

\section{The Romantic Conservative Tradition}

In addition to liberalism and republicanism, we can identify a third major tradition of writing about social cohesion in the West. This derives mainly from the German romanticism of the late eighteenth century and, just as republicanism was a reaction against liberalism, this can be seen as a reaction against French Enlightenment rationalism. Its tangled lines of descent, in France and England as well as in Germany, make it the most difficult of the intellectual 
currents to trace, but it undoubtedly had a common source whose premises about the nature of societal cohesion were quite distinctive. Raymond Williams (1961) and Terry Eagleton (1975) have referred to the tradition in the broadest terms as 'romantic' or 'organic' conservatism. All three words capture precisely an important element of the tradition of thinking about society and the state. Cohesive societies here are conceived in terms of stable and durable social hierarchies which are bound together by cultural tradition and by the deference of the individual to the social order and acceptance of his or her allotted place in it. Notions of individual liberty and equality are weak or absent and there is no dichotomy between the individual and society. The latter are seen as fused in an organic whole whose natural harmony is attested by time-honoured cultural traditions embedded in the 'Volk'. Language, culture and tradition are the true markers of identity, rather than politics or human rights. The collective 'folk' replaces the individual 'citizen' as the basic building-block of society.

Johann Gottfried von Herder, the late eighteenth-century German poet, philosopher and literary critic, can be seen as the major progenitor of the tradition. It was he who popularised the notion of the Volk and provided a philosophical rationale for its centrality in the social thought of German and central European intellectuals for generations to come, albeit that his ideas were taken up in ways he clearly never intended. Herder believed that we can only truly be and think within our native cultural traditions and through our mother-tongue language. Civilization, he wrote 'grows best, and I would say only, in the particularity of our nation, in its inherited and constantly transmitted vernacular.' (quoted in Kohn, 2008, 433) He saw folk traditions as the natural expression of national community and collected and published folk songs from many regions as testament to these traditions. His writings led to a revival of interest in folk culture far and wide. As Hans Kohn has written, his 'appeal to the cultural creative force of folk language and folk tradition aroused a new interest and a new pride not only in Germans, but in Czechs, Letts, Serbs and Finns.' (2008, 429).

Herder, however, was the product of a cosmopolitan and humanist intelligentsia in Germany at the time of the late eighteenth-century Sturm und Drang movement, and was by no means the xenophobic nationalist that some of his later followers took him to be. He believed in national cultures, but his views were strictly relativistic and no culture was seen to be better than any other. '[O]ne people,' he wrote, 'should learn incessantly with and from other peoples, until all have understood the difficult lessons, that no people is especially chosen by 
God, but that truth must be sought and the garden of the common good cultivated by all.' (quoted in Kohn, 2008, 433) He thought not in terms of races but of 'the human race' which 'is one whole.' (ibid) Herder detested the militarism of his Prussian homeland and despised anti-Semites. He celebrated national cultures but was no friend to aggressive nationalism. 'To speak of fatherland opposed to fatherland in a bloody combat,' he wrote' is the worst kind of barbarism possible in the human language.' (quoted in Kohn, 2008, 441). Nevertheless, Herder's thought did tend towards the essentialising of national cultures. Although he noted some changes, he tended to view national cultures as undivided, organic wholes with more or less permanent historical trajectories. Hence, although he himself supported the French Revolution, his ideas, not surprisingly, were most readily taken up by conservatives. Two legacies derive from his and other romantic writings about national community.

The more ‘benign' legacy has been traced by Eagleton (1975) and Williams (1961) in the history of conservative romantic thought in Britain. William Coleridge, following his disillusionment with the course of the Revolution in France, was greatly influenced by the German romantics and had similarly anti-rationalist conceptions of organic traditional communities and the 'spirit of the people'. His influence runs through Carlyle, with his hostility to the harsh 'cash-nexus' of industrial society and the cold calculus of liberal Political Economy, on through Disraeli, Arnold and Ruskin, with their critique of the spiritually impoverished nature of liberal individualism, and then on to the fin-de-siècle atavistic romanticism of the pre-Raphaelites poets and painters, the designer and socialist thinker, William Morris, and the neo-Hegelian idealism of the liberal political philosopher, T. H. Green. Eagleton describes the elusive amalgam of Burkean conservatism and German idealism as an attempt by the Victorian bourgeoisie to re-legitimate the impoverished empiricist liberalism' of the time, 'exploiting the symbolically fertile, metaphysically coercive resources of Romantic humanism, with its nostalgic, reactionary, quasi-feudal social models, to stabilise and ratify bourgeois property relations.' (1975, 81-2). Eagleton is perhaps overly reductive in how he sees the object of their cultural project but there was no doubt that Matthew Arnold was seeking to enrich what he saw as the narrow materialism of liberal middle class values in England and that this had to do with making the social order more secure. Culture and Anarchy (1932) explicitly seeks to mitigate the 'philistinism' of middle class liberalism with a new culture of 'the best that has been thought and said,' and to counter liberal individualism with a revived role for the state. 'Our prevalent notion is,' he writes, 
'that it is a most happy and important thing for a man to do merely as he likes....we have not the notion, so familiar on the continent and to antiquity, of the state - the nation in its collective and corporate character, entrusted with the stringent powers for the general advantage in the name of an interest wider than that of individuals (Arnold, 1869, 75). In the twentieth century there continued to be echoes of this 'organic romanticisim' in the conservative philosophy of Michael Oakeshott and more recently in the work of the conservative philosopher of aesthetics, Roger Scruton. In his famous essay On Being Conservative Oakeshott explained that 'to be conservative ...is to prefer the familiar to the unknown, to prefer the tried to the untried, fact to mystery, the actual to the possible, the limited to the unbounded, the near to the distant, the sufficient to the superabundant, the convenient to the perfect, present laughter to utopian bliss.' (Oakeshott, 1991, 408)

A quite moderate, often nostalgic, sense of national consciousness pervades much of British conservative thought. It is the certainties of the national past and the pragmatic adaptations of the present which are celebrated. Habit and custom are cherished because they are rooted and organic. Even prejudice, according to Edmund Burke, was good because it was authentic and born of experience, rather than from abstract ideals (1986). National consciousness meant conserving the national traditions rather than stridently asserting the national future. However, political and social philosophy turned in a quite different direction in nineteenthcentury Germany. German nationalism was essentially born in 1806, in an explosive reaction against the Napoleonic occupation, and continued thereafter to be both vehemently antiFrench and stridently xenophobic in general (Greenfeld, 2003b). The intellectuals of the German romantic movement had already become disillusioned by the failure of German Enlightenment thought to bring social and political progress in German states and had by and large turned against the French Revolution. They were now humiliated by French aggression and thus became the standard-bearers for the new national assertiveness. Herder and Goethe kept faith with the Revolution and rational cosmopolitan thought, but Schlegel, Fichte, and many others of their generation, became deeply anti-rationalist and nationalistic (Greenfeld, 2003a).

Nationalism came late to the German states and it had weak liberal political foundations on which to build. Consequently, according to Hans Kohn (2008) and Liah Greenfeld (2003a), it assumed extreme and rebarbative forms. Herder had believed society to be an organic totality where the individual found his true expression and identity in the collective folk culture. 
Increasingly, post 1806, German thought subsumed the individual entirely into the corporate social identity whose highest expression was the state. Johann Fichte, who became one of the foremost ideologues of the new national revival in Prussia, called, in his celebrated Addresses to the German Nation, for a total effort of the Prussian people to build a new corporate state. This was to be based on 'a new moral order' to whose 'sublime will' each individual should be subordinate' (cited in Green, 1990). National education would be the expression of this new corporate spiritual identity and the means for national regeneration. 'By means of education we want to mould Germany into a corporate body, which will be stimulated and animated in all individual members by the same interest.' (quoted in Bowen, 258-90). Social cohesion came to be seen in terms of the submission of the individual to the state, since only the state could ensure that the individual could find true his or her expression in the identity of the Volk.

The 'purity' and uniqueness of German language and culture was now widely celebrated. At the same time the conception of folk identity became cast in increasingly racial terms, which were not only anti-French and but also openly anti-Semitic. Hostility to Jews had been a significant current in German thought since the Reformation; Luther had famously fulminated against Jews. But it now became much more pronounced. As the German nationalist historian, Henrich von Treitschke, later put it: '[t]he powerful excitement of the war of liberation [against the French] brought to light all the secrets of the German character; amid the general ferment all the old and profound hostility to everything Judaic once more made itself manifest.' (quoted in Greenfeld, 2003a, 379) The formerly liberal and cosmopolitan poet, literary critic and scholar, Karl Schlegel, came to see the world in increasingly racial terms. 'It is much more appropriate to nature,' he now wrote 'that the human race be strictly separated into nations than that several nations should be fused as has happened in recent times.' (quoted in Greenfeld, 2003a, 369). Jews were excoriated for the evils of cosmopolitanism, corruption and soulless money capitalism. Fichte, like Schlegel formerly a liberal and internationalist, wrote that: '[t]he only way I can see to give the Jews civil rights is to cut off their heads in a single night and equip them with new ones devoid of any Jewish ideas.' (quoted in Greenfeld, 2003a, 2003a, 383) Professor Friel of Heidelberg University, no less visceral than Fichte, and casting his aspersions more widely, wrote in his 1816 treatise On the Menace of the Jews to Welfare and Character of the German: 'Jews are 
a social pest which owes its special spread to money and is accompanied by misery, tyranny and taxes.' (quoted in Greenfeld, 2003a, 385).

Not all German thought, of course, reflected these sentiments. Goethe, for instance, remained a liberal, as did Herder, although the latter died before the furies of the new nationalism were unleashed. But there is no doubting that the confluence of the morbidly extreme irrationalism and racism of the romantic nationalists, and the Hegelian idealisation of the state, produced a particularly toxic version of nationalist thought which was to have a deadly historical legacy. John Gray (2007) has recently argued that Nazism owed as much to the modernist utopianism of the Enlightenment rationalists and their positivist heirs because the National Socialists used pseudo racial science and the technology of terror to promote the Aryan ideal. But the argument would get little support from historians, not least because there is such an unmistakeable intellectual lineage from Fichte, Friel and Schlegel through Nietzsche and Wagner to the Nazis. As Greenfeld says 'a direct line connected Hitler to the idealistic patriots of the wars of liberation.' (2003a, 384). But tributaries ran through conservative antiEnlightenment traditions in other countries too. The question is why they came to dominate in some historical contexts rather than others.

\section{Section Three: The Social Origins of Social Cohesion Traditions}

It is one thing to identify different intellectual traditions of social cohesion, as we have attempted to do above. But to identify 'regimes of social cohesion' is a more difficult task. To begin with the term regime implies more than a body of ideas. It also connotes a structure of rules and regulations that must be underpinned by particular institutional forms. This is implied in many of the policy definitions of social cohesion we discussed in the first section. It is also implicit in Durkheim's actual analysis of social solidarity, even though he at one point defined social cohesion as a purely moral phenomenon, as we quoted above. So, whilst we may use the term regime as an ideal type - in Weber's sense of a stylised model which captures the key and defining characteristics of a particular set of actual social forms - we must ensure that the model points to both ideological and institutional features of specific social systems, even though it may not fully correspond to any one of them. 
The second point is that the term regime usually implies a relatively stable and durable set of relationships. To regulation theorists, who have perhaps made most use of the concept, a 'regime' denotes a set of relationships which obtain over historical periods of some length, certainly longer than a conjuncture or 'political settlement,' to use terms familiar from political science, but shorter than, for instance, the duration of a 'mode of production' such as, in Marxist historiography, 'feudalism' or 'capitalism.' To give an example from political economy, Bob Jessop talks of the Keynesian National Welfare State to refer to a type of capitalist organisation deemed to be dominant in many capitalist countries roughly in the period between 1945 and 1970 (Jessop, 2002). To give another example, the comparative sociologist, Gosta Esping-Andersen, in his book Three Worlds of Welfare Capitalism (1990), seeks to identify three different types of welfare regime in Western Europe which he refers to as 'liberal', 'conservative, neo-corporatist' and 'social democratic'. The types of welfare system are identified in terms different regimes found in countries belonging to particular regions in Europe in the post Second World War period, but are also explained in terms of longer duration traditions of those regions that last over a century.

In talking of 'regional regimes of social cohesion' we are hypothesizing that certain sets of social relationships which constitute a particular general type of social cohesion may be evident across a number of countries and over an extended period of time. They may be genuinely regional in a geographical sense, as with for instance 'German-speaking countries', or only metaphorically so if they merely reflect similarity across a group of countries - such as the English-speaking countries - which are not geographically contiguous but which have certain historically-evolved cultural or socio-economic affinities. In terms of the time frame, the hypothesis assumes that there are certain longue-durée historical patterns, or trajectories, of different countries or regions which are distinctive and which persist, despite historical change, over lengthy periods of time. Institutional economists talk of 'path-dependency' to point to the way in which certain social or institutional characteristics of a national or regional economy or social formation may partially define (and limit) the possible paths for future development, thus leading to long-term distinguishing patterns. However, neither the longue-durée historians, like Ferdinand Braudel (1981) or Barrington Moore (1973), nor the path-dependency theorists, posit wholly pre-determined patterns of development. Nor do they rule out the possibility of revolutions or historical ruptures which send a country or regional on a quite different path (Skocpol, 1979). 
If we use the term 'regional regimes' in the way described above, what then is the historical evidence that such regimes may exist or have existed? Are there regimes which we can identify which are more dominant in countries in certain regions than in others? Can we point to long-term traditions, which demonstrate how these affinities have emerged in particular clusters of countries over time? The historical evidence for a distinctive liberal tradition and liberal regime type of social cohesion Britain and the US is quite strong, although how far this extends to other English-speaking countries is debatable. Likewise, historical analysis clearly identifies the strong tradition of social democracy, and the social cohesion regime which is associated here with that, in the Nordic region, even though social democracy has been a powerful force for brief periods in countries in other regions. The republican tradition is widely associated with patterns of development in France but it is not clear how far this can be identified now in other countries, even those which have been historically greatly influenced by France. Even more problematic is the 'romantic conservative tradition.' How far, and how exclusively, can this be associated with Germany and the German-speaking countries? Can the patterns be identified in post-war history as well as in the preceding century and a half? Do they constitute anything like a 'regime' in recent history? We can only briefly allude to some of the historical arguments before turning to a more quantitative analytical approach.

In the historiography since the nineteenth century liberalism and British historical development are virtually co-terminus. This is not only because the dominant nineteenthcentury 'Whig Interpretation of History' (Butterfield, 1959) put the evolution of civic and political freedoms at the centre of the story of British, and particularly English, progressive historical development, along with Protestantism and gradualist democratisation. Liberalism is at the heart of most histories of whatever political hue. Britain was frequently characterised by eighteenth-century writers, both at home and abroad, as the land of liberty, and liberalism, although not confined to Britain, was widely regarded as a pre-eminently British tradition during the nineteenth century. The centrality of liberalism to British historical development continues to be emphasised in political, social and economic histories of whatever stripe. For Eric Hobsbawm, the Marxist historian, liberalism, along with Britain's colonial past and its first-comer status as an industrial power, provide the keys to British developmental peculiarities. 'By the middle of the nineteenth century,' he writes, 'government policy in Britain came as near laissez-faire as has ever been practicable in a modern state,' adding that 
few countries had ever been dominated by an a priori doctrine as Britain was by laissez-faire (1969, 223). Liberalism, with its extreme emphasis on individual liberties, is also the key motif in the account of modern British political history by the liberal social democratic political philosopher, David Marquand. 'More thoroughly,' he writes, 'than any other country in Europe, Britain's culture was permeated with the individualism which its intellectuals codified and justified.' (1988, 7). Others have traced the origins of British liberalism further back. In Alan Macfarlane's Origins of English Individualism (1978) it was the success of fourteenth-century sheep farming and wool and cloth production which laid the basis for the early transition from feudalism to commercial agriculture and, therefore, for the rise of English individualism. For Andrew Gamble in Britain in Decline (1981) the story starts with the Tudor revolution in Government.

Gamble's account of British development starts with the early achievement of territorial integrity and the nation state. It was the successful early consolidation of the strong state under the Tudors, combined with the strategic advantages of island insularity (and so naval power and colonial extension) and successful commercial agriculture which allowed royal absolutism in England to be cut short in the seventeenth century. The heirs of 1688 were the Whig gentry and it was they who laid the foundations of centuries of liberal capitalism. The settlement created a state where individual liberties were highly regarded and where suspicion of central power was widespread. England in the eighteenth century, writes Gamble, became the acknowledged land of liberty, and the freedoms and relative social mobility that this engendered were in no small part responsible for the early onset of industrial revolution (see also Perkin, 1985). And it was Britain’s early industrialisation, as Gamble, Marquand and Hobsbawm, have consistently argued, which entrenched the liberal order. Successful industrialisation, which occurred initially from the 'bottom up,' and without wholesale state intervention as later in continental Europe, confirmed the faith in the market as the main driver of development and the belief in the virtues of limited government. Since the Tudors, Britain had developed her colonial trade, and consequent financial strength, by the usual mercantilist deployment of state power in the pursuit of trade advantages, and, despite Adam Smith's precocious advocacy of free-trade in 1785, had continued to do so well into the Victorian era. However, by the 1840s, with Britain's exports in manufactured goods already dominating world markets, it made national economic sense to switch to free-trade and hence the final historic completion of the circle of liberal thought with the 1844 abolition 
of the protectionist corn laws. Britain could, and did, now proclaim itself as world leader in market liberalism and free trade. In so doing it could prolong its advantages of industrial priority against other nations; in effect, as the German national economist, Frederick List, argued, to 'kick away the ladder...in order to deprive others of the means of climbing up after...' $(1885,47)$.

If specific geopolitical conditions, and a particular historical evolution of the state, provided a material basis for the long run entrenchment of liberal values in Britain, then the conditions in the newly formed American Republic were in many ways all the more propitious. The British settlers in North America had taken with them all the liberal notions of private property, civic rights and individual freedoms against the state which they inherited from the intellectual traditions derived from John Locke (Bailyn, 1977). These were enhanced by the struggle against British taxation and then for independence from the British state and were made more radical through the influence of political agitators like Tom Paine during the revolutionary years. Liberalism in the US became more anti-state even than in Britain because political opinion in the early Republic sought to leave behind what were seen as the corruption and state tyrannies of the 'old Europe.'

Liberal individualism was also bolstered in America by the social and economic conditions which seemed to favour opportunity and social mobility. As the German sociologist, Werner Sombart (1976), argued, these conditions, which gave credence to the universal promise of capitalism, reduced the attraction of alternative ideologies, such as socialism (1976). Boundless resources, cheap land, and relative labour shortage, as well as the safety valve of the western frontier, offered the chance of mobility, or rather the belief in that chance, to rather more people than in Europe. The absence of pre-capitalist social relations, and the relatively democratic caste of the culture and political system, made the distance between social groups appear less than in reality it was (Green, 1990). Those who had not yet prospered from the system believed that the chance was available to them. So, even if stories of rags to riches success, propagated by Horatio Alger's novels, were less common in life real than in fiction, the myth of a classless society with unlimited opportunity took hold and became part of the American Dream. Under such conditions, and with such potent national myths, it is not surprising that America became the home, par excellence, of the rugged individualism which we associate with its liberal traditions. 
The liberal path of development in Britain and the United States, and the individualist notion of the social order associated with it, has been sharply contrasted, by many historians (Anderson, 1974; Greenfeld, 2003b; Kohn, 2008; Moore, 1973 Taylor, 1978) with the different paths to modernity followed by the Germany and the states in central and eastern Europe generally. The debate has been focused particularly on the variant forms of nationalism that are said to have accompanied the process of modernisation and state formation in countries in the West and in countries east of Elbe in the late eighteenth and early nineteenth centuries. A pivotal figure in this debate was Hans Kohn, the historian of nationalism and ardent advocate of liberal ‘civic' forms of nationalism.

Kohn famously argued that when nationalism arose in the late eighteenth and early nineteenth century it took very different forms in the West and the East. Typically, in countries like England, France, the United States and the Netherlands, which experienced early economic and political modernisation, or which established themselves early as nation states, nationalism, when it came, assumed a political or civic form. By contrast, in Germany, and other more backward states to the east, where liberalism was less entrenched, and where the formation of nation states came later, nationalism took on more ethno-cultural forms. As Kohn writes:

Where the third estate became powerful in the eighteenth century - as in Great Britain, in France, and in the United States - nationalism found its expression predominantly but never exclusively in political and economic changes. Where, on the other hand, the third estate was weak and only in the budding state at the beginning of the nineteenth century, as in Germany and Italy and amongst the Slavonic people, nationalism found expression predominantly in the cultural field. Amongst these peoples, at the beginning it was not so much the nation state as the Volkgeist and its manifestation in literature and folklore, in the mother tongue, and in history, which became the centre of nationalism. $(2008,4)$.

Whereas nationalism in these western states followed on from, or coincided with, the consolidation of territorially-secure sovereign states, in central and eastern European countries, it predated modern state consolidation and had, perforce, to become a movement for the creation of new nation states. As Kohn writes: 
Outside the Western World, in Central and Eastern Europe, and in Asia, nationalism came not only later, but also at a more backward stage of development; the frontiers of an existing state and of rising nationality rarely coincided; nationalism, there grew in protest and in conflict with the existing state pattern, not primarily to transform it into a people's state but to redraw the political boundaries in conformity with ethnographic demands. (2008, p. 329)

Liberal nationalism, he argues, placed the emphasis on the political nature of the nation, meaning that 'nation states' could well be multi-ethnic or even multi-national, as long as they were national in the sense of being sovereign people's states. Indeed, as Eric Hobsbawm later argued (1990), liberal nationalism in Europe in the early part of the nineteenth century assumed that even new state formation would normally be additive, in a national sense, rather than secessionist, since nation states to be viable had to meet a certain size criterion as, for instance, propounded by the Italian nationalist, Mazzini (Hobsbawm, 1990).

Although Kohn's thesis is widely endorsed in the historiography of eighteenth- and nineteenth- century state formation, it has been substantially criticised in recent years (Kuzio, 2002) on two grounds. Firstly, it is claimed that it sets up a false dichotomy between so called 'civic' and 'ethnic' forms of nationalism, and secondly that it presents a determinist picture of historical development which rules out the possibility of states shifting from more ethnocultural models to more civic models of nationalism over time.

There is little warrant for the second of these assertions. Kohn specifically says that: '[t]he nature of nations is not fixed for all time; they are the product of social and intellectual development of countless graduations of behaviour and reaction, some of which are hardly discernable in the flux of the past.' (2008, 329) His own analysis in The Idea of Nationalism (2008) focuses on the origins of nationalism in Europe and, in fact, the main analysis does not go beyond 1820. But where he does briefly sketch the trajectory of nationalism through the later parts of the century, he notes, as Hobsbawm (1990) was later to do, that there was a secular shift in the nature of nationalism across Europe after 1848. This was when liberalism was widely in decline, and specifically in the period after 1870, when the pseudo-science of race, developed in the 1850s by Count Gobineau in France, began to take hold in the popular imagination and, in the climate of intensified imperial rivalry, fuelled racist discourses in many countries both East and West (Hobsbawm, 1987). 
On the second count, Kohn's account is more vulnerable. It is certainly the case that his judgements on nationalism are coloured by his strong liberal political leanings. In his celebration of the virtues of civic forms of nationalism, he tends to underplay the degree to which national identity, even in liberal states, was fashioned out of the cultural dominance of particular ethnic groups, as for instance with the WASP culture in the US. The theorist of nationalism, A. D. Smith, makes a similar point about the typical dominance of a particular 'ethnie' in the formation of most so-called 'civic' nation states (Smith, 1995). However, this does not invalidate Kohn's central premise that nationalism in this period and after had a relatively more ethno-cultural focus in central and eastern European states than in western states. There were at least three very good reasons for this which have been extensively explored in other historical accounts (Anderson, 1974; Greenfeld, 2003b; Taylor, 1982). Firstly, the territorial integrity of states in central and eastern Europe was much less established than it was in the western states at the onset of nationalism. Germany had been a collection of small princedoms, divided between Catholicism and Protestantism, and had been unable, and unwilling, to unite as a single German state. Territorial boundaries here were weak and transient, as in many other areas of central and eastern Europe. Without a single state uniting German peoples, German nationalism had no political or state identity on which to base itself and no choice, in a sense, but to fall back on language and culture as the defining moments of national identity. Furthermore, socio-economic and political development was backward in Europe to the east of the Elbe.

Until the French occupation spurred state modernisation, the German states were still under the yoke of serfdom, whose life the absolutist monarchs, whilst reforming the superstructures of the state, had managed to prolong. As Perry Anderson writes: 'The absolutist state in the East...was the repressive state of a feudal class that had just erased the traditional freedoms of the poor. It was a device for the consolidation of serfdom, in a landscape scoured of autonomous urban life and resistance. The manorial reaction in the East meant that the new world had to be implanted from above, by main force.' (Anderson, 1974, 13)

Because of the persistence of the old regime in Germany and the other lands east of the Elbe, the dense networks of civil society, which had grown through the more autonomous commercial life of the towns in the West, and which had supported rise of civic freedom and political reform, had not developed here. The peasantry were largely servile and conservative, and the commercial bourgeoisie remained weak. Only the educated class - the 
Bildungsburgertum in German states - had developed as a distinctive middle class but these were both highly dependent on royal patronage, and politically marginalised and impotent. In short, economic and social relations had not developed in the East to the point when liberalism, and liberal ideas of nationalism, could take root.

When these societies to the East were forced, under pressure from the advancing West, to modernise they needed, like all societies, some ideological means to weld their people together. The state was not available as a unifying idea, since it actually divided peoples. Political visions generally, had little binding power, because these states had not yet developed compelling notions of a political order which could engage and mobilise the masses. Instead it was traditional folk culture which was called upon to provide the sense of identity which would bind the people to the new social order that was being constructed. Thus an ethno-cultural nationalism became, in fact, the basis of social cohesion, such as it existed in these states.

The historical accounts of the different paths of development in the different regions do, therefore, provide some material basis and explanation for the existence of different regional traditions of social cohesion - at least for this period of transition to the modern, industrialised capitalist state. It remains to be seen, however, whether and in what ways these traditions have remained identifiably regional in the following century.

\section{Section Four: Lineages and Mutations of Social Cohesion Traditions in the Twentieth Century}

The western intellectual traditions of social cohesion which we have identified in the nineteenth century underwent some major modifications through the twentieth century because the political philosophies and material foundations on which they were based were transformed and re-transformed by social upheavals and war.

Classical liberalism transformed itself into a rejuvenated movement of social liberal reform in northern Europe at around the turn of the century; only later to expire in the face of the political and social fall-out from WW1. It was all but eclipsed for a generation between the world wars, as most European countries succumbed to some or other form of authoritarian rule (Mazower, 1999). When it returned as a political force after WW2 it had to share the 
centre ground with social and Christian democracy. It was not to become a dominant political ideology again until the collapse of the post-war Keynesian consensus in the 1970s ushered in a resurgent neo-liberalism (AKA neo-conservatism in the US), which fanned out from Britain and America across an increasingly globalised - and Americanised - developed world. French republican traditions were likewise buffeted by the mass movements of the twentieth century, spawning various rightist and leftist progeny, but they remained relatively intact in their core principles, at least in France if not in the southern European states which fell to Fascism and dictatorship before re-emerging as democracies within the European Union (EU) in the 1980s. But republicanism tout court became less distinctive as a tradition in the late twentieth century as EU states converged around a new social market political settlement which French republicanism had played a major, but not solo, role in forging. The romantic conservative tradition in mainland Europe had, as we have seen, already been captured by extreme xenophobic nationalism in Germany after 1806 and this intellectual current was to gain increasing momentum over the next century - contributing finally to the Aryan supremacist doctrines of the Nazis in the 1930s. Defeat in war, however, brought a wholesale reconstruction of the political and economic foundations of German society in the post-war period, and likewise, if arguably through a less ideologically thorough-going process, in Austria and Switzerland. The ethno-cultural traditions of pre-war Germany were largely attenuated, and its former Volkische philosophical currents only retained a strong influence elsewhere - in the new central and eastern European states which formed after the fall of the Berlin wall (Brubaker, 1996). The dominant political and economic ideologies of north-west Europe were now those of social and Christian democracy and these furnished, alongside liberalism, the three major surviving traditions of social cohesion which we need to trace.

\section{Liberalism}

The century after WW1 saw the rapid eclipse of the Liberal Party as a major political force in Britain, but not, as we can now see in retrospect, the waning of Britain's dominant liberal traditions. The thirty-year period of the post-war Keynesian national welfare state (Jessop, 2002) was the progeny of the final war years and Attlee's major reforming post-war Labour government, and was carried forward in its core principles by the 'Butskellite' consensus on full employment and welfare of subsequent centrist Conservative and left-centre Labour governments. It appeared at the time as a major shift of the political centre ground in Britain towards a kind of liberal social democracy. Thirty years on from its collapse in the mid 
1970s, this seems more like an interlude, albeit an important one, in the long-run evolution of British liberalism as a dominant political philosophy. Save for a brief period after WW2, when the wartime legacy of successful state planning and common sacrifice was still potent underpinning the initially universalist and solidaristic principles of the Beveridgean welfare state reforms (Addison, 1977; Calder, 1969) - dominant notions of social cohesion in Britain have remained anchored in the classic liberal principles laid down by the nineteenth-century political economists: those of individual freedoms and individual property rights, moderated only by a somewhat vague but growing meritocratic belief in equality of opportunity and social safety-nets supposedly vouchsafed by the welfare state. Unlike in social democratic Nordic states, as we shall see, equality never came to be seen as a necessary condition of societal cohesion, and nor has the state been seen as its primary guarantor, beyond, at least, in its role in maintaining the basic apparatus of law and order and the welfare state.

British liberalism abandoned its doctrinaire adherence to pure laissez-faire principles in the last two decades of the nineteenth century, partly because the incremental extensions of the franchise brought it under increasing pressure for reform from skilled working-class voters, and partly because of the overwhelming need to tackle the myriad social problems which it became clear could not be mitigated by voluntarist measures. Rather than being the result of any conspiracy to abandon liberal principles, as Dicey maintained, this was more a question of pragmatic adaptation to pressing social realities (Polanyi, 1957). Nevertheless, it did take British liberalism in the direction of the social liberalism more typical of continental and Nordic Europe, culminating in Lloyd George’s pre-WW1 initiatives on pensions and national insurance (borrowed in fact from Bismarck’ conservative 1880s reforms in Germany) which laid the early foundations of Britain's welfare state. However, the liberal renewal was shortlived. World war decisively discredited the old liberal order, which many held responsible for the final denouement of the mounting pre-war imperial rivalries (Polanyi, 1957). The war strengthened the already surging pre-war labour movements which gave birth to the labour and social democratic parties which could displace liberals as the major carriers of social reform; it also fuelled the radical right and left mass political movements, first in the form of Communism after Russia's 1917 revolution, and then with the rise of Fascism and Nazism. These together formed the political pincer movement in Europe which was to squeeze out the middle ground in politics, and virtually vanquish democracy in continental Europe for twenty years. When democracy was largely restored to Western Europe after WW2, and as national 
economies gradually gave way during the post-war boom to the reopening of trade, liberalism re-emerged but now in a political space that was also occupied by social and Christian democracy on the Continent and by the Labour Party in Britain.

The inheritors of the post-war political settlement in Britain, and the major builders (if not sole architects) of the welfare state, were the Labour Party. Their achievements in the austere post-war years were substantial, laying the foundations of a near-consensus Keynesian politics of the full employment welfare state which seemed to point in the same directions as continental social democracy and certainly put Britain, for a time, in the vanguard of public health provision. By the 1960s, with full-employment, expanding job opportunities, and the unionisation of unskilled workers, Britain had become more egalitarian in income distribution than at any time before or since. However, in three crucial ways it had not embraced social democracy at all but remained wedded to a social liberal model developed before WW1. Firstly, the labour movement had remained somewhat insular and inward-looking. Its trades unions were highly fragmented - divided up between rival craft unions, and with a substantial cleavage between craft unionism and the growing general workers unions. Consequently they failed to act in the concerted way that continental union movements were able to do, typically organised, as the latter were, as industrial unions, and increasingly under the influence of social democratic politics and neo-corporatist forms of labour market organisation. In fact, both unions and employers in Britain failed to develop powerful encompassing peak associations which could concert and discipline their members and coordinate bargaining on a sector-wide basis (Marquand, 1988). It was this segmented and inward-looking labour movement that gave rise to the distinctive ideology of 'labourism' which was the Labour Party's version of social democracy (Milliband, 1975). Secondly, labourism, unlike continental social democracy, was always highly eclectic ideologically and lacking in clear theoretical principles; it had also failed to transform itself from a class party into a party of the 'people' as the Nordic social democratic parties had done in the 1920s and 1930s (Esping-Andersen, 1985) and as the German SDP had done after the war. Thirdly, the state remained in essence a liberal apparatus, neither tasked with, nor equipped for, carrying out the kind of state developmental policies typical of social democratic regimes in Scandinavia and or the more étatist republican regimes in France (Marquand, 1998).

The British post-war state made retaining full employment its major objective and it attempted to do this through interventionist Keynesian demand management policies. 
However, Keynesianism was interventionist in macro-economic management but essentially liberal in its politics. Keynes had believed demand side intervention to prevent recession and mass unemployment, but he had little to say about supply-side intervention and did not believe that redistribution was the proper function of the state, beyond, that is, through the latter's role in maintaining full employment. Macro-economic management of the economy was arms-length intervention; it was never meant to extend to the more pro-active forms of supply-side management practised by developmental states to boost productivity and competitiveness; and the state was essentially ill-equipped for this function. In two key areas of industrial policy and incomes policy the British state recorded a series of failures throughout the period. Both Harold Macmillan’s tripartite National Development Council, and Harold Wilson's later Department of Economic Affairs, failed to develop industrial policies which would enhance Britain’s lagging productivity and competitiveness (Marquand, 1988). Likewise the Keynesian state had no effective means to manage wage inflation under conditions of full employment. Hence the repeated stop-go cycles of wage inflation, followed by balance of payment and sterling crises, which governments could only halt by reducing demand through slowing the economy with increased taxation or interest rates. Repeated attempts at prices and incomes policy, by Prime Ministers Edward Heath and Harold Wilson in the 1970s, each failed, as trade unions declined to act collectively in maintaining wage and price stability.

Britain remained, in relative terms, quite cohesive as a society during the 1950s and 1960s, a state of affairs no doubt helped by rising real incomes, more equal income distribution and enhanced welfare and education provision, the latter particularly after 1960. It was also becoming a more tolerant society, not least due to Home Secretary Roy Jenkins' sweeping abolition of formerly restrictive and discriminatory laws on obscenity, abortion and homosexual activity (Judt, 2005; Marwick, 1999). However, in crucial respects, this was still a distinctively minimalist liberal form of cohesion which was legitimated by the greater opportunities and lifestyle choices available to individuals but not anchored in deeper forms of social solidarity. Labour market and trade union organisation was far from encompassing and certainly did not encourage solidarity beyond the narrow confines of sectional interests; in fact labour, in large measure, just reflected the individualism of the dominant liberal creed. As David Marquand has argued, the 'sectionalism, which has always characterised the British 
labour movement, is the product of a culture permeated by Benthamite individualism'. (Maquand, 1988, 164).

By the early 1970s the 'Butskellite' consensus around the principal objectives of the Keynesian National Welfare State had broken down: the victim of the gathering global crisis of capital accumulation (profits squeeze) (Glyn, 2007) and the seemingly intractable domestic problem of economic 'stagflation.' The latter resulted from repeated Conservative and Labour government failures to deal with wage inflation through incomes policy, and was then compounded by the recessionary oil price hike of 1973. The crisis dragged on until public sector strikes during the so-called 'winter of discontent' in 1979 brought down the weakened and politically bankrupt Labour government. Margaret Thatcher brought the Conservative Party back to government with a new free-market mission to tame the unions and generally 'roll back the frontiers of the state' so that the entrepreneurial drive could be restored to the British economy. In the event public spending was not reduced, not least due to the massive social expenditures incurred as monetarist policy caused unemployment to rise over 3 million, but large parts of the British economy were privatised and financial and labour markets were substantially de-deregulated. The neo-liberal project, progressively deepening during 18 years of Conservative rule and continued, barely attenuated, after 1997 by New Labour, entrenched the liberal orthodoxies of the British state which had only been partially abandoned during the post-war years. The free market, only lightly regulated, individual freedom and choice, and private initiative were once again the ascendant values. Wide-scale redundancies during the early Thatcher years, coupled with a trend towards increasing inequality in incomes which continued through to 2008, no doubt took their toll on social cohesion, as a consumerist individualism increasingly displaced notions of the public realm and collective social goods. But rising employment rates from the mid 1980s, together with a rapidly broadening base of home and share ownership, gave some credibility to the claims of improved opportunities and choice - albeit that social mobility was actually in decline (Blandon, Gregg and Machin, 2005) - and in part obscured the steady erosion of trust (Hall, 1999) and binding community ties in British social life. Margaret Thatcher had famously declared that 'society does not exist' just as Jeremy Bentham had once claimed that community was a 'fiction'. 'Freedom' and 'opportunity' in the market were once again the main principles that should hold society together. 
Thatcherism in Britain was, of course, only one manifestation of the global neo-liberal order which the United States had increasingly sought to impose since the 1970s and which became the dominant modality of globalisation during the next 30 years. The US, as previously discussed, had always manifested a more extreme version of liberal individualism than Britain, even at the high points of the latter's laissez-faire policy, albeit that the US was a late and partial post-war convert to free trade (Chang, 2007). The Lockean belief in the untrenchable rights of individual property was more absolute than in Britain, and the liberal hostility to the central state more pronounced (de Tocqueville, 1956). There was no social liberal moment in nineteenth and early twentieth century America, to match the pre-WW1 reforms in Britain, and, despite its precocious championing of public education as a nationbuilding project (Green, 1990; Tyack, 1974), the US never created a welfare state in the sense understood in Europe (Showroneck, 1982). President Obama is still currently struggling to win political support for legislation to create something approaching a US public health service.

Franklin Roosevelt's New Deal in the 1930s, precipitated by the biggest financial crash and subsequent economic slump in the history of capitalism, did indeed challenge the basic assumptions of liberalism for a generation, and represented a more radical social reform than anything attempted in the UK. It involved not only a massive experiment in Keynesian demand management but also a programme of public works to stimulate the economy on a scale never attempted elsewhere. Contrary to all previous political opinion, it allowed the federal state a massively ambitious interventionist role which was still evident through the 1960s in President Kennedy’s 'New Frontier’ programme and the 'Great Society' social reforms of his successor, Lyndon Johnson. Not surprisingly, the New Deal generation, and the post-war generation after them, represent, for Putnam, the high water mark of civic activism and social capital in American history (Putnam, 2000). But by the 1970s the US was reverting again to its fundamentalist, pro-market, anti-state liberal principles.

By the early 1970s, the ballooning costs of war in Vietnam and resultant balance of payments deficits prompted the Nixon administration to abandon the gold convertibility of the dollar and its global role as banker of last resort, and thus to dismantle the dollar-based fixed exchange rates system, set up at Bretton Woods, which was the centre piece of the post-war Keynesian international system for financial stability (Hutton, 2002). This, and the subsequent removal of capital controls promoted by America, led to the rapid globalisation of 
financial markets characteristic of the next three decades. It was Ronald Reagan's election to the Presidency in 1980, shortly after Margaret Thatcher became Prime Minister in Britain, which heralded the dawn of a new era of free-market liberalism in the US, characterised by widespread de-regulation and combined with aggressive (paradoxically Keynesian) tax cutting. Inspired by the free-market economics of Friedrich von Hayek and Milton Friedman, but also by the post-Nietchzean political philosophy of Leo Strauss (Gray, 2007), a neoconservative elite coalesced during the Reagan presidency which had wider ambitions, not least in American foreign policy which was to become increasingly unilateralist. In the subsequent decades the US increasingly sought to mould the global economy along freemarket lines, as best served its economic interests, using GATT, and subsequently WTO, to de-regulate telecoms and to promote intellectual property rights and free trade in services, and the IMF and the World Bank to enforce the so-called Washington Consensus policies on developing countries. Their so-called Structural Adjustment Policies, the price developing countries paid for aid, typically included financial deregulation, the removal of capital controls and trade barriers, budgetary austerity and wide-scale privatisation. They tended to be excessively recessionary, as in the aftermath of the 1987 Asian financial crisis, but they had the merit of opening up developing country markets to US investment and trade, thus further boosting the momentum of American neo-liberal globalisation (Stiglitz, 2002).

Back at home, US society became increasingly polarised, as tax cuts and new stock-option reward schemes inflated executive salaries, while middle and low income employees saw wages decline, the low-skilled increasingly marginalised in an economy transformed through skills-biased technological change. In the 1980s the top 1 percent of American families saw their income double while the incomes of the bottom 20 percent dropped by 10 percent (Hutton, 2002, 118). Average wages fell for all but the top 20 percent of the workforce by 20 percent in the 20 years to 1995 (Hutton, 2002, 164). By the end of the century American society was divided as never before, with both the rich and the poor, in their different ways, seceding from mainstream civic life. This was graphically illustrated by the two million plus incarcerated and the three million odd American families who now lived in 'gated communities' protected from the outside world by private security guards, and serviced with private health and educational provision (Reich, 2000; Hutton, 2002). Putnam, in his celebrated 'Bowling Alone' study, not surprisingly, found that social capital and civic community was in rapid decline in America (Putnam, 2002). 


\section{Republicanism and Romantic Conservatism}

Nineteenth-century republicanism and romantic conservatism both left important intellectual legacies to the twentieth century and still influence thinking in parts of Europe in the new millennium. Republican thought has undoubtedly left its mark on the European Union whose structures and objectives have been heavily shaped by France. Neither has the ethno-cultural, organicist thought of the romantic conservative tradition completely disappeared from the intellectual discourses in western Europe. But since the post WW2 reconstruction of the German-speaking countries which formed its heartland, it is no longer a dominant force, at least in the West. Post-war western continental Europe has substantially converged in its structures and policies, not least under the influence of the European Union, and republicanism and organic conservatism are but some of the elements which have fused in a new political economy, which we will later typify as that of the 'European social market'. We need spend less time tracing their currents but some distinctive lines of descent and influence remain important to note.

French republicanism has been characterised by its distinctive attitudes towards the state and the importance of the public realm, the character of nationhood and the ideal of direct, participatory democracy. These characteristics have been modified but not transformed during the past two centuries.

French republican thought has invariably placed great stress on the role of the state, both as the guarantor of order and social solidarity, and as a dynamic force in economic development. This centralised tradition, as de Tocqueville rightly observed (1955), was not the invention of the Jacobins: it was the legacy of the Ancien Régime which the Revolution reinforced and which Napoleon subsequently utilised in his development of a modern state apparatus, replete its universalistic legal codes and standardised country-wide administrative structures emanating in tentacular fashion from Paris. Successive Republics have modified the structures including, in the 1980s, by creating a greater role for regional government, but France has remained a relatively centralised polity. In the post-WW2 era the state also assumed some of the characteristics of a 'developmental state' - or as the French call it, the 'économie concertée' - with pro-active state planning and industrial policy driven by the elite corps of highly-trained technocrats in the central state departments working in close cooperation with leaders of public and private corporations (Marquand, 1988). The 
Napoleonic legacy left its mark in southern Europe generally, and the typically centralised administrative structures of republican state power - if not the state developmentalism - have also been characteristic of southern Europe as a whole, and particularly of Greece, Spain, and Portugal, notwithstanding the regionalist reforms in the past 20 years in Italy and Spain. France, geographically unique in straddling both the south and north of Europe, has also left its substantial mark on the European Union, whose original centre of gravity was to the north, not least in the European Commission, which was largely modelled on French bureaucratic lines. What is of prime concern here, however, is the ongoing tradition in republican thought of the primacy role of the state as a guarantor of social cohesion. As Durkheim reminded us, the state cannot do it all alone, and civil society has a vital role to play, even in the republican scheme. But what is distinctive, finally, in this tradition, is the central role of the state in promoting national identity and in furnishing the institutional structures - of welfare, education and distribution- which are believed underpin social solidarity.

The republican notion of nationhood has also been distinctive. In the French tradition, the nation was always conceived in essentially political terms, in relation to the institutional and territorial frame of the state. As Rogers Brubaker writes: 'Revolutionary and republican definitions of nationhood and citizenship - unitarist, universalist and secular - reinforced what was already in the Ancien Régime an essentially political understanding of nationhood' $(1992,1)$, sharply contrasted with the ethno-cultural understandings more typical of Germany and the German-speaking countries. French citizenship law has reflected this. The Revolution allowed citizenship to those born of French descent but also to foreign residents who wished to assume the rights and obligations of citizenship by declaration of an oath. ${ }^{5}$ By 1889 French citizenship had been granted to all foreign persons who lived there from birth until the age of majority. The principle of 'jus soli' - which France shares with English-speaking countries contrasts markedly with the 'jus sanguinis' principles that have, until very recently, underpinned the more ethno-cultural citizenship laws in Germany, for instance, where entitlement depended on ancestry not place of birth, and where naturalisation rights were extremely limited for those without German ancestry. While territoriality and political belonging have formed the basis of citizenship and nationhood in republican thought - ruling out a predominantly ethnic conception of national identity - language and culture have, of course, always mattered. France has historically adopted a quite assimilationist approach to

\footnotetext{
${ }^{5}$ Napoleon subsequently restricted rights for foreigners to those born for the third generation in France who elected for citizenship at the age of majority. Information from Bryony Hoskins.
} 
dealing with cultural diversity, albeit that this is conceived primarily in terms of the integration of outsiders into the secular public political culture. Despite sharp recent controversies about the wearing of religious dress in classrooms, the French state still upholds the traditional republican belief that schools are secular institutions and officially forbids students to dress in ways that signal their religious affiliation (Corbett and Moon, 1996). However, increasing ethnic diversity in France has put mounting strain on the traditional assimilationist policy. In practise it becomes more difficult to insulate the state and the public sphere from the politics of cultural difference, and many no longer believe this is desirable, albeit that the principle of laicité in the public realm remains sacrosanct.

The third distinctive feature of the republican tradition relates to the importance accorded to active citizenship which goes back, as we saw, to Rousseau's social contract. The focus here is on participation in formal, usually national, politics rather than on local civic activism which is emphasised more in the liberal tradition. This idea remains at the heart of republican traditions and, as we saw in the first section, is one of the republican contributions, along with the stress on shared values, to the ideology of the European Union. The republican tradition has thus remained distinctive in a number of ways. However, France is also centrally part of the European Union, which it has both shaped and been shaped by, and it becomes increasingly difficult to differentiate between the concepts of social cohesion which are characteristic of the republican tradition and those which predominate in the discourse of the European social market.

The historical trajectory of the romantic conservative intellectual tradition, most associated with Germany, is quite different. It was a major component of the European zeitgeist of late nineteenth and early twentieth century which contributed to the development of Nazi racist ideology in the 1920s and 1930s, but after the horrors of WW2 was largely banished from western European official discourse on social cohesion. The rise of Nazism cannot, of course, be solely attributed to an ethno-cultural philosophical tradition most predominant in Germany, but also evident elsewhere in Europe. German Nazism was also the product of other exceptional forces, including the national humiliation and resentment over defeat in WW1 and the subsequently punitive terms of the Versailles treaty, the perceived problems of the German irredenta in neighbouring states, and then the deep economic slump in Germany in the early 1930s. The total eclipse of the centre political ground, crushed between the rising nationalist right and a Communist movement, which refused to make common cause with 
social democracy following the disastrous policy of the Third International, also played its part. But the extreme racist ideology of Hitler and the German NSDAP cannot either be explained fully without reference to the extreme racist discourses which had its roots in the ethno-cultural and increasingly nationalist philosophy of the romantic conservative tradition as it had evolved after 1806 in central Europe. Fascist movements arose out of similar political and economic forces elsewhere in Europe, but the Mediterranean variety of Fascism, in Mussolini's Italy and Franco's Spain, never exalted anti-semitism to the core of its ideology as did the Nazis and their kindred movements in central and eastern Europe. It can hardly be forgotten that the Nazis found active support for their genocidal policies in many, if not most, countries of central and eastern Europe (Mazower, 2008), and that Bulgaria was the only Axis power largely to resist the Final Solution (if we don’t count Mussolini’s pragmatic equivocations) (Mann, 2005).

With some justice, then, post-war Western Europeans have tended to regard ethno-cultural notions of social cohesion with some suspicion, and post-war western Europe has for the most part been constructed on more civic principles. Most notably, Germany made a quite rapid and remarkable transition as it was re-constructed as a liberal federal state which apportioned limited power to central government. Under the guidance from 1949 of the Economic Minister, Ludwig Erhard, its economy was also reconstructed along social market lines. Some of the neo-corporatist structures of this economy had antecedents in the guild structures of the nineteenth century (Thelen, 2004; Streeck, 1997), just as the evolving welfare system owed much to its Bismarckian origins. Nevertheless this was a wholesale transformation, and nowhere more so than in the political culture. The romantic conservative intellectual tradition has, arguably, retained its residual influence in central and eastern Europe, particularly in former Soviet satellite states after the fall of the Berlin Wall. But it has no part in the dominant political philosophy of post-war Germany. Germany, now re-united, now stands at the heart of a European Union whose dominant conceptions of social cohesion draw not on earlier German traditions, but on a mixture of social and Christian democracy and French republicanism. Following the 2000 Lisbon EU conference and, particularly after the 2004 Kok report on employment, the EU has increasingly adopted a more liberal agenda for boosting economic competitiveness in the member states. But the idea of 'Social Europe,' encapsulated in the famous social chapter of the Maastrict Treaty, to which all countries 
barring Britain signed up, has not entirely disappeared, and remains the official foundation of social Europe’s model of social cohesion.

\section{Social Democracy}

European social democracy, from its inception in the 1880s, but especially in its Nordic form from the late 1920s, contains a quite distinctive conception of social cohesion. This contrasts sharply with the mainstream liberal tradition and is also clearly distinguishable from the social market conception in the post-war era. Originally an offshoot of Marxist revolutionary socialism, social democracy retained the egalitarian traditions of its socialist progenitors even after it had sloughed off the theoretical framework of Marxism and reconciled itself to a reformist, parliamentary road. In its Nordic variant, if not elsewhere, social democracy has continued to view equalisation of incomes as a primary goal and an essential pre-condition of social cohesion. It also insists on the promotion of social solidarity as a primary political objective. Unlike Marxist socialism, which viewed social solidarity exclusively in intra-class terms - as it was bound to do since class struggle lay at the heart of its theory of history and political programme - Nordic social democracy began from the late 1920s to conceptualise social solidarity in cross-class terms, as a 'people's solidarity'. Swedish social democrats in the 1920s had already started to propagate the idea of the 'People's Home' (EspingAndersen, 1985). It was this conception which underpinned the exceptionally universalistic design of the post-war welfare states in Scandinavian and other Nordic countries.

The original European social democratic parties, including the Social Democratic Federation in Britain and the Social Democratic Workers Party of Germany, founded in 1869 under the influence of Marx and Engels, were avowedly Marxist parties committed to revolutionary change, even if Marx himself reviled the incipient parliamentary reformism of their Gotha Programme adopted in 1875. But it was the 1891 Efert Programme, jointly authored by Eduard Bernstein, August Bebel and Karl Kautsky, and adopted by the re-formed German Social Democratic Party (SDP), which explicitly renounced revolution in favour of parliamentary reform, and incurred the wrath of the revolutionists who later reversed the policy. Bernstein, who went on to lead the 'revisionist' faction of the SDP, deviated further from Kautsky's more orthodox Marxism, denying both the imminence of the overthrow of capitalism and the unreformable nature of the capitalist system itself. Social democratic parties of all sorts remained within the Second International, alongside revolutionary socialist 
parties, until that split after WW1. But revisionists and orthodox Marxists in the SDP remained at odds, substantially weakening the SDP as a political force in Germany during the Weimar Republic. It was not until well after WW2 - at the historic 1959 Bad Godesberg conference - that the SDP renounced class struggle and orthodox Marxism.

Social Democracy in Scandinavia, however, took a different route. Social democratic parties were all founded originally as workers' parties, in alliance with national trades union movements (the Danish SDP in 1878, the Norwegian DNA in 1887 and the Swedish SAP in 1889) (Esping-Andersen, 1985b). But by the late 1920s, they had already announced themselves as people's parties, representing workers and small farmers, and increasingly, during the 1930s, forging alliances with the petit bourgeoisie. Sweden's social democratic leader and major theorist, Hjalmar Branting, was himself a Bernsteinian revisionst, and other leaders, such as Gustav Bang in Denmark, carried little of the Marxian orthodox baggage of the German SDP leaders. Facing relatively little political competition from national communist parties, and committed to a pragmatic, alliance-building political strategy, Scandinavian social democratic parties were quick to gain parliamentary power. The Danish social democrats first won office in 1924 and, from the 1930s on, social democratic parties have dominated government in all three countries.

A unique combination of historical factors may have contributed to the predominance of social democracy in Nordic politics since the 1920s. The political rise of social liberalism, and subsequently of social democracy in all these countries was no doubt aided by the relative absence of a large aristocratic landed class, as well as, in several cases, by the relatively weak and fragmented nature of the bourgeoisie. And the lack of a powerful reactionary class allowed democratisation in the latter part of the nineteenth century to follow a relatively smooth path. Social democracy may also have benefitted from the relative cultural homogeneity of the Scandinavia states in its formative period. However, of overwhelming importance in all the Nordic countries was the numerical prominence of a class of small and medium-sized farmers who were politically conscious and organised and progressive in their outlook. Social democratic parties managed to forge successful workerpeasant alliances which formed the bedrock of their support, and, often through formidable organisational capacity, mobilised a majority behind their policies. As Esping-Andersen writes: 'In brief, the character of the Nordic peasantry offers the most convincing explanation of why Scandinavian social democracy succeeded to such an extent, why the Nordic 
countries pioneered the modern welfare state, and, ultimately, why these three countries came to converge politically.' (Esping-Andersen, 1985, 88). The crowning achievement of Nordic social democracy was, indeed, the post-war construction of exceptionally generous and comprehensive welfare provision by the state, and this had important implications for the nature of social cohesion in these countries. As Esping-Andersen argues 'universalism and institutionalism can be viewed as the basic organisational principle for the construction of solidarity.' (ibid, 176)

\section{Section Five: Contemporary Regimes of Social Cohesion and their Institutional Foundations}

We can now begin to specify more precisely the components of different contemporary regimes of social cohesion. We do this firstly through a qualitative analysis of the institutions and social attributes which are found in various literatures to be relevant to the production and maintenance of social cohesion in different forms in different countries and regions (or clusters of countries). In the subsequent section we use statistical analysis of cross-national data on institutional characteristics and social behaviours and attitudes to further specify the regimes and to put existing theories to additional empirical 'tests'. It should be re-stated, however, that in the research process itself the qualitative and quantitative analyses have been iterative rather than sequential. Despite the order of presentation here, the quantitative analysis has in fact been constitutive in the development of the theoretical models, modifying our interpretation of various aspects of the theories in the literature which we present first.

As discussed in section three, regimes of social cohesion can be seen as relatively durable (but not immutable) configurations of social attitudes and behaviours contributing to societywide social bonding that are underpinned by particular institutional arrangements. Regimes are generally construed as 'ideal-types' - stylized systems which show the logical relations between various components which can be found in a number of cases, although not all in each one. In terms of social cohesion they are understood primarily in terms of national systems, since social cohesion is defined here as a state-level phenomenon, and since many of the constitutive components of a given form of cohesion will be state-level structures and cultural peculiarities which are measured at the national level. However, any national regime will also be dependent on supra-national global and regional structures, systems and flows, 
which must also be accounted for. The national institutional structures most relevant to social cohesion include the laws and regulations governing property and ownership, including company law; the organisation of the labour market; the arrangements for wage setting and income re-distribution and the welfare system. There is a substantial literature on which we draw on the 'varieties of capitalism' (eg Albert, 1993; Crouch, Finegold and Sato, 1999; Crouch and Streeck, 2006; Dore, 2000; Esping-Andersen, 1999; Gray, 1998; Hall and Soskice, 2001; Hutton, 1995, 2002; Nelson, 1993; Nickell and Layard, 1998; Regini, 1995; Thelen, 2004;) which focuses mainly on company law, labour market organisation, wage setting mechanisms, training and innovation systems and firm-level work organisation and product/market strategies. There is also a substantial literature on welfare state regimes on which we draw more selectively (Esping-Andersen, 1985; 1990; Marquand, 1988). Other literatures on areas such as immigration and race relations policy, housing policy, and education would also be relevant but for reasons of space and time we do not seek to cover all these here, important though they may be to the underlying foundations of social cohesion. ${ }^{6}$

Our historical analysis to this point has identified a number of intellectual traditions and corresponding regimes of social cohesion which have been dominant within different regions (or country clusters) at different points of time. These have not been seen as static and the analysis thus far has sought to show how these have emerged and mutated over the past two centuries. Nevertheless there has been found to be sufficient continuity in certain traditions and systems to justify the identification of various dominant regional types evolving in partially path-dependent ways. The major regimes types which we have identified which have come to dominate in the western developed countries in the recent period have been labelled as 'liberal', 'social market' and 'social democratic'. We also find partial evidence of a residual type in central and eastern Europe (deriving in part from the romantic conservative tradition which we identified in the nineteenth century) and of a variation on the social market model in southern Europe, although this does not have the coherence of a regime type, not least because of the very substantial differences in economic and social characteristics associated with different levels of development in the southern European countries. The liberal model is represented most clearly by the Britain and the US, although elements of it would also seem to apply to other English-speaking countries. The social market model is best represented by Germany, Austria, Switzerland, Belgium and other

\footnotetext{
${ }^{6}$ How important can be seen by the catastrophic effects of home ownership and home loan policies on the economies and social fabrics in the US and Britain in recent years.
} 
north-western continental European countries, although some southern European countries share some of the characteristics of this model. The social democratic model is most clearly associated with the Nordic countries, although there is some overlap in the characteristics of this 'regime' and the social market regime. In the final part of this section we also provisionally identify elements of an east Asian model of social cohesion, referring principally to Japan and the east Asian Tiger Economies.

The country groupings conform to some extent with the country groupings identified in the varieties of capitalism literature. Works in this tradition invariably postulate a neo-liberal model of capitalism - variously described as 'shareholder capitalism' (Hutton, 2002), 'stockholder capitalism' (Dore, 2000) or 'liberal market economies' (Hall and Soskice, 2001). Britain and the US are the main examples provided of this form of capitalism but other English-speaking countries are sometimes included - for instance Australia, Canada, Ireland and New Zealand in the Hall and Soskice account (2001). In one version the Britain is seen to lie somewhere between the US and Europe (Hutton, 2002). For the most part, little quantitative or qualitative evidence is provided for extending the model to most developed English-speaking countries, and some other accounts classify some of these other countries with other models (Ireland as akin to 'core Europe' in the account of de Mooig and Tan, 2003, for instance). Works on the varieties of capitalism typically contrast the neo-liberal model with one other model of capitalism. This is variously designated as 'stakeholder capitalism' (Hutton, 2002), 'relational capitalism' (Dore, 2000), ‘coordinated market economies' (Hall and Soskice, 2001) and 'Rhineland capitalism' (Albert, 1993). The identification of just two polarised models seems somewhat arbitrary and sometimes appears as more of a hermeneutic comparative device, rather than the result of systematic classification across developed countries. The component characteristics of these models are often very similar in the different accounts, but the countries taken as primary exemplars often vary considerably. So for Dore (2000) Japan is the primary example of 'relational capitalism', whereas Hutton's analysis of 'stakeholder capitalism' (2002) focuses on Germany and, to a lesser extent, Austria, with some reference to what he describes as different variants of this model in Scandinavia and southern Europe. Albert's account of 'Rhineland capitalism' is more inclusive, embracing primarily Austria, Germany and Switzerland but, on the fringe, also France, Japan and Sweden. Hall and Soskice (2001) have a yet larger set of countries as exemplars of 'coordinated market economies', including: 
Germany, Japan, Switzerland, Netherlands, Belgium, Sweden, Norway, Denmark, Finland and Austria.

Our own account of social cohesion regimes here corresponds only partially with the variety of capitalism models. Our 'liberal' model includes the English-speaking countries with the Britain and the US as the core, as in other accounts. On some indicators the US comes out as an outlier, far more extreme in its liberalism than even Britain from which it inherited the tradition, but we do not find that Britain is midway is between the USA and continental Europe, as it appears in Hutton's account. Unlike the varieties of capitalism literature, which identifies only two main regimes, lumping most of north-western continental Europe (including Scandinavia) together, we find three quite distinctive regimes in the West, with a clear distinction between the social democratic regimes of the Nordic countries, and the social market regimes of non-Nordic north-west 'mainland' Europe (the geographical terms are inadequate here since Norway, Sweden, Finland, and Jutland are all technically part of the Continent, even if Zealand and other Danish islands, Iceland, and Greenland are not!). However, like most of the varieties of capitalism literature, we find the southern European countries to be only loosely, or partially, related to the north-west European cluster, with France typically somewhere between North and the South, as befits its geo-historical development (see Braudel, 1979).

What we are presenting here is essentially, therefore, a tripodic model for Europe, unlike the binary model of the varieties of capitalism literature. In fact our theory is much closer in its clustering of countries to the theory developed by Esping-Andersen in his Three Worlds of Welfare Capitalism (1990) where he distinguishes between the 'liberal' model (Englishspeaking countries, the 'social democratic' model (Nordic countries) and the 'conservative corporatist' model (non-Nordic north-Western European countries plus Italy). The close parallelism is obviously not accidental since we have drawn substantially on his theory which, being about welfare states, clearly has great pertinence for any model of social cohesion regimes. However, we use many indicators not used in his analyses which also show country clusterings similar to the ones he finds for his welfare state regime indicators.

It should also be noted that Esping-Andersen sees Catholicism as an important aspect of the 'conservative regime' and consequently, in his original formulation of the theory (1990), found little difficulty in accommodating Italy and other southern European countries to this 
regime. We, on the other hand, locate the geographical centre of gravity of the 'social market' regime firmly in north-west Europe and find southern European states only weakly associated with this model. This conforms more with Esping-Andersen's more recent revisions to his thesis (1997) where he notes that southern European welfare systems only partially conform to conservative corporatist regime type of northern Europe on account of their much less comprehensive social provision which has forced a continued reliance on traditional familialistic forms of welfare provision.

\section{The Liberal Regime of Social Cohesion}

The liberal regime of social cohesion relies for its legitimacy on a widespread belief in the benefits of opportunity, individual freedom and choice, and rewards based on merit. In addition to these core beliefs, it regards high levels of civic association as an important social cement and generally believes itself to be tolerant of diversity. In the liberal regime, social cohesion is not seen to depend on economic equality, and the state and its public institutions are not taken to be the guarantors of social cohesion, beyond their role in maintaining law and order and a minimum safety net for those least able to help themselves. Put simply, the individual comes before the state, and freedom is more prized than equality. The basic principles can be seen to run, like a red thread, through all areas of social organisation from corporate governance, labour market organisation to welfare provision.

In the Lockean universe the right to individual private property is one of the fundamental natural rights. Property rights are more absolute and unconditional in Britain and the US than in other countries where ownership brings with it obligations as well as rights. This is nowhere more evident than in the law governing company ownership. Company law and corporate governance in Britain and the US make firms accountable to their shareholders alone, rather than to shareholders and other stakeholders as in many continental countries. Companies are seen as bundles of contracts (Hutton, 2002) or bundles of shares (Albert, 1993) rather than communities involving different stakeholders with equally valid interests. Shareholder value thus drives company strategy, placing a premium on both rising share values and generous dividends. Unlike in Rhineland model countries, where banks make long-term investments and hold much of the equity in medium-sized and larger firms, the majority of company shares in Britain and the US are held by individuals and institutional investors, who are all seeking rapid returns on their capital. Companies are consequently 
forced to adopt short-termist strategies to maximise shareholder value and raise dividend payments. Profits are more likely to be distributed in dividends than re-invested in research and development and, in the absence of stakeholder model barriers to hostile take-overs, value enhancement is often sought through mergers and acquisitions rather than through the patient process of innovation and the building productive capacity (Hutton, 2002). In contrast to the 'stakeholder' or 'relational' models of corporate governance, firms in the shareholder model are seen as endlessly shifting sets of legally enforceable contracts but not as communities of shared interests. The firm exists to make profit not to promote solidarities and long-term relationships and is rarely seen as a source of cohesion.

In the liberal model the notion of solidarity is equally absent from the labour market. Flexible labour markets are seen as the holy grail of the free-market economy because they are deemed to promote efficiency, company profitability and higher employment rates (although the evidence for this is far from conclusive) (Layard, 2005). In Britain and the US employment protection is relatively weak, making hire and fire easy and less expensive. This has facilitated the creation of many low paid, part-time and temporary jobs, particularly in the service industries, which increases overall employment rates, but it has not necessarily benefitted innovation and the development of high performance workplaces. It is also debateable whether labour market flexibility is actually the reason why Britain and the US have higher employment rates than continental stakeholder economies. The major difference between the labour markets in Britain and the US and in the social market economies is the lower rate of female labour force participation in the latter which can be attributed as much to the relatively gradual abandonment of family-centred Catholic traditions of households based on sole male breadwinners. Employment rates of males between 25 and 65 are similar across both types of economy (Hutton, 2002).

Wage-setting mechanisms are also market-driven and lack the more solidaristic qualities found in many stakeholder economies (both social market and social democratic). Minimum wages tend to be set low, thus having little overall impact on wage determination. Whilst some - usually public - sectors have maintained national wage bargaining, wage levels in most companies are fixed by market supply and demand. Compared with stakeholder-style economies, Britain and the US have relatively few jobs where statutory license to practise rules intervene in supply and demand wage setting, and sectoral agreements between representative social partner organisations, which fix qualification requirements and pay 
bands for broad swathes of occupations in stakeholder economies, are relatively rare. Whereas centralised wage bargaining by encompassing social partner organisations in stakeholder economies encourages solidaristic wage setting behaviour, since multiple interests have to be reconciled (Streeck, 1989), in systems with fragmented and localised bargaining market strength is likely to determine outcomes. Cross-national evidence on wage-setting procedures and wages, suggests that systems with more centralised and coordinated bargaining procedures (and higher minimum wages) will deliver lower levels of wage inequality, without necessarily raising overall employment levels (Mason et al, 2008; Nickel and Layard, 1998).

Welfare arrangements differ between Britain and the US, most obviously in the absence of a comprehensive public health system in the US to compare with the taxation-based National Health Service created in post-war Britain. However, according to Esping-Andersen's theory both Britain and the US have liberal welfare systems which are less universalistic and less 'de-commodifying' than those in either the conservative or social democratic models. ${ }^{7}$ Esping-Andersen writes that 'decommodification occurs when a service is rendered as a matter of right, and when a person can maintain a livelihood without reliance on the market.' (Esping-Andersen, 1990, 12). When it was first set up according to Beveridge's plan, Britain's NHS looked the most de-commodifying and universalistic of the solutions to public health care. However, it was not able to maintain sufficient quality, according the EspingAndersen, and was eventually supplemented by widespread use of private health services funded through private insurance schemes which were entirely market based. Aside from the federal Medicare and Medicaid programmes, which provide limited insurance for the over 65s and to those on low incomes respectively, the US relies entirely almost entirely on a private health care system afforded by those who have private insurance cover. In 2000 still 43 million American were without any health insurance (Hutton, 2002).

Pensions have also become less than universalistic in both countries. The State Retirement Pension scheme introduced by Lloyd George in 1908 was non-contributory and flat-rated. The US Social Security Act created a pension scheme based initially on strictly actuarial principles, but membership soon became compulsory and pensions became significantly redistributive. However, as Esping-Andersen argues, 'as with British pensions, social security

\footnotetext{
${ }^{7}$ The recent debate about the relative merits of health care in Britain and the US brings out the substantial differences in the systems which Esping-Andersen rather underplays.
} 
in the US was not meant to crowd out the private pension market and individualism. Hence benefits and contributions were pegged to fairly low standards, and the general aim was that the system be as market-conforming as possible.' $(1990,64)$. By the end of the twentieth century the real value of pensions in both countries had been allowed to drop to such a point that they could no longer claim to sustain people in their old age. They were now taxed in Britain, and their value in both countries became substantially less than what was available under the social insurance schemes operating in continental Europe. Supplementary private insurance schemes were increasingly encouraged and adopted. At the same time unemployment benefits have become increasingly targetted and subject to means testing. Under the welfare-to-work type programmes in Britain and the US, the duration of eligibility for contributions-based unemployment benefits has been shortened and benefits made subject to active job search conditions, as is also the case with the non-contributory benefits which are also more subject to means-testing.

For Esping-Andersen, it is the preponderance of targeting and means-testing in public benefits, combined with the necessarily widespread use of supplementary market-based private insurance and service provision, which makes the liberal welfare state both less universalistic and less solidaristic than its social democratic and conservative equivalents.

De-regulated labour markets, regressive tax reforms and, to a lesser extent, restrictions in welfare benefits, have led to sharply increasing household income equality in Britain and the US. The pay distribution has been stretched out at both ends but most dramatically at the top. Executive pay in both countries has ballooned since the 1970s, partly due to reduced taxation on higher incomes and partly to the growing tendency for companies to reward senior executives with share options and bonuses in addition to their already escalating basic salary packages. Already by the early 1990s, according to Albert (1993), CEO earnings were disproportionately high in the US, at 110 times average employee earnings (compared with 17 times in Japan and 23 times in Germany). Senior executive pay was enhanced during the 1990s through share options packages, whose cumulative value in the US in 2000 had risen to over $\$ 600$ billion, up more than tenfold in a decade (Hutton, 2002, 24). At the same time wages at the bottom end (and also in the middle in the US) were stagnating - or worse declining in absolute terms, as in the US. The least qualified were particularly badly hit since skills-biased technological change put an increasing premium on qualifications and left the 
unskilled or under-qualified increasingly marginalised in sectors competing with low-wage Asian economies (Thurow, 1993).

Inequality has risen in most developed countries during the last two decades but its increase has been most rapid in Britain and the US. Comparative data on household income inequality (usually measured by the Gini coefficient) tends to lag considerably. However, EspingAndersen's review of existing data provides a good guide to the trends across countries for the 1980s and 1990s. The UK and the US saw the largest increases in the decade from 1986 with the Gini coefficient for household income inequality rising 28 percent for the UK and 24 percent for the US. For similar ten year periods rises remained below 13 percent in Nordic countries (Denmark, +1; Finland, + 4; Norway, + 7; Sweden, +12) and core European countries (Belgium +10; West Germany +7; Italy +13) with France unchanged and the Netherlands actually registering a decline (-5) (Esping-Andersen, 2005, 12)

By the end of the century the US had by far the worst record on inequality, with the richest 20 percent of Americans earning nine times more on average than the poorest 20 percent, a scale of inequality 50 percent higher than in Japan, Germany and France (Hutton, 2002, 149). But Britain's record was also dismal. By 2006 its income inequality was higher than in all bar six countries in the EU 25, with only Portugal and Greece in western Europe faring worse. Using Gini data from the late 1990s for a wider range of countries, and taking the average of the national coefficients for each country group, Figure 1, which gives the averages of country Ginis for each country group, shows that income distribution is most equal in the Nordic states, somewhat less equal in core Europe, and most unequal in the English-speaking countries.

The distribution of wealth has also become more uneven in Britain and the US and is far more unequal than in most comparable countries. In the US the share of wealth of the top one percent jumped 25 per cent from the mid 1970s to the mid 1990s, mainly on account of a redistribution from the rich to the very rich (Esping-Andersen, 2005, 10). In Britain, after nearly a century of decline, wealth inequality also increased under New Labour between 1997 and 2006, with the proportion of assets owned by the richest 10 percent rising from 47 percent to 54 percent. According to Esping-Andersen's figures, by the end of the century wealth was much more concentrated in the US than in Europe. The share of wealth possessed by the top 10 percent of the population was 35 percent in the US, roughly 25 percent in 
Figure 1 - Income Inequality by Country Group based on Gini Coefficient figures for the late 1990s

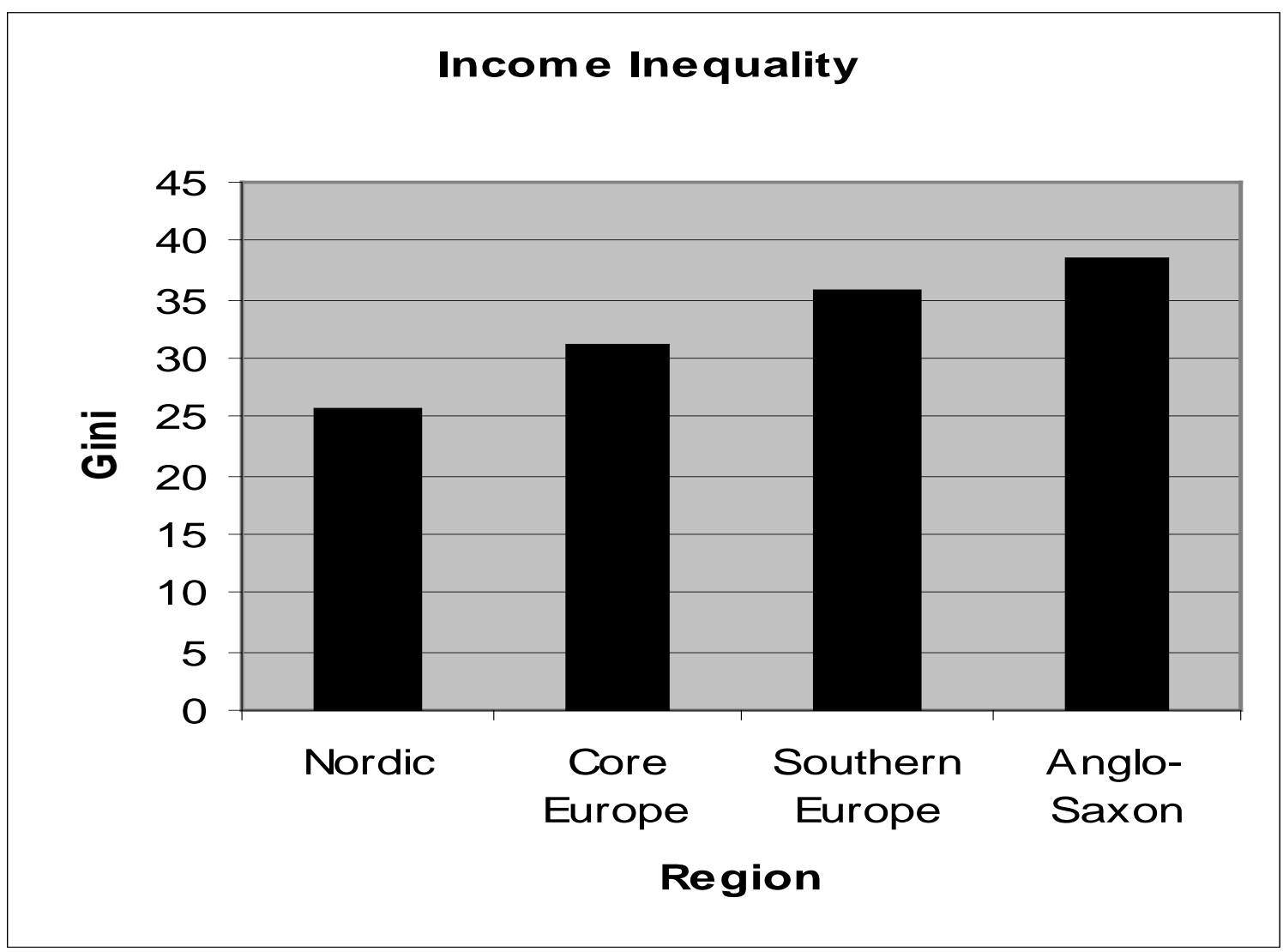

Canada, Denmark and France, but only about 15 per cent in Sweden (2005, 10). Given the higher levels of inequality in both wealth and incomes in Britain and the US the UK it is not surprising that inter-generational social mobility, according to a recent study, appears low by comparison with the Nordic countries and Germany (Blandon, Gregg and Machin, 2005). Mobility is normally higher in countries with lower income inequality, presumably because there is less distance to travel between the bottom and the top (or vice versa) (EspingAndersen, 2005). But rising wealth inequality is also likely to lock in privilege and disadvantage from generation to generation.

The full social consequences of three decades of rising inequality in the Britain and the US reversing a long previous trend towards equalization - may not be fully understood for some time. The trends on various social outcomes are not all pointing in the same direction. Hall has found declining levels of trust (in people and institutions) in the Britain over this period 
(Hall, 1999) and greater polarisation in levels of trust between different social classes. Putnam (2000) finds that social capital has declined on most measures in the US, although some critics argue that he fails to take into account new forms of associational membership in his measures of civic association. But industrial conflict has also dropped in Britain with declining union membership and weakening union organisation. Crime rates, for certain categories of crime at least, have also improved in both countries, although how much of the latter is due to changing demographics - and the declining proportion of crime-prone youth is still debated. There are some very graphic signs of social polarisation in the US, not least in the proliferation of gated communities and, more extreme still, the new independent incorporated cities, such as California's Hidden and Rolling Hills, which have declared political independence and are exempted from state taxes. Formally known as Home-Owners Associations these are self-policing and restricted communities which literally chose who comes in and who is kept out (Hutton, 2002). Taken together with the increasing isolation of urban ghetto communities in many major cities, this presents a frightening picture of increasing social fragmentation (Reich, 1991; 2001).

With rising inequality and low social mobility in the Britain and the US, it is perhaps surprising that the choice and opportunity ideology so trumpeted by politicians retained sufficient credibility to provide any kind of social cement during the 1990s and 2000s. However, high rates of employment, seemingly robust economic growth, and a consumption boom made possible by cheap imports, easy credit, and expanding private debt backed by inflating house prices, probably contributed to such optimism and cohesion as there was in these two countries, however illusory its foundations may seem to have been in retrospect. It can be no coincidence then that official discourses around social cohesion place such emphasis on employment. This has been particularly the case in Britain under New Labour, where 'social inclusion' has become the favourite policy term in place of social cohesion. While French academics may have originally propagated this concept to embrace the multiple ways in which individuals may be integrated into social and economic life - and thus able to participate and benefit fully as citizens (Giddens, 2005) - its use by British policy makers has been much more narrowly confined to the idea of inclusion in waged employment. Clearly employment can provide a platform and the means for individual integration in many aspects of the 'good society.' But absent from the discourse of social inclusion is any discussion of the variable quality of working life and the fact that extremely unequal material rewards for 
work will ensure unequal access to society's benefits. The large groups of low paid and insecure employees form a substantial part of the poor in both countries but they are not a major focus of policy.

\section{The Social Market Regime of Social Cohesion}

The social market regime of social cohesion differs from the liberal regime in the greater emphasis placed on the importance shared values and active participation on national political life, and in the greater reliance placed on the state to generate the conditions for social cohesion. The social market, it could be said, tends to institutionalise the sources of social cohesion.

Property rights in social market economies are not absolute in the way they are under the liberal regime, since ownership is invariably thought to entail obligations as well as rights. Company law and principles of corporate governance in Germany, and several other social market economies, are based on a concept of accountability to multiple stakeholders, including the workforce and consumers, rather than solely to shareholders. Article 76 of German company law requires managers to run their businesses in the interests of the entire organization (Hutton, 2002). Company capitalisation in Germany relies much more heavily on long-term finance from banks - the so called 'patient' capital which, along with the laws making hostile take-overs difficult, is often thought to encourage more long-term perspectives on building successful businesses. There is less pressure to show short-term increases in share value in each quarterly company report, and dividend pay-outs are generally low - at 20-30 percent of profits rather than the 80 percent more typical in the US (Hutton, 2002). Banks thus own a substantial part of the shares in companies, alongside individual shareholders and institutional investors.

However, it is not just patterns of ownership which make German companies stakeholder organisations. Co-determination laws (Mitbestimmung) give employees representatives rights alongside managers, shareholders and other stakeholders. The Mitbestimmung system goes back to the 1922 Works Council Law which gave elected workers in large companies a role in overseeing collective agreements and in nominating, along with shareholders, the members of the supervisory board. The latter became part of a two-tier system of control over the 
corporation, whereby supervisory boards (Aufsichtsrat), representative of workers as well as managers, shareholders and major creditors, oversee the managerial executive (Vorstand). Now, according to the 1992 Law, all firms employing more than five people must have Works Councils which must approve all hirings, dismissals, transfers, work allocations, and alterations in the scale and speed of production. Legislation in 1976 gave workers equal representation on the supervisory boards of all companies with over 2000 employees, with the shareholder's chairperson exercising the casting vote (Perkin, 1996).

German-style industrial democracy has often been credited, at least in part, with the success of German companies in developing the innovative, high-skills, high-value added production systems which Streeck sees as the foundation of the 'diversified quality production' which has kept Germany as the world's top exporter (Streeck, 1997). It is also promotes more solidaristic behaviour between the different stakeholders and social partners. The organisation of the labour market can be seen to have similarly solidaristic effects. The majority of employees in Germany are union members and are covered by the sectoral agreements between employer and employee peak bodies which not only define the qualifications required for particular occupations but also the pay bands for different jobs. This is believed to discourage firms from poaching employees trained by other firms through offering wage premia, and thus provides an incentive for company-based training and for participation in Germany's exceptionally comprehensive apprenticeship system which has been a major boon to productivity and innovation (Streeck, 1997). German law requires firms to join and fund chambers of commerce which perform an important role in concerting firm behaviour in each sector with respect to training and other areas where cooperation is thought to be beneficial. Industrial unionism, which tends to bring together employees in all occupations in a given sector, also serves to concert the interests of different groups of employees. In both cases, interest-group intermediation through encompassing representative bodies encourages more solidaristic behaviour since many interests have to be reconciled and concerted.

Labour market organisation in social market economies tends to promote greater wage equality at the same time as it promotes solidarity amongst employees and cooperation between social partners. The welfare systems in countries characterised by the social market can also be seen as solidaristic in one sense, but, on the other hand, are not in principle egalitarian, according to Esping-Andersen (1990). 
The origins of 'conservative corporatist' welfare systems in Germany and Austria, as with their apprentice training systems (Thelen, 2004), lay in the early guild systems which provided members with social welfare and protection as well as professional socialisation. While the guilds were being dismantled in the eighteenth and nineteenth centuries their underlying principles were incorporated into the ideologies of corporate associationism and mutualism. Corporatism evolved, according to Esping-Andersen 'as a major conservative response to the social fragmentation and individualism brought forth by markets and industry. It was a central theme in Durkheims's analysis of how to combat anomie; it emerged as the cornerstone of Papal and Catholic social policy; and it [later] found...expression in Fascist ideology.' (1990, 60). The welfare reforms brought in by Bismarck in Germany and von Taaffe in Austria were a conservative strategy to head off liberalism by re-asserting the power of the state and reinforcing the hierarchical nature of corporate identities amongst the traditional status groups. Social insurance was organised around the occupational status groups, each granted their own specific set of rights and privileges, but ultimately organised by the state not the market. Bismarck's 1891 pension legislation, and the pension system which evolved thereafter, can be interpreted, according Esping-Andersen, as an étatism with partial concessions to liberalism (actuarialism) and to conservative corporatism (compulsory occupationally distinct schemes) $(1990,59)$. The state-corporatist model which was pursued mainly in countries such as Germany, Austria, Italy and France, says Esping-Andersen, resulted in a labyrinth of status-specific insurance funds backed by state provision. Adenauer's pension reform in 1957 in Germany entrenched the system by introducing earnings-related benefits. To Esping-Andersen the conservative corporatist model of welfare is de-commodifying in the sense that it places little reliance on the market, and solidaristic, in that it promotes status group and family solidarity. However, it remains very hierarchical (and patriarchal in the sense that non-working wives are dependent on the male for social insurance, and has little re-distributional effect).

The neo-corporatist model of labour market organisation and welfare provision which dominates in social market economies has certainly underpinned social cohesion in a number of crucial ways. It has help to concert both employer and employee interests, promoting solidaristic behaviours amongst diverse groups of firms and workers; has facilitated constructive social partner cooperation, and has underpinned the strong professional identities amongst broadly defined occupational groups and industrial sectors. Until relatively recently, 
it also seemed to act positively on wage equalisation, although recent research suggests that this effect may be diminishing as a discreet low-paid workforce becomes more visible within the traditionally well-paid German workforce (Mason et al, 2008). However, the solidarity of the employed has had its counterpart in the marginalisation of the unemployed who, due to powerful unionisation and strong employment protection, have faced considerable barriers in gaining entry to employment. Generous benefits may have somewhat mitigated their plight, but extreme pressures on social spending in Germany are already beginning to erode this. Germany's codetermination system is also under threat. There is increasing foreign capitalisation of German companies, including through some notable hostile take-overs, and many large companies are out-sourcing much of their production abroad, which puts strains on traditional modes of co-determination. In 1996728 companies were co-determined under the terms of the 1976 law (with only 75 companies with over 2000 employees excluded); and 98 percent of plants with over 250 workers had Works Councils. However, the 'codetermination-free zone' increased by about one fifth between the mid eighties and the end of the century, and the process continues as companies seek greater flexibility and resort more frequently to local bargaining and local solutions. Increasingly large companies are exiting the sectoral agreements which have formed the basis of labour market co-ordination in Germany (Max Planck Institute, 1998).

How far the corporatist structure of the social market model can be maintained remains to be seen. In its absence, a major foundation stone of the social market model of social cohesion would have disappeared.

\section{The Social Democratic Regime of Social Cohesion}

The social democratic model of social cohesion relies, like the social market model, on solidaristic labour market organisation and generous social benefits. As in the other model of social cohesion it is state-led and highly institutionalised. However, the social democratic regime differs in the crucial respect that it places equality at the centre of its social philosophy.

The social democracies in the Nordic countries have many of the neo-corporatist features of labour market organisation found elsewhere in north-Western Europe. Companies do not always operate such fully-fledged systems of industrial democracy as prevails in Germany but peak-level social partner cooperation is equally evident. Trade union coverage is even 
more extensive in Scandinavia than in the German-speaking countries, and centralised trade union bargaining dominates, particularly in Sweden. Initial training is less dependent on formalised apprenticeship systems, although apprenticeships are still extensive in Denmark, but social partner involvement in state-led forms of initial training is still high. Employment protection is high in some areas and benefits are more generous than anywhere in Europe. What is more distinctive is the 'flexicurity system' pioneered in Denmark which combines relatively relaxed rules on hiring and firing with very generous support for those who loose their jobs (Bredgaard, Larsen, and Masden, 2005). This encourages labour mobility and is believed to boost employment rates. But employment levels were already much higher in the Nordic countries than in social market Europe, not least because the non-patriarchal familyfriendly employment and benefit policies, including universal and largely gratuitous preschool provision, combined with generous parental leave entitlements, have helped to boost female employment rates to very high levels.

What most distinguishes Nordic labour market organisation is it combination of high employment rates with low income inequality. Economic policy-makers often consider these mutually incompatible. But flexible employment policy combined with concerted centralised wage bargaining and extensive Active Labour Market policies to get redundant workers back into work appear to have exempted the social democratic models from the assumed trade off between social equity and economic efficiency (Nickel and Layard, 1998). These welfare states have the highest taxation and social spending in Europe, while, in most cases, achieving labour productivity levels higher than in the US. High employment rates boost average income in GDP per capita above the levels achieved in equally productive social market economies, which have less people in work.

The Nordic welfare states are notorious for the extent and quality of their social provision, not only in health, social benefits and pre-school education, but also in public transport provision. In Esping-Andersen's account, the social democratic welfare regime embodies the principles of universalism and de-commodification to a far greater degree than other regimes. The welfare systems created after WW2 along similar lines in all the Nordic countries, were originally based on the universalistic Beveridgean principles for the British National Health service - that is including universal access to services funded out of general taxation. However, according to Esping-Andersen, they were better able to maintain the quality of services demanded by users and to meet all expectations by supplementing universal benefits 
with benefits graduated to accustomed earnings. This has kept the middle class loyal to a system which thus commanded universal solidaristic support.

In addition to their welfare systems, Nordic education systems also, arguably, provide a crucial foundation for social cohesion in all the Nordic countries (Green et al. 1996). The promotion of social solidarity has always been a core objective of public education in Nordic countries and this objective has informed both the curricula and the structures of the education systems. Since WW2 the Nordic countries have all introduced a uniquely radical version of comprehensive schooling which includes non-selective and almost totally unstreamed neighbourhood comprehensive schools throughout the public system (Wiborg, 2009). These schools provide all-through primary/lower secondary provision so that students typically stay with the same base class, and thus the same classmates and core teachers, throughout their compulsory schooling. The intention behind this form of school organisation is partly to provide an emotionally supportive and socially cohesive environment within which individual development and group socialisation can occur. It also has the unintended consequence that relatively little school choosing occurs in these systems, even where school choice is legally permitted, since parents will normally elect to send their children to the local primary school where they will then stay, unless the family moves area, until they finish lower secondary school. Nordic education systems are amongst the most egalitarian in the developed world. According to the repeated PISA surveys of skills in literacy, Maths and Science, 15 year olds in Nordic countries display a narrower variation in skills than in most other countries and the influence of social background on their attainment is weaker than in most other countries (OECD, 2007). Although other factors external to the schools may play a part it this, it seems likely that it is the form of school organisation that is also promoting equality of outcomes (Green, 2008).

On any estimation equality is at the heart of the social democratic models of social cohesion. Nordic countries have relatively low levels of income inequality, according to the Gini Coefficient measure (Esping-Andersen, 2005), and research suggests that in the Nordic countries studied social mobility is also relatively high (Blandon et al, 2005). Egalitarian education systems have probably contributed not only to relative equality of performance amongst those completing compulsory schooling but also to low levels of variations in skills amongst the adult population. Nordic countries are also distinctive in the high levels of general trust amongst the adult population, as repeated World Values surveys have shown. 
How far social and educational equality are contributing to this is hard to determine but, as Green et al show (2006), there is a strong positive correlation across countries between skills equality amongst adults and aggregate levels of trust.

Trust is taken by many analysts to be a key marker of social cohesion in society. Given the very high levels of trust in Nordic countries we should probably include this alongside relative equality amongst the characteristic features of the social democratic regime of social cohesion.

\section{Figure 2 Skills Equality and General Trust ${ }^{8}$}

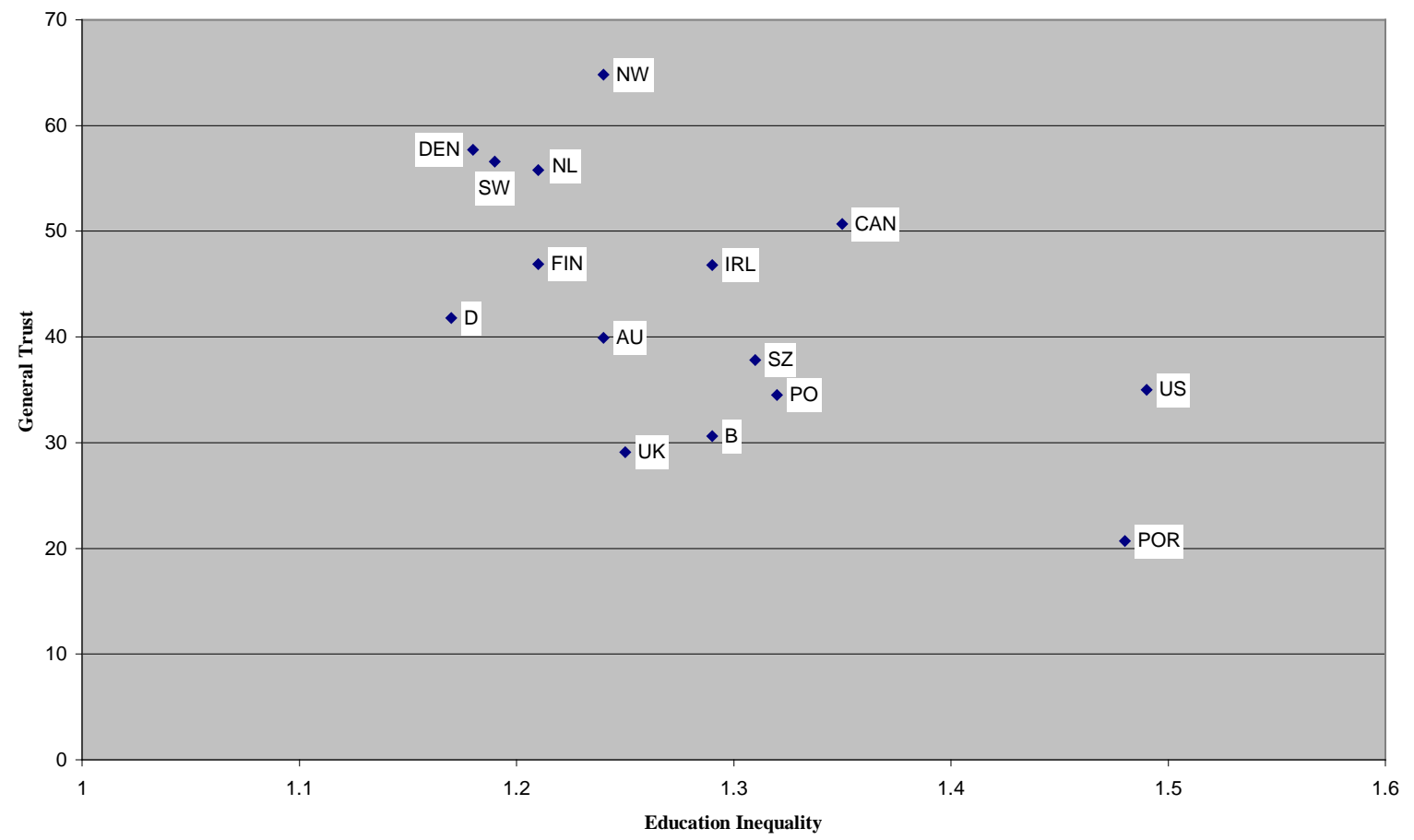

\section{A Note on East Asia}

We have not sought here to trace the intellectual traditions of writings on social cohesion in east Asia, although there is, of course, a large body of scholarly work on Confucian traditions, both in Chinese and English, which would be relevant to such an endeavour.

\footnotetext{
${ }^{8}$ The table is taken from Green et al (2006) op. cit. The data on trust is generated from pooling the data on the relevant question from the 1990 and 1995 sweeps of the World Values Survey. The measure for educational equality is based on test score ratio for groups with different levels of education using data on literacy scores in the International Adult Literacy Survey.
} 
However, it is worth briefly discussing the claims of recent works on comparative political economy, welfare regimes and 'Asian Values' which invariably pose the question of whether we can speak of an Asian, or more specifically an east Asian, model in these domains. Since some of the work in these areas claims that such a thing can be identified, we may also pose the question of whether there may be a distinctive east Asian regime of social cohesion. The question will be discussed firstly in terms of the values relating to social cohesion which are often seen to predominate in east Asian societies, and secondly in terms of the social and economic structures which may be deemed to support them.

\section{Values: an Asian or Confucian model?}

According to the discourse around 'Asian Values' which has developed since the 1990s, one can identify a distinctive set of beliefs, relating to social cohesion, which are particularly associated with east Asian nations. Societies in east Asia are seen as being cohesive and disciplined, factors which - the opinion goes - have contributed to their social stability and economic success in recent decades. Despite the fact that the debates frequently refer to Asian values in general, the discourse has often - though not exclusively - been about Confucian traditions in east Asia.

This discourse celebrating 'Asian Values' succeeded, and to some extent was a reaction to, a preceding discourse that was negative or dismissive towards 'Confucianism' and its compatibility with modernity. Weber attributed east Asian 'backwardness' largely to the deadening influence of Confucian conformism, and so did many reformers and modernizers, from Fukuzawa Yukichi in Meiji Japan to Mao Zedong in the China of the Cultural Revolution. At the same time, a conservative form of Confucianism, calculated to promote de-politicization and 'respect for authority', was espoused and popularized by authoritarian east Asian regimes - such as the Nationalist Kuomintanag (KMT) in Taiwan - and by the British colonial authorities in Hong Kong. Certainly, from the late nineteenth century to late twentieth, Confucianism was more likely to be associated, within east Asia and in the West, with Asian backwardness and underdevelopment than with the successes of a distinctively ‘Asian’ brand of modernity. 
Both the celebratory and derogatory discourses on Confucianism are modern attempts to use the precepts articulated by Confucius between the sixth and fifth century BC, either as a tool for a political end - whatever this may be - or as an explanation for current phenomena. And both involve re-interpreting the ancient teachings of Confucius in a modern context, teachings that were originally formulated in and with reference to antiquity.

The basic idea in Confucianism is self-cultivation in the Dao (道) or the Way. Throughout the Analects - a collection of sayings by Confucius - the Sage discourses on the Way, and how individuals, and particularly rulers and gentlemen, should act. But Confucianism is not merely about individual self-improvement; it is an ethical, social, and political system in which man is seen as a social and political being. The point of self-cultivation for the gentleman (君子) is not only that he might be diligent in what he does, it is ultimately to 'ease the lot of the whole populace' (Waley, 1935a, 191-192). ${ }^{9}$ Hence, there is a sense in which the gentleman is expected to take responsibility for the wellbeing of the people, and to act in according with this - in other words, to epitomise the virtue of 'benevolence' (仁).

'Social cohesion’ is translated into Chinese as ‘社会凝聚力’. In the Analects, the term that is more commonly used with reference to the social and political sphere is rendered in modern Chinese as '安定 (天下)’. Sometimes translated as 'to pacify', it means to bring peace and stability (to All Under Heaven, i.e. China, conceived as the entire civilised world). Occasionally, the term 'harmony' is also used. For instance, Confucius thought that the gentleman should 'act in harmony' with others, but not seek blindly to be like them（‘君子和 $\square$,切不盲从附和, Analects, 13.23). Hence, in the Analects at least, there is the notion of harmony, and peace and stability, rather than social cohesion in the modern understanding of the term.

In this worldview, peace and stability were not a matter of a balance of and interaction among various social and political institutions, policies, and practices designed for social cohesion; it was about the wise rule of a ruler who is guided and aided in his efforts by scholars and gentlemen. And for Confucius, deriving the principles of statecraft comprised rediscovering

\footnotetext{
${ }^{9}$ The original text of the Analects is in classical Chinese; we used an English translation by Waley, and a version in modern Chinese by Confucius Publishing.
} 
'the one infallible method of rule (that) had been practised by certain rulers of old' (Waley, 1935b, 30). Where rulers and gentlemen act in accordance with the Way, peace and stability would reign in the land, and there would not be disputes or reproaches from the populace (Analects 16.1, 16.2). Hence, the emphasis in Confucian discourse in the Analects is on social and political peace and stability which includes a contented populace.

There is also an emphasis on shared understandings - on the moral principles and actions prescribed by the Way, as well as the practice of rituals (礼). Broader than the Western idea of etiquette, the concept of rituals also includes moral values, customs, and rules of behaviour. In Confucian thought, therefore, peace and stability are predicated on a shared set of understandings relating to personal and social ethics, and rituals or practices or, more precisely, the set of understandings as found in the Way. In addition to wise rule of a ruler, it is the shared understandings, and the practice of these, that constitute the 'glue' that holds a Confucian society together, and bring peace and stability to the land.

Confucianism is an ancient philosophy that has been re-interpreted over the centuries. Indeed, the essentials of what is nowadays loosely referred to as 'Confucianism' were only really systematically codified by Neo-Confucian scholars during the Song dynasty, and remained the subject of often intense scholastic controversy throughout the dynastic period. In modern times, particularly since the 1990s, there have been attempts to project the precepts of Confucianism onto a more generalized theory of contemporary Asian culture. The political and academic debate on 'Asian’ values and democracies was triggered by (mainly Westernbased) academics trying to account for the economic success of Japan and the Asian tiger economies by referring to the values in those societies. This gave impetus to politicians like Lee Kuan Yew and Mahathir Muhammad, not only to attribute the success of their countries (Singapore and Malaysia respectively) to 'Asian' values, but also to articulate these in contradistinction to the 'western' ones. Lee and Mahathir regarded the West as decadent societies in which rampant individualism had caused irreparable damage. In contrast, 'Asian' values were family-oriented, privileged society over the individual, and included hard work, thrift, and education. For Lee, Singapore's success was due to the fact that its people 'placed the importance of the welfare of society above the individual', and he also attributed the social cohesion of the country to this 'basic Confucianist concept' (Lee, cited in Khan, 2001, 20). 
Claims that there is a set of values that can be said to characterise certain societies in Asia are not restricted to politicians in the region. A number of scholars have also argued that the value systems in east Asian states have important characteristics in common. Tu, for instance, believes that an east Asian modernity has developed that has assumed 'cultural forms substantially different from those of Western Europe and North America', and that this needs to be understood from a Confucian perspective ( $\mathrm{Tu}, 2000,257,261)$. While the Confucian tradition has been 'reconfigured in a new constellation' in east Asian societies, distinctive characteristics nonetheless still remain, e.g. 'an agriculture-based economy, family-centred social structure, and paternalistic polity', 'network capitalism, soft authoritarianism, group spirit, consensus formation, and human relatedness', 'sympathy, distributive justice, duty consciousness, ritual, public-spiritedness, and group orientation'; in such societies, governments also tend to provide leadership in the economy, the family is the basic unity of society, there is an emphasis on education and self-cultivation, and 'organic solidarity’ is as important as the law in ensuring social stability, if not more so (Tu, 2000, 262, $264-265)$.

For his part, Montgomery (1997) observes that Asian countries tend to favour loyalty to the family and community over respect for individual claims. Given that differences in values and priorities are often distinctive in that these seem 'to aggregate into complexes characterizing a nation, a society, a culture', Glazer notes that societies on the eastern rim of the Pacific tend to be more individualistic in nature, and those on the western rim more collective, and that this is a view shared not only by the politicians, but also by members of the elite in those societies (see Glazer, 1997, 53). In her examination of a number of countries in Asia, Chan too concludes that that these polities have some factors in common, including a communitarian approach to the individual and society, a greater acceptance of and respect for authority and hierarchy, a dominant (single) political party system, and a centralised bureaucracy and a strong state (see Chan, 1993, 22-24).

In addition, common characteristics relating to social cohesion have also been identified in some Asian societies. Surveying the levels of social cohesion in south-east Asia from the 1960s through to the late 1990, Siddique observes that the periods of social cohesion coincided with those of economic growth, and posits that it is economic growth, and the 
attendant possibility of upward social mobility, that gives people a stake in society, that comprise the 'glue' that binds heterogeneous societies together (see Siddique, 2001, 29).

There is also evidence the levels the civic participation in some Asian countries, and the impact of this on democracy and social cohesion, could differ from those in the West. In the World Values Survey (see Figure 7), for example, Japan is among the countries with the lowest scores for both passive and active civic participation. And, using data from the Asianbarometer 2005-6 survey on countries including South Korea, Taiwan and Singapore, Park and Lee report a number of fascinating findings. There is a relatively low level of associational membership in these countries, with 29 percent of people in Taiwan, 24 percent of people in South Korea, and just 10 percent of people in Singapore reporting membership of at least one association. The most popular social groups are identity-based groups - such as alumni associations, sports and recreational groups, or religious groups - that tend 'to emphasize primordial identities rather than economic interests', and are 'likely to encourage in-group solidarity or the 'dark side’ of social capital' (Park and Lee, 2007, 10). Park and Lee (2007) also report weak or no correlation between associational membership and social trust in these countries, and no significant relationship with reciprocity, and citizenship norms (13 - 14). Neither are Park and Lee able to identify any relationship between associational membership and attachment to democracy, support for institutional pluralism, or the rule of law (15 - 16); however, there was a correlation with a rejection of 'authoritarian alternatives (to democracy) such as civilian and military dictatorships' (16). At the same time, associational membership is linked with political efficacy and voting in South Korea and Taiwan, but not Singapore, but is positively linked with interest in politics, campaign activity, contact activity, and protest activity in all three countries (18 - 20). Park and Lee's findings have interesting implications, not only for the level and nature of civic participation in east Asian societies, but also for its role in social cohesion. Certainly, there seems to be a case that the institutions and mechanisms for building and maintaining social cohesion in these societies may be different from those in the West.

Despite the quite widespread support amongst Asian politicians and scholars East and West for the notion of distinctive Asian or Confucian values, a number of substantial problems with the whole discourse can be identified. Firstly, there is the criticism that the values often listed as Asian are by no means unique to the region. Second, the idea of a specific and 
distinctive set of Asian values is too overly generalised to have much analytical value. The characteristics identified relate, in fact, mainly to east Asian societies and, in some versions, primarily to those with strong Confucian traditions. So Japan might be included in this view, but the south Asian states would be rather peripheral to it. Secondly, there is a distinct tendency in these accounts to essentialise ethnic or national cultures, ignoring the cultural divisions within states such as Singapore that are multi-ethnic and have multiple religious traditions. And fourthly, the accounts are often prone to static views which take national traditions and cultures as immutable.

There is no claim here that the 'Asian' or 'Confucian' values are unique to the region, merely that there is a particular constellation of values that characterise the values in the area and, in any case, we are limiting our claims to the area of east Asia where the bulk of the population and culture can be said to have Sinic influence. And, in as much as it is possible to talk about an authentic culture in these societies, it is possible to talk about a particular, culturally linked version of social cohesion. Moreover, as has been argued, there does appear to be some consensus from scholars in different fields - including philosophy, political theory and, as will be seen, socio-economic theory - that there are institutions and practices in east Asian societies that display characteristics different from those in the West. This being the case, it is plausible to posit that the values undergirding social policy and practice in east Asia differ from those in the West and, further, that these may bear resemblance to the principles espoused in Confucian thought. In some ways, the particular set of values associated with east Asian societies are ideal ones, as often as not proven in their breach as in their observance. That there are divergences in the interpretation and practice of these values is not surprising given the different socio-political factors that and historical trajectory that apply to each country (see Tu, 2000, $263-4$ ).

Hence, it is perhaps possible to argue for a distinctive set of values underlying socio-political institutions in east Asia where Confucianism has been a predominant influence and, as Tu (2000) has suggested, to attempt to develop a historically nuanced and socially complex interpretation of the evolution of Confucian traditions in the context of these societies. 


\section{Economic and Social Policy in East Asia}

It has been suggested that arguments in recent research about an east Asian model are not confined to the sphere of values. In fact an equally strong case can be made with respect to the distinctive economic and social policies that have been adopted in the region. In terms of economic policy, this relates both to theories of east Asian economic development and to contemporary characterisations of east Asian economies.

Comparative political economists, such as Ronald Dore (2002), Chalmers Johnson (1982), Robert Wade (1990) and Alice Amsden (1989), have contributed substantially to the varieties of capitalism debate by identifying features of a number of east Asian political economies which are quite distinctive and which, they claim, have made possible a form of rapid economic development substantially at variance with the economic developmental models of neo-classical economics. These authors have all pointed to the distinctive form of 'state-led development' that has been observed in Japan since World War Two and in South Korea, Taiwan and Singapore since the early 1960s. In their writings, as well as in the writings of others such as Castells (1992) and Woo-Cumings (1999), the key factor explaining rapid economic development in a number of east Asian states has been the existence of 'developmental states' - governments and state bureaucracies which have been committed to leading economic development 'from the front' and whose legitimacy has largely depended on their success in this project. Developmental states, they argue, have successfully followed the strategy of export-led development recommended by liberal economists, precisely by departing from the liberal free-market policies of neo-classical economics. Instead of following free market, free trade orthodoxies, governments have intervened substantially in the market both through industrial policies and through neo-mercantilist strategic trading policies (Green et al, 2007).

The key role of the government and state bureaucracies has been emphasised in many accounts of contemporary economic organisation in Japan and the east Asian tiger economies. Chalmers Johnson (1982) characterised economic organisation in post-war Japan as 'plan rational' - that is to say as somewhere between western-style mixed economies and the 'command economies' of former Communist states in terms of levels of state involvement in economic planning. Both he and Alice Amsden (1989), in the latter's writings 
on South Korea, also emphasise the close connections between civil servants in departments of state and the large private companies, and the various ways in which the bureaucracies use tax concessions and subsidies of various kinds to influence investment decisions to secure particular outcomes in terms of industrial structure. According to Wade (1990) the economies of Taiwan, and several other east Asian states, exhibit a form of 'state-guided capitalism' which can be contrasted with the more limited role of government in the economy typical in various forms of market or 'mixed' economies in developed western states.

The structure of the large corporate conglomerates - the Keiretsu in Japan and Chaebol in South Korea - is also seen by many political economists to be highly distinctive. Ron Dore's (2002) characterisation of 'relational capitalism' in Japan, which he contrasts with the 'stockmarket' capitalism in the West, rests heavily on the organisation and role of the large corporations. Japan's large conglomerates include numerous companies either 'vertically integrated' within specific sectors or 'horizontally integrated' across multiple sectors. These companies are typically linked together through cross-shareholdings, which protect companies against hostile take-overs, and by stable supply chain agreements which allow concerted approaches to process and product improvement. These arrangements, according to Dore, not only favour long-term investment and but also long-term approaches to building productive capacity, improving quality, and expanding market share. The 'relational' - as opposed to contractual - basis of economic organisation is also, according to Dore, exhibited in employment practises within the large firms.

Core workers in large firms in Japan have traditionally benefitted from long-term employment policies, seniority-based pay systems and extensive social benefits provided by the employer. The principle of 'lifetime employment' has, until recently, been extended to all 'core workers' in Japan's large companies and is only now gradually being reduced (Dore, 2002). It was, in part, made possible by the structure of the conglomerates which allowed the major firms to avoid making staff redundant when they were surplus to requirements by transferring them to affiliated firms, albeit on lower pay grades. This commitment by companies to lifetime employment and seniority pay for core staff derived from the desire to promote employee loyalty and productivity. It also allowed the large firms to invest heavily in employee training without fear of losing their investment to other companies who might poach their staff (Crouch et al, 1999). Firms have also promoted loyalty amongst core staff 
by offering numerous social benefits such financial and other assistance with marriages and funerals (Perkin, 1996). These organisational characteristics, which are part of what Dore means by 'relational' capitalism, make the firm more like a social unit, with multiple stakeholders, than a contractual organisation responsible only for making profits for shareholders. Indeed private shareholders have traditionally had relatively little power over Japanese corporations, and dividend pay-outs are generally low by comparison with shareholder economies (Hutton, 2002). In fact the large firms are often referred to in Japan as family-like (iemoto) organisations (Perkins, 1996). Although it is only in the large firms where these practices occur, such firms employ a substantial part of the workforce in Japan. This allows Dore (2002), Hutton (2002) and others to claim that firm organisation in Japan promotes intra-firm solidarity rather in the way that industrial democracy does in Germany, although the model here is rightly characterised as distinctly more paternalistic in its forms.

Such a system does come with some undesirable economic consequences. For instance, Woo-Cumings cites Theodore Lowi as describing the model as being in a 'state of permanent receivership' - 'an institution large enough to be a significant factor in the community has its stability underwritten (the system promotes brankruptcy but the state cannot let it go bankrupt)' (Woo-Cumings, 1999, 12). ${ }^{10}$ It need hardly be pointed out that there are also possibly more general negative social consequences of a Confucian based system of values as well - too much deference and respect for one's superiors (including political leaders), an unquestioning acceptance of authoritarianism whatever form this takes, a lack of consideration for individual interests and rights and so on.

How far the distinctive economic traits discussed above constitute an east Asian economic model is hotly debated. Most of the research within the varieties of capitalism tradition has focused on Japan, South Korea, Singapore and Taiwan. Clearly some common characteristics can be detected amongst these economies, not least as a result of Japan's colonial influence and continued status as an exemplar economy. Indeed one theory of east Asian development, referred to as the 'flying geese' model, is explicitly based on the presumption of the formative nature of Japanese influence across the region (Kwan, 2002; Furuoka, 2005). However, it is also true to say that few studies find many common characteristics across a broader range of east Asian economies, which would include Hong Kong and various other developing

\footnotetext{
${ }^{10}$ Although, this criticism may equally well be applied to a number of western economies now.
} 
economies in south-east Asia, such Malaysia, Thailand and Vietnam. More research is beginning to come out on the specific characteristics of economic development in mainland China, but China is usually deemed to be too singular - by virtue of its size and political system - for its economy to be easily assimilated to any east Asian model of capitalism. Even amongst the more restricted set of economies including Japan, South Korea, Singapore and Taiwan there are notable differences, not least in relation to the degree of openness to foreign investment, the systems for skills formation, and the typical nature of governance in the large corporations (Brown et al, 2001; Green, 1999)

However, for these countries at least there is still one major common characteristic which is the distinctive relation between the state and the market. In as much as there is an east Asian economic model it rests on the idea of the developmental state and state-led development. The centrality of the state in these economies and those of south-east Asia also has important implications for the nature of social cohesion. Indeed, as was seen earlier, Siddique (2001) observes that it was economic growth and the possibility of social mobility that comprised the 'glue' that bound together heterogeneous societies in south-east Asia during their period of development; she also notes that economic growth and social cohesion in these societies are government-led, with the state being directly involved not only in development planning, but also in incorporating the populace into a vision of the country’s future and giving them a stake in it (see Siddique, 2001, 29).

In terms of social policy a similar debate occurs about the distinctiveness and commonalities of the east Asian welfare states. Esping-Andersen (1997) has observed that many developed east Asian societies have relatively low levels of public social spending compared with other developed countries. He also points to the importance of the family and the ideology of familialism in the welfare systems in east Asia generally. However, he does not support the notion of an east Asian model of welfare. In fact, his analysis of Japan leads him to conclude that welfare provision in that country should be characterised as a hybrid form, rather than as a distinctive model of welfare state in its own right, since it combines both a corporatist emphasis on status-differentiated occupational insurance with a widespread reliance on private market provision, as in liberal welfare state models. Other writers on welfare provision in east Asia do make claims about a distinctive east Asian model. 
Walker and Wong (2005) refer in their writings to 'Confucian welfare states' and a 'Confucian welfare cluster'. And Jones writes in terms of the 'Confucian welfare state' which she describes as: 'Conservative corporatism without (Western-style) worker participation; subsidiarity without the Church; solidarity without equality; laissez faire without libertarianism' (Jones, 1993, cited in White and Goodman, 1998, 12). Examining the welfare systems of Singapore, South Korea, Taiwan, Hong Kong, Japan, and China, White and Goodman (1998) conclude that there are 'certain key aspects' in east Asian welfare that are common and distinctive.

The notion of state-provided or guaranteed welfare as a social right of citizens is weakly developed. Rather, non-state agencies - community, firm and family have been expected to play a major welfare role in both financing and providing welfare services in an ideological context wherein self-mutual help is encouraged and dependence on the state discouraged, indeed stigmatised (White and Goodman, 1998, 14).

More specifically, White and Goodman claim:

The principle of social insurance (wholly or partially funded) is favoured over other means of financing, notably through taxation-based, pay-as-you-go schemes. ...[S]tate-sponsored welfare programmes in the three north-east Asian states Japan, South Korea and Taiwan - have tended to develop as a fragmented array of particular schemes for core social groups, an institutional segmentation which both reflects and reinforces differentials in power and status in society. (White and Goodman, 1998, 14).

This last point may apply to some east Asian nations more than others, and Goodman and White, like Walker and Wong (2005), acknowledge that there are differences in welfare systems in the region. But they concur that there are common features in these societies where social policy is concerned, citing as characterising features 'low social expenditures, low benefit levels, priority for spending on education and government as 'regulator' rather than provider' (Walker and Wong, 2005, 9). 
We conclude this section tentatively. East Asian societies are arguably too diverse to characterise in terms of a particular model, whether this be in relation to forms of capitalism or to welfare and social cohesion regimes. However, there is evidence of certain commonalities in east Asian societies, and particularly those with a common and predominant Confucian heritage. These relate not only to the cultural distinctiveness of these societies, but also to the institutions in which these values find expression. At the same time, the level and nature of civic participation and the ways this impacts on social cohesion arguably differs from that in the West. The commonalities point to the importance of the family and the state in supporting social cohesion, as well as to the common assumption that social cohesion requires a binding and shared culture which is more likely to occur in more ethnically homogenous societies but - notwithstanding the accounts attempting to essentialise ethnic or national cultures - which can also be cultivated by the state in multi-ethnic communities like Singapore. Indeed, patriotic and moral education in many of these societies plays a vital role in socialising children into the values conducive to these distinctive forms of collectivism, social discipline and social cohesion. The commonalities also suggest that successful economic development is unusually important for the maintenance of state legitimacy in many east Asian societies, and that social cohesion is often construed as a topdown process which is highly dependent on state authority.

\section{Section Six: Quantitative Analysis of Regimes of Social Cohesion}

\section{Data and methods}

We draw from a rich variety of data sources to explore whether the putative regimes derived from existing theory can be substantiated by statistical analysis of the social characteristics of contemporary western societies. Some of these represent collections of robust administrative data on topics such as income inequality, crime, and social expenditure (OECD, ILO, World Bank, UN) while others are collections of survey data on attitudes and reported behaviour based on nationwide samples (European Values Study/World Values Survey - EVS/WVS; International Social Survey Program - ISSP). 
Table 1 establishes the link between theory and data. It presents the social cohesion components which the previous section has highlighted as the distinctive features of the liberal, social-democratic, social market, and east Asian regimes (Column I). Column II shows with which regime a particular component is associated. A plus signifies that the component in question is considered an essential part of the tradition; a minus means that the component's antipole is part of the tradition. Where a component is imputed to be neither strongly positive not strongly negative on a tradition, the tradition is left out of the table. For instance, value diversity is considered a key element of the liberal tradition while value homogeneity is seen as characteristic of the social market and east-Asian tradition. Column III presents the indicators tapping the components. 
Table 1. Components of social cohesion regimes

\begin{tabular}{|c|c|c|}
\hline Component & Tradition/regime & Indicator(s) \\
\hline & & Indicators based on administrative data \\
\hline Inequality & $\begin{array}{l}\text { Social Democratic (-) } \\
\text { Liberal }(+)\end{array}$ & Gini coefficient on household income \\
\hline Wage regulation & $\begin{array}{l}\text { Social Democratic (+) } \\
\text { Social Market (+) } \\
\text { Liberal (-) }\end{array}$ & $\begin{array}{l}\text { - Union coverage: proportion of employees covered } \\
\text { by collective agreements }(1<25 \% ; 2=25-70 \% ; 3> \\
75 \%) \\
\text { - Centralization of wage bargaining (Scale: } 1 \\
\text { [maximum decentralization] to } 17 \text { [maximum } \\
\text { centralization]) }\end{array}$ \\
\hline $\begin{array}{l}\text { Employment } \\
\text { protection }\end{array}$ & $\begin{array}{l}\text { Liberal (-) } \\
\text { Social market (+) }\end{array}$ & $\begin{array}{l}\text { Employment protection legislation } 1998 \text { (Scale: } 1 \text { "most } \\
\text { liberal” to } 6 \text { “most strict”) }\end{array}$ \\
\hline $\begin{array}{l}\text { State } \\
\text { involvement }\end{array}$ & $\begin{array}{l}\text { Liberal (-); } \\
\text { Social democratic }(+) \text {; } \\
\text { Social market }(+) ;\end{array}$ & Public employment as percentage of total employment 2000 \\
\hline Welfare state & $\begin{array}{l}\text { Liberal (-); } \\
\text { Social democratic (+) }\end{array}$ & Public social expenditure as percentage of GDP 2000 \\
\hline $\begin{array}{l}\text { Ethno-racial } \\
\text { diversity }\end{array}$ & $\begin{array}{l}\text { Liberal }(+) \\
\text { East-Asian (-) }\end{array}$ & Proportion of the population born abroad 2000 \\
\hline Crime / disorder & $\begin{array}{l}\text { Liberal (+) } \\
\text { East Asian (-) } \\
\text { Social Market (-) }\end{array}$ & $\begin{array}{l}\text { - Homicide rate } 1999 \text { (number of homicides per } \\
\text { 100.000) } \\
\text { - Violent crime } 2000 \text { (number of homicides, rapes } \\
\text { and robberies per 100.000) }\end{array}$ \\
\hline & & Measures based on survey data \\
\hline Value diversity & $\begin{array}{l}\text { Social market (-) } \\
\text { East Asian (-) } \\
\text { Liberal (+) }\end{array}$ & $\begin{array}{l}\text { Composite indicator representing the dispersion of opinions } \\
\text { on seven issues (Scale: }-6.4 \text { [most homogenous] to } 12.0 \\
\text { [most diverse]) }\end{array}$ \\
\hline $\begin{array}{l}\text { Active civic } \\
\text { participation }\end{array}$ & $\begin{array}{l}\text { Liberal (+) } \\
\text { East Asian (-) }\end{array}$ & $\begin{array}{l}\text { Number of different organizations respondent does } \\
\text { voluntary work for; national average }\end{array}$ \\
\hline
\end{tabular}




\begin{tabular}{|c|c|c|}
\hline $\begin{array}{l}\text { Passive } \\
\text { participation in } \\
\text { nationwide } \\
\text { organizations }\end{array}$ & $\begin{array}{l}\text { Social market }(+) \\
\text { Social democratic }(+) \\
\text { East Asian }(-)\end{array}$ & $\begin{array}{l}\text { Number of different organizations respondent considers } \\
\text { him/herself to belong to; national average }\end{array}$ \\
\hline $\begin{array}{l}\text { Freedom vs } \\
\text { equality }\end{array}$ & $\begin{array}{l}\text { Liberal (+); } \\
\text { Social market (-); } \\
\text { Social democratic (-) }\end{array}$ & $\begin{array}{l}\text { Freedom or equality more important; percentage preferring } \\
\text { freedom }\end{array}$ \\
\hline $\begin{array}{l}\text { Merit vs } \\
\text { equality }\end{array}$ & $\begin{array}{l}\text { Liberal (+); } \\
\text { Social market }(+) \text {; } \\
\text { Social democratic (-) }\end{array}$ & $\begin{array}{l}\text { Pay according to performance; percentage saying it is fair } \\
\text { that one secretary is paid more than the other if (s)he works } \\
\text { better }\end{array}$ \\
\hline $\begin{array}{l}\text { Ethnocultural } \\
\text { versus civic } \\
\text { identities }\end{array}$ & $\begin{array}{l}\text { Romantic conservative (+); } \\
\text { East Asian (+); Liberal (-) }\end{array}$ & $\begin{array}{l}\text { Strength of cultural relative to political conceptions of } \\
\text { national identity; average } \\
\text { (Scale: - } 1.0 \text { [political conceptions strongest] to .65 [cultural } \\
\text { conceptions strongest]) }\end{array}$ \\
\hline Ethnic tolerance & $\begin{array}{l}\text { Liberal (+); Romantic } \\
\text { conservative (-); East Asian } \\
(-)\end{array}$ & $\begin{array}{ll} & \text { Xenophobia index; average (inverse indicator) } \\
\text { - } & \text { Percentage not mentioning immigrants/foreign } \\
& \text { workers as groups one would not like to have as } \\
& \text { neighbours } \\
\end{array}$ \\
\hline Social hierarchy & $\begin{array}{l}\text { East Asian }(+) \text {; } \\
\text { Social market }(+)\end{array}$ & $\begin{array}{l}\text { Percentage saying one should always love and respect one's } \\
\text { parents }\end{array}$ \\
\hline Gender equality & $\begin{array}{l}\text { East Asian (-) } \\
\text { Social market (-) } \\
\text { Social democratic }(+) \\
\text { Liberal }(+)\end{array}$ & $\begin{array}{l}\text { Percentage disagreeing with the opinion that in times of } \\
\text { scarcity men have more right to a job than women }\end{array}$ \\
\hline
\end{tabular}

Appendix 1 provides the full details of the indicators and the data sources they were derived from. Here we confine ourselves to explaining why we selected the indicators that we did. Some indicators speak for themselves and thus do not require additional explanation. Selecting the Gini coefficient on household income as indicator of inequality is for instance self-evident and in line with many other studies. Similarly, the two indicators for ethnic tolerance are self-explanatory. The two indicators for wage regulation, which were derived from Nickell and Layard (1998), also speak for themselves. Union coverage, i.e. the percentage of workers covered by collective agreements between unions and employer organizations, and the degree of centralization of wage bargaining, can both be seen as key features of the corporatist character of the social market model. Nickell and Layard note that 
it is quite possible for the majority of workers to have their wages determined by collective agreements even though union membership is low, citing France and Spain as examples (op. cit., 3041). Possibly, this reflects a widespread belief in social market societies that it is perfectly acceptable to allow interest organisations representing only a minority of workers and employers to have a large say in labour market issues as long as they ensure stability and social peace. This would certainly be consistent with the idea proposed by some scholars (e.g. Dubet, 2007) that social cohesion in much of core mainland Western Europe and particularly among the political left is primarily understood in a Durkheimian sense, i.e. as the capacity of institutions to retain overall harmony and unity.

We captured ethno-racial diversity by using UN data on migrants (i.e. people born abroad) as a percentage of the total population. Although this indicator is likely to underestimate actual diversity as it only takes first generation migrants into account, it does ensure good crossnational comparability and provides an indication of a society's openness which is partly what the diversity component seeks to express. Disorder/crime was tapped with two indicators: violent crime and homicide, the latter being a subset of the former. These are two of the few crime indicators for which there is fairly reliable data fit for international comparison. On the one hand, the violent crime indicator is more appealing than the homicide indicator since it is more encompassing, but on the other hand it has missing data for several important countries and its legal definitions are likely to differ more between countries than those for homicide, hampering comparability. Since each indicator has different pros and cons we will use both indicators.

Turning to the indicators based on survey data, we decided to use the dispersion of opinions on a range of contentious issues reflecting only substantive values as an indicator of value diversity. We expect liberal societies to particularly stand out on pluralism regarding such values rather than basic values, i.e. values seen to be constitutive of liberal democratic societies, since a broad consensus on the latter is also cherished in the liberal tradition. The indicator for active civic participation, which reflects self-reported voluntary work for a range of organizations differing in profile and scope, is inspired by the notion that it is actual involvement in grass-roots organizations that characterizes the civil societies of liberal countries (de Tocqueville, 1956; Putnam, 2000). By contrast, the indicator for passive participation only measures self-reported belonging to several nationwide organizations (religious denominations, unions, political parties, professional organization), since it is the 
detached forms of participation in highly institutionalised (or interest) organizations which we hold to be typical of societies associated with social market and social democratic regime.

The indicator tapping the 'freedom versus equality' component reflects this component literally as it asks respondents to state which of the two principles - freedom or equality they consider more important. The indicator for the 'merit versus equality' component requires more explanation. We considered the 'pay according to performance' indicator to be an appropriate proxy for the last-named component because the wording of the item on which the indicator is based (see Appendix 1) nicely addresses the tension between merit and equality as principles determining remuneration in work relations. If traditions have left their mark on contemporary attitudes, we would expect to see liberal English-speaking societies prioritizing freedom and merit over equality and the countries with more collective traditions doing the reverse. We further note that the items used for the two indicators avoid any reference to the prevailing conditions in a country so as to minimize the risk that respondents have taken these conditions into account in stating their preference for one or the other principle. For survey data to be internationally comparable, the responses have to reflect absolute support for some opinion or principle, not support relative to the given conditions in a country. Of course, it can never be ruled out that such a 'relative to prevailing conditions' bias has affected respondents' answers but researchers can at least reduce this risk by not selecting items which contain an explicit reference to the existing situation in a country (e.g. items asking whether more should be done to relieve poverty, combat unemployment, etc).

We tapped ethno-cultural and civic conceptions of nationhood by means of a scale representing cultural relative to political conceptions of national identity. The higher the score on this scale, the more importance is attached to cultural versus political markers of national identity. Finally, considering the items on which the indicators for ethnic tolerance are based (see once again Appendix 1), we emphasize that ethnic tolerance should be understood as the out-group attitudes of the dominant group.

A word of caution applies to the indicators representing national averages. These averages can hide important variation within countries on the attitudes of interest. It is thus possible that countries having similar mean values on some attitude show different variations. Conversely, countries with different mean values may have such large within country variations that it cannot be concluded that country having a higher mean score on some 
outcome of interest than another is very meaningful. We checked the within country variance on the four indicators representing national averages by calculating means and confidence intervals (see Figures 3 to 6). Confidence intervals are based on both the variance in the outcomes of interest and the size of the national sample: the larger the variance and the smaller the sample size, the larger the confidence intervals. The mean values of two countries are not significantly different from one another if their confidence intervals overlap. Consequently, the larger the confidence intervals, the smaller the chance of finding significant mean differences between countries. Figures 3 to 6 show that the confidence intervals are generally small compared to the differences in mean values between countries, indicating that most of the mean differences between countries are significant. Our indicators based on national averages are thus quite robust in terms of highlighting between country differences.

Figure 3. Passive civic participation (means and 95\% confidence intervals) (WVS wave 4)

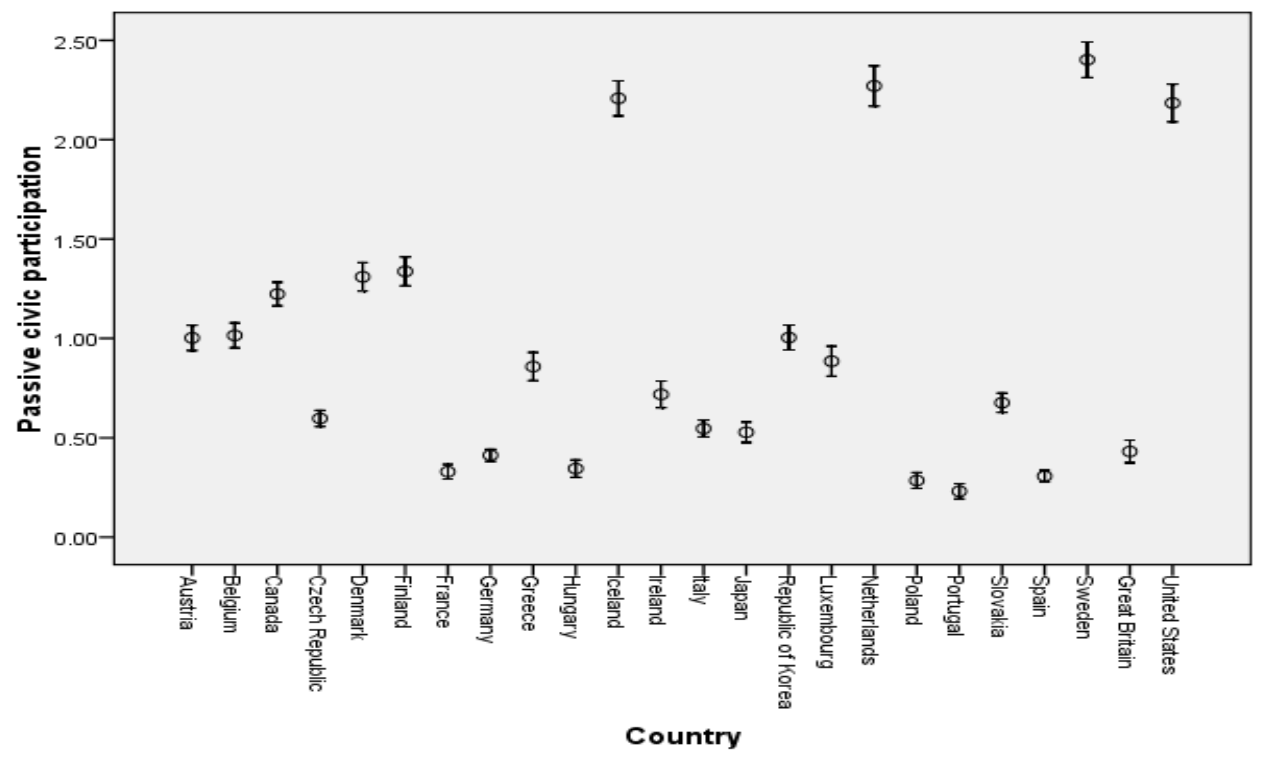


Figure 4. Active civic participation (means and $95 \%$ confidence intervals) (WVS wave 4)

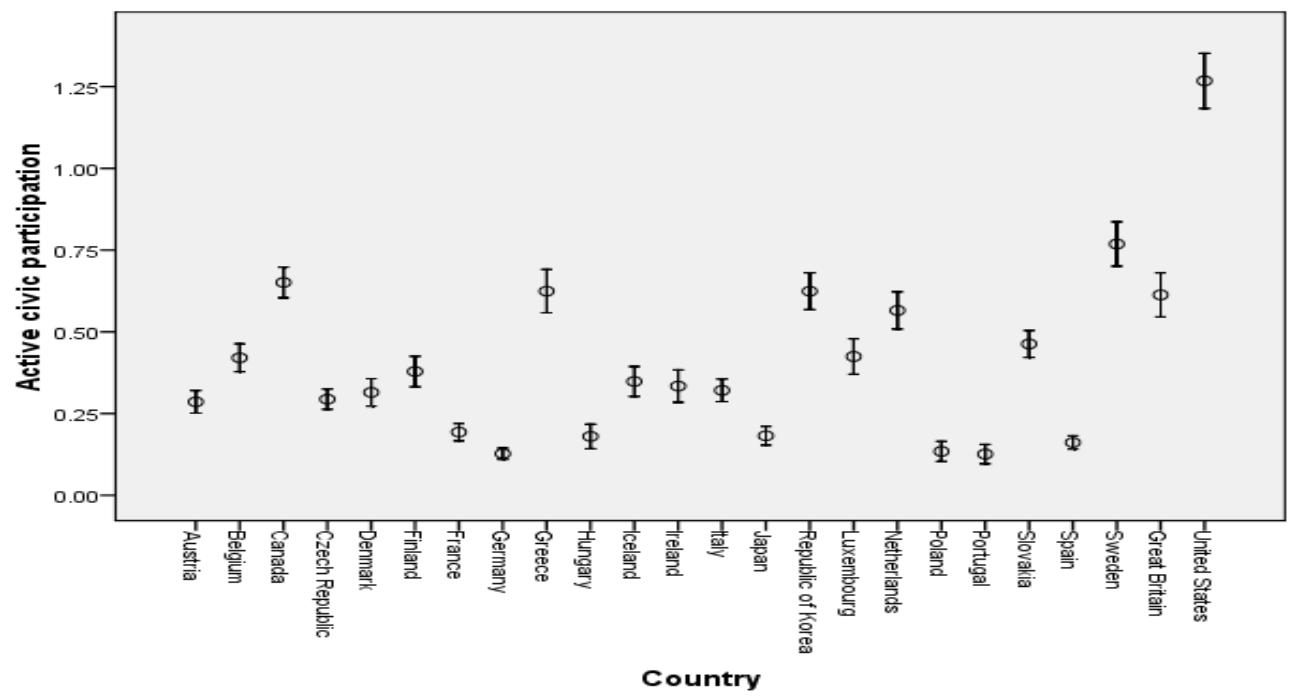

Figure 5. Cultural versus political conceptions of national identity (means and $95 \%$ confidence intervals) (ISSP 1995)

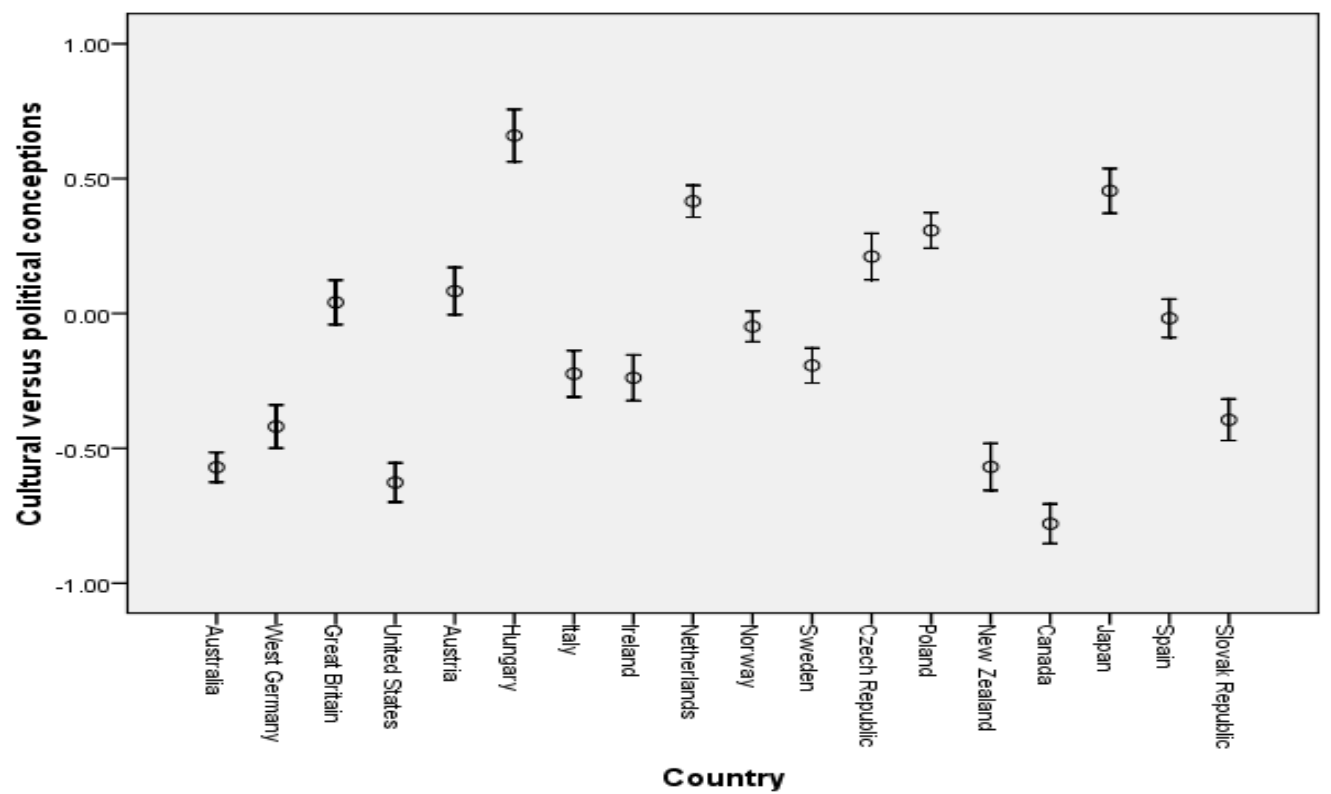


Figure 6. Xenophobia (means and 95\% confidence intervals) (ISSP 1995)

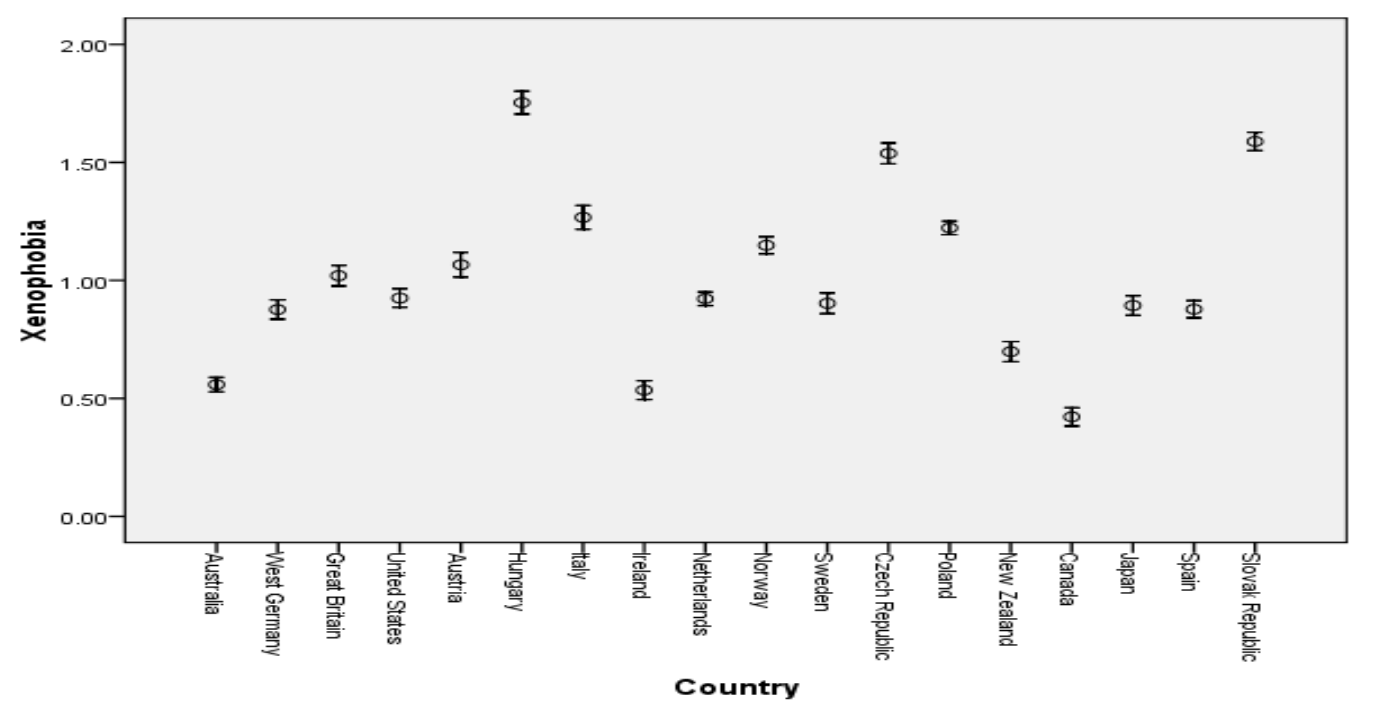

We restricted the selection of cases to those developed countries which could be identified as representing a distinct social cohesion tradition to a smaller or larger degree. Consequently, we selected the OECD states minus Turkey and Mexico. Table 2 shows with which traditions these states are associated in existing theories. The question marks indicate that we are not quite sure whether the countries concerned can be seen as representing the stated tradition. Esping-Andersen (1990) lumps the Mediterranean countries together with France, the Benelux and the German-speaking states in a conservative welfare regime on the basis of shared Catholic heritage, but others have argued that the Mediterranean states constitute a separate cluster (Leibfried, 1992). Hence the question marks behind Italy, Spain, Portugal and Greece. In similar vein, it is difficult to place Ireland as its Catholic culture distinguishes it from the other English-speaking states. The ensuing analyses will explore to what extent these and the other countries conform to the traditions they are said to represent.

We used scatter plots to analyse whether regional patterns could be observed in conformity with the social cohesion regimes. A scatter plot not only enables a precise and transparent assessment of a relation between two variables, it also offers an insightful graphic representation of the scores of the cases on the two variables and of the degree to which cases cluster, provided the number of cases displayed is not too large. 
Table 2. Countries associated with hypothesised social cohesion regimes

\begin{tabular}{|lllll|}
\hline Liberal & Social market & $\begin{array}{l}\text { Social- } \\
\text { democratic }\end{array}$ & East Asian & $\begin{array}{l}\text { (residual) } \\
\text { Romantic } \\
\text { conservative }\end{array}$ \\
\hline Great Britain (GB) & France (FRA) & Sweden (SWE) & Japan (JAP) & Germany (GER) \\
\hline United States (US) & Germany (GER) & Denmark (DEN & S Korea (KOR) & Austria (AU) \\
\hline Canada (CAN) & Austria (AU) & Norway (NOR) & Switzerland (SWI) \\
\hline Australia (AUS) & Switzerland (SWI) & Finland (FIN) & Luxembourg (LUX \\
\hline New Zealand NZe & Belgium (B) & Iceland & (ICE) & Poland (POL) \\
\hline Ireland (IRE) (?) & Netherlands (NL) & & Slovak Rep (SLV) \\
\hline & Luxembourg LUX & & Hungary (HUN) \\
\hline & Italy (ITA) (?) & & \\
\hline & Spain (SP) (?) & & \\
\hline & Portugal (POR) (?) & & \\
\hline
\end{tabular}

Though providing detailed information, scatter plots only allow for an assessment of country positions on just two variables. In order to assess the groupings countries based on all indicators at once, we will conduct a cluster analysis, the details of which we will discuss further below. This type of analysis allows us to explore to what extent the countries cluster in the groups presented by Table 2 .

However, with cluster analysis it is not possible to assess the degree to which the country clusters match the putative regimes substantively. In other words, if a cluster analysis yields a coherent English-speaking liberal cluster of countries, we still do not know whether this cluster shows relatively high values on inequality, value diversity, and active civic participation, etc. In order to assess the substantive match we pursue two strategies. The first strategy involves a two-step procedure in which the first step consists of the creation of indexes reflecting each of the traditions substantively. Subsequently, the countries are ranked on these indexes. This procedure allows us to explore whether the countries associated with a particular tradition indeed top the ranking order of countries on the corresponding index. In 
this way, both the clustering of countries (in terms of countries linked with a particular tradition forming a continuous group of countries on the ranking order) and their substantive position can be investigated. The construction of these indexes will be discussed in further detail below.

A drawback of the first strategy is that indexes merely reflect theoretical constructs. In other words, these constructs cannot be understood as coherent dimensions or syndromes representing variations in clearly observable phenomena. For this to be the case the variables included in the indexes should co-vary. Consequently, the second strategy entails identifying such syndromes by conducting factor analysis on all the social cohesion indicators. We will assess to what extent the dimensions yielded by this analysis correspond to the indexes and thus to the putative regimes substantively. Additionally, we will save the country scores on the dimensions. Scatter plots of these scores will allow us to assess both the group cohesion and the substantive agreement of countries linked with a particular tradition. This strategy thus has the advantage of not only reducing complexity by synthesizing the many indicators but also of producing coherent meaningful syndromes on which the countries can be scored and ranked.

\section{Findings}

\section{Scatterplots}

We now turn to an assessment of the social cohesion components using scatterplots (Figures 7-17). Do the cross-country patterns on these components match the social cohesion regimes both substantively and in terms of country groupings? In other words, do the countries associated with the liberal regime indeed show higher rates of inequality and less state involvement, a preference for freedom over equality, and more support for political conceptions of nationhood than other countries and do they cluster as a group?

We begin by assessing the cross-country patterns on inequality and crime (Figure 7). With regard to the scatter plot presenting homicide it can be seen that the outliers of US, POR and POL, at first sight, obscure clear clusters. Beyond these outliers clusters do emerge however: (a) the English-speaking countries combine high inequality with low-medium homicide; (b) 
Southern Europe combines medium-high inequality with low homicide; (c) Nordic countries combine low values on both indicators (except Finland with its high score on homicide).

As regards inequality, these patterns are consistent with theoretical expectations as it is indeed the countries associated with the liberal tradition which show above average rates of income inequality. The country positions on homicide are not entirely as expected as, discounting the US, it is not necessarily in the liberal states that the highest homicide rates can be found.

\section{Figure 7. Inequality and Crime}

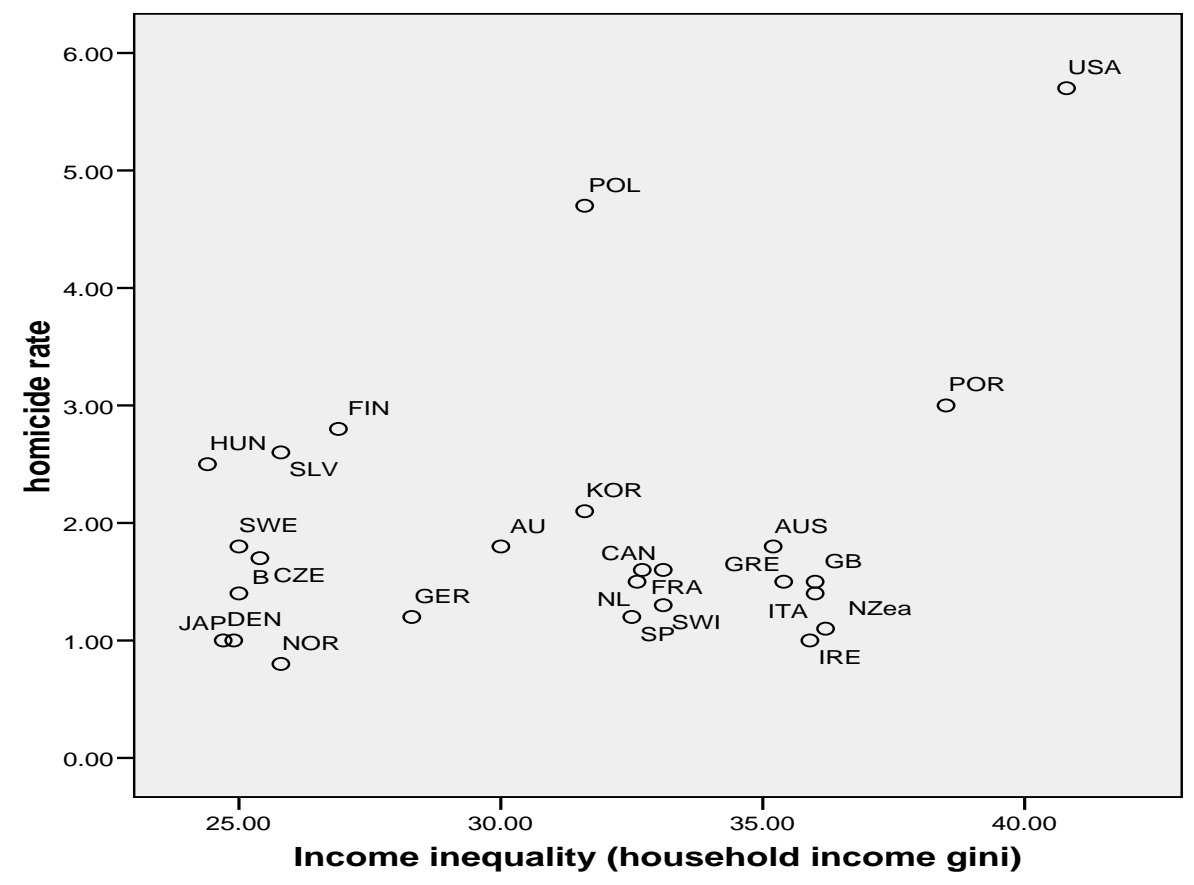




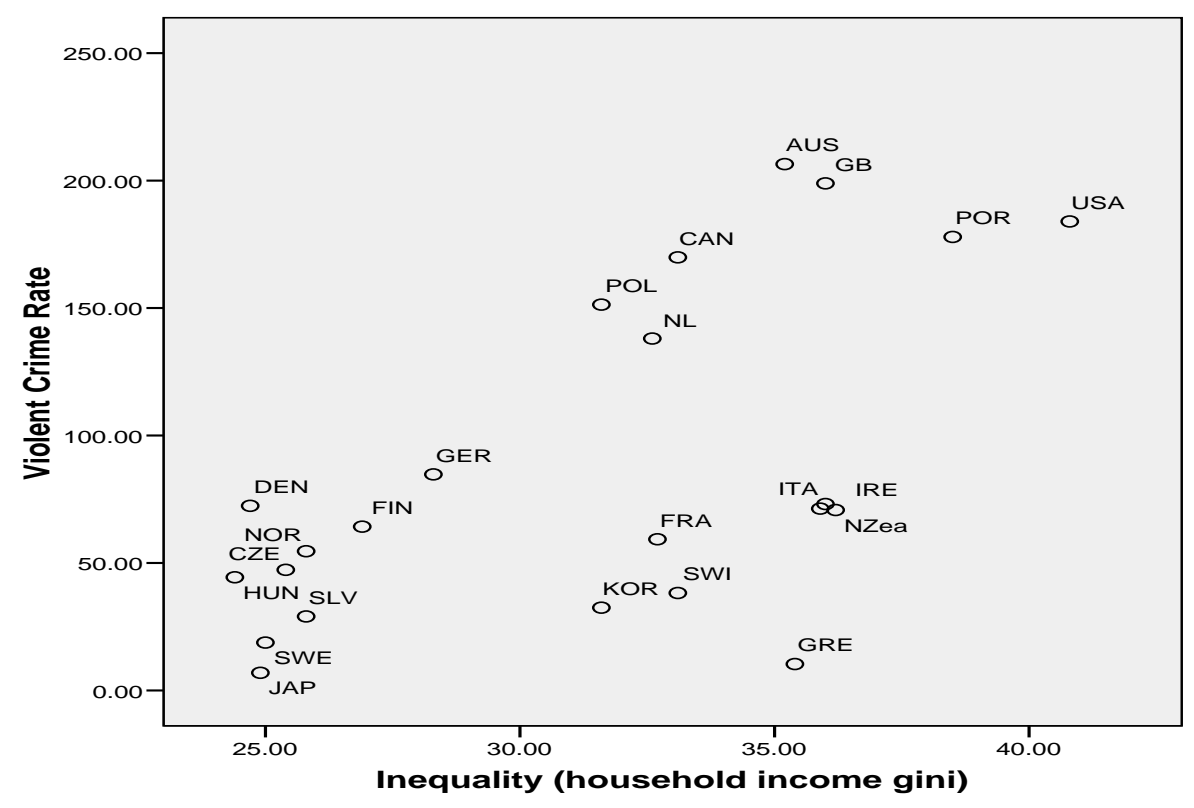

On violent crime, the more encompassing indicator of crime, the patterns are more in conformity with expectation, however (see second scatter plot). The liberal countries emerge as a distinct cluster combining high violent crime rates with high inequality. Thus, the low homicide rate in Britain, Canada and Australia obscures the fact that these countries have rather high rates of less serious types of violent crime. Judging by the shape of the cloud of points, there further appears to be a positive relation between inequality and violent crime, an observation confirmed by correlational analysis $(r=.60 ; \mathrm{p}=.003)$. Using different data sources, Green et al (2006) have also found a strong positive relation between inequality and violent crime, which indicates that the result is quite robust. Nonetheless, there are some countries for which this relationship does not apply. With the exception of Portugal, Southern European countries, for instance, combine relatively high levels of inequality with relatively low rates of violent crime. These countries thus appear to assume a separate position within the group of countries linked to a social market tradition. Other clear country clusters emerging from the scatter plot are the Nordics (low inequality and low-medium violent crime), Eastern Europe (low inequality and low-medium crime, Poland excepted) and East Asia (low on violent crime and low to low-medium on inequality).

Moving to the two indicators of wage regulation, the scatter plot of Figure 8 at first sight shows a bizarre pattern: the country points are arranged in three horizontal lines. This pattern is explained by the fact that Union Coverage has just three values (see Table 1). On close 
inspection clear country clusters in line with expectation do emerge, however. Except for Australia and Ireland, all English-speaking states have low values on both union coverage and centralization of wage bargaining, which is in agreement with the notion that central arrangements regulating individual employer-employee relations have no place in liberal societies. Other distinct clusters are the Nordics (high values on both indicators) and Mediterranean Europe (high on union coverage; low on centralization). The clustering of the Mediterranean countries shows that a distinctive social market regime comprising all the countries of Column Two of Table Two cannot be identified, an impression only reinforced by the wide range of values on centralization among the North-West European states associated with this tradition (compare the low value of France with the high values of Germany and Austria for instance). Corporatist arrangements yielding central, cross-sector wage agreements thus seem to be a specific feature of the German-speaking and Nordic countries.

Some have argued that centralised wage bargaining plays a key role in reducing income inequality by ensuring standard levels of pay across all companies nationwide within a given sector (OECD 1997; Nickel and Layard 1998). Figure 9 indeed shows a strong negative relation between centralised wage bargaining and income inequality $(\mathrm{r}=-.62 ; \mathrm{p}<=.004 ; \mathrm{N}=$ 20). Given the strength of the correlation, this factor could well be more important in explaining variations in income inequality than the level and degree of universality of social benefits. Indeed, correlating the proportion of public spending on welfare (which, admittedly is a rather crude measure as it does not give information on the inequality of benefits) to income inequality produces an $\mathrm{r}$ of just $-.37(\mathrm{p}=.06 ; \mathrm{N}=25)$.

With regard to state involvement and employment protection, the English-speaking states also cluster tightly (see Figure 10). In keeping with liberal traditions they assume low values on both indicators, particularly on employment protection. As expected, the Nordic countries all have high rates of state involvement but they differ on employment protection, the legislation in Norway being the most and in Denmark being the least protective. Once again, a distinct Mediterranean cluster can be identified marked by very high rates of employment protection and low to middling degrees of state involvement. The north-west continental countries also show relatively high rates of employment protection but their rates of state involvement vary quite considerably (compare the relatively low rates in Germany and 
Figure 8. Wage regulation: union coverage and centralization of wage bargaining

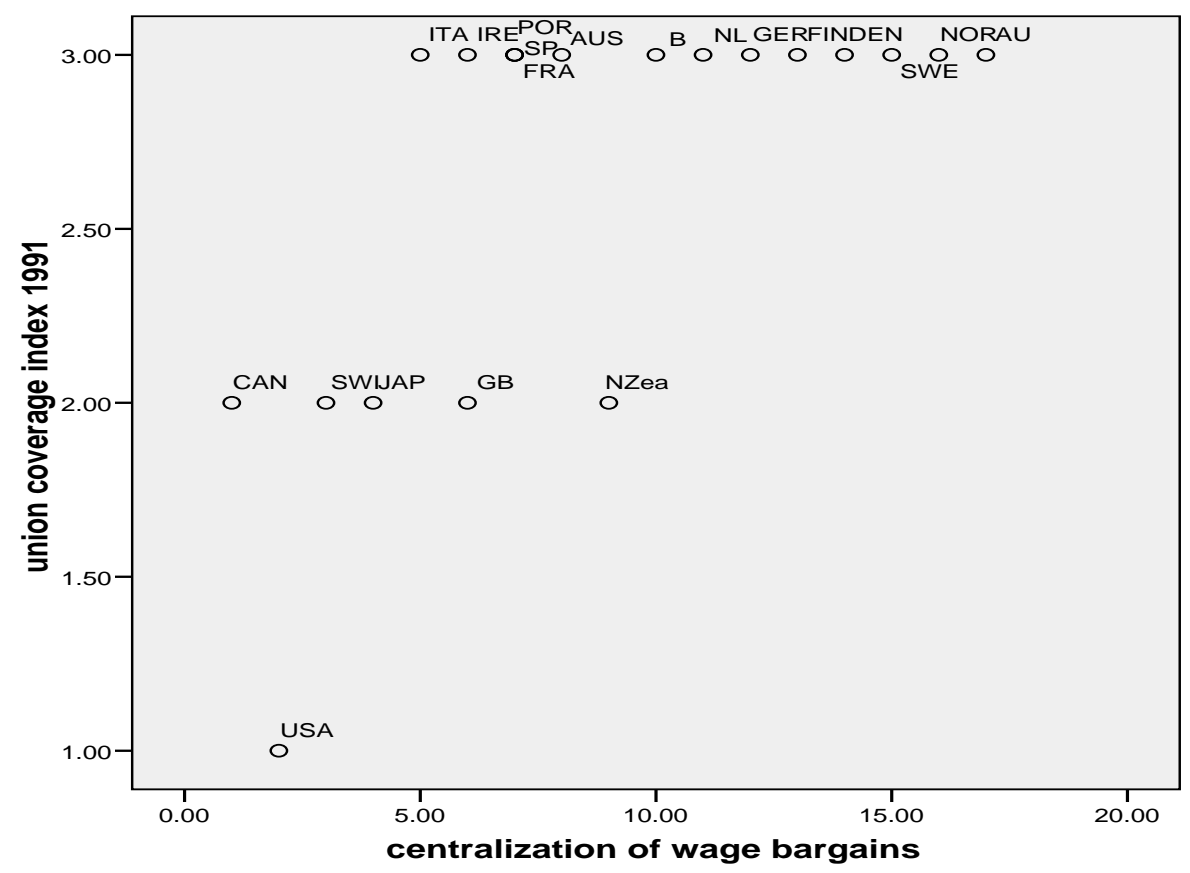

Figure 9. Income inequality by centralization of wage bargaining

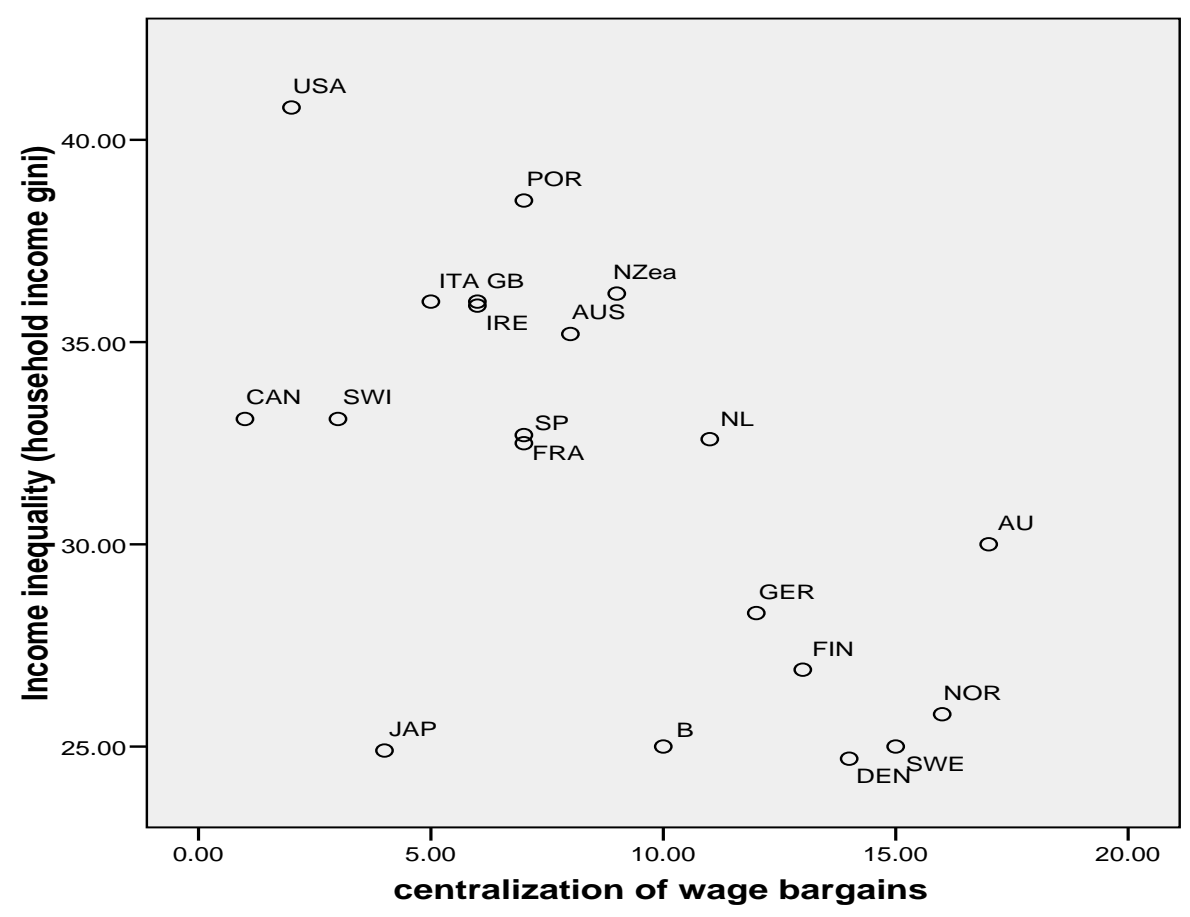


Austria with the relatively high ones in France, Belgium and the Netherlands). Once again, therefore, the social market regime only shows up as a coherent group of countries if you exclude the southern European states. Interestingly, the east-European countries do emerge as a distinct cluster characterized by high rates of state involvement and only low-medium rates of employment protection. While the high rates of state involvement may well reflect a legacy of the state controlled economy of communist times, the latter must have been brought about by the liberal market reforms following communism. If so, the two indicators would seem to differ remarkably in the degree to which they are affected by path dependency. In other words, it may be much more difficult for states to change levels of state involvement than it is for them to move to a more flexible or more regulated labour market. Similar differences in the degree of path dependency could well apply to other indicators of social cohesion. Finally, we note that we cannot assess whether a distinct east Asian cluster can be found because of missing values for Korea.

Plotting ethno-racial diversity against the welfare state (Figure 11) produces the same familiar country groupings. Once again, though slightly less cohesive than before, an English-speaking cluster emerges marked by relatively high levels of diversity and low levels of public social expenditure. This conforms to the image of liberal societies as open, inclusive communities offering only residual social protection because of the predominant belief in laissez-faire, private solutions and meritocracy. Once again the social market group of countries is quite internally diverse if you try to include the southern European states in this group. Two distinct clusters emerge within it: a Mediterranean group combining low diversity with medium levels of public social spending and a cohesive group of core northwest European countries (FRA, B, GER, AU) marked by medium to high levels of diversity and high levels of public social spending. This finding combined with those of the previous scatter plots suggests that Leibfried's earlier noted criticism on Esping-Andersen's country groupings was correct and that it is consequently more appropriate to identify a separate Mediterranean cluster existing alongside a north-west European one than to lump the countries of the two groups together in one conservative or social market regime. In view of the high levels of social spending in the last-named group, it would also seem to be more fitting to apply the label of social market to the north-west European countries only. 
Figure 10. State involvement and employment protection

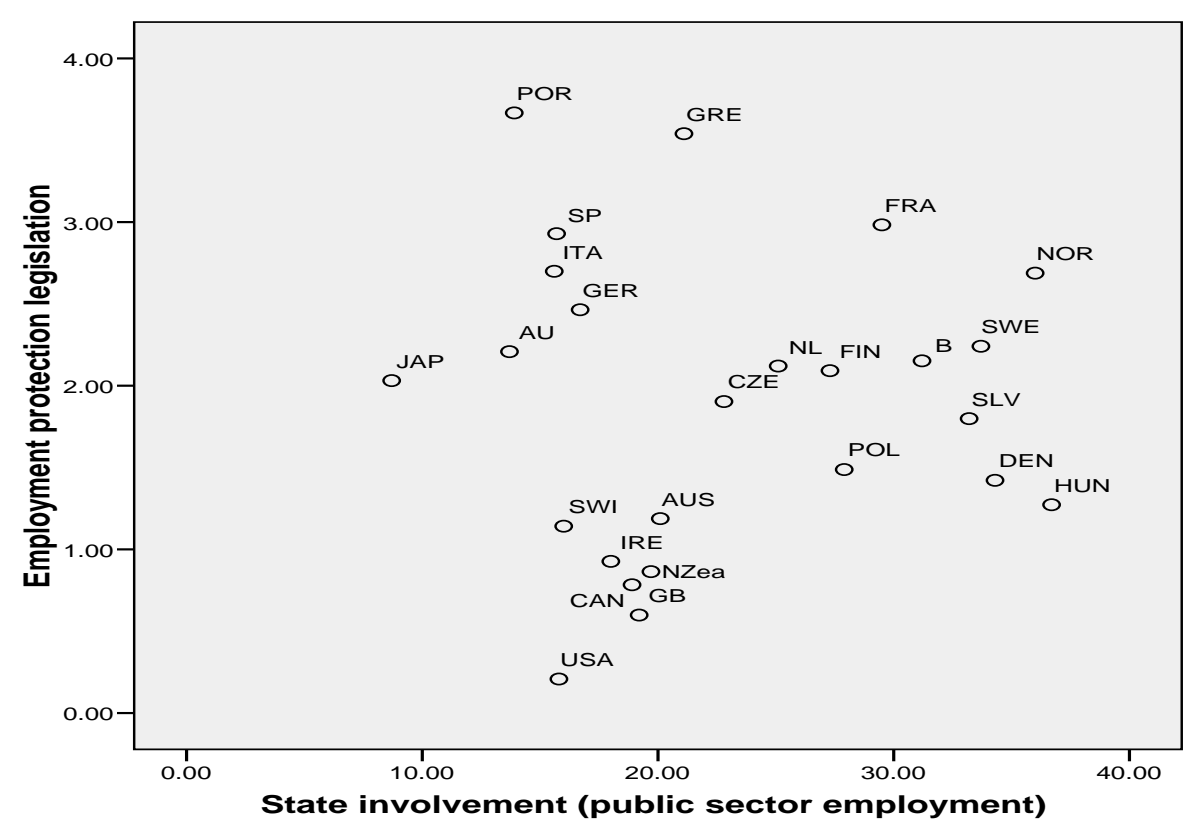

Figure 11. Ethno-racial diversity and welfare state

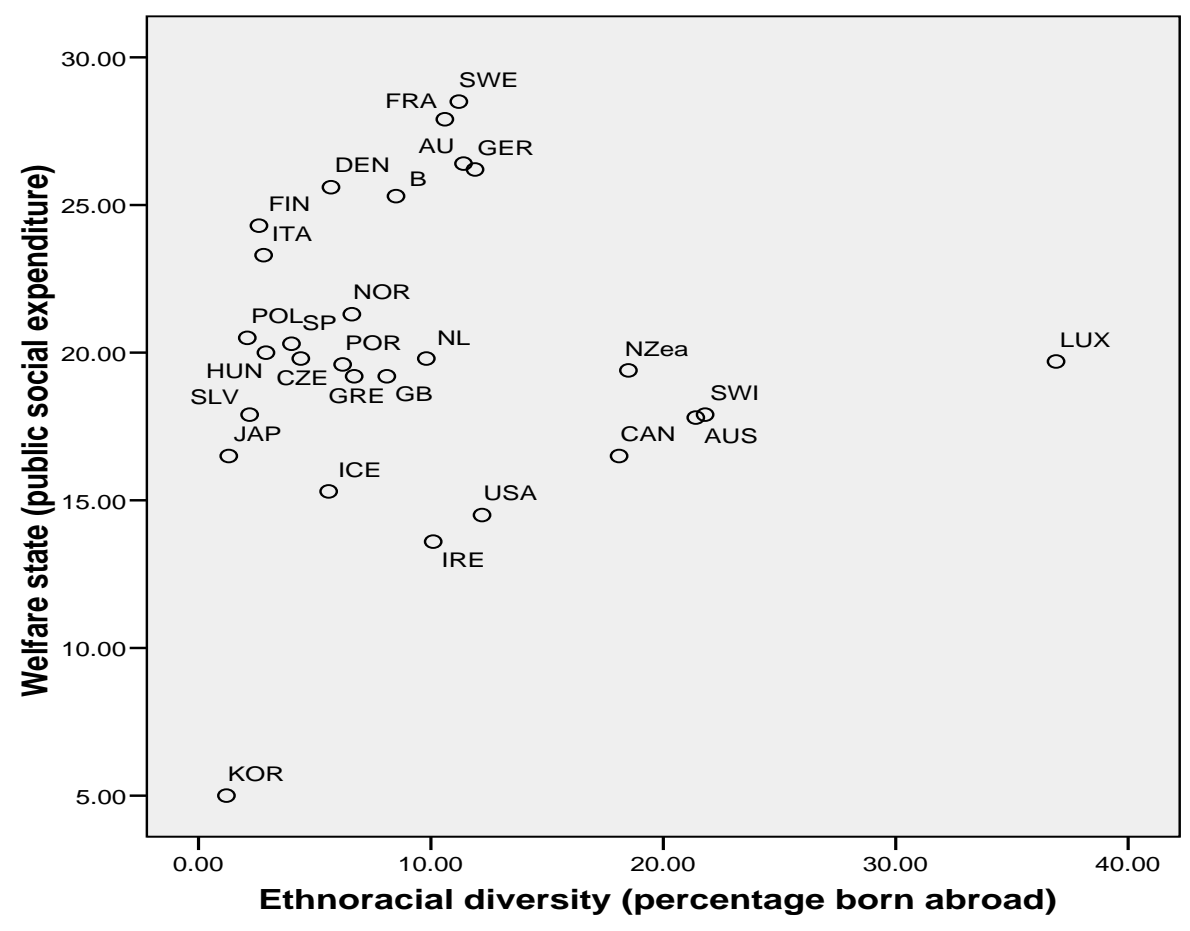


Excepting Iceland, the Nordics also form a fairly cohesive group, showing low to medium diversity and high welfare spending. Eastern European countries also cluster tightly combining low diversity with low/medium spending. As expected the east Asian countries are very low on diversity although they differ somewhat on social spending (Korea very low; Japan low-medium).

On a different note, it is interesting to observe there is no relation between diversity and public social spending. Obviously, this does not support the claim advanced by some (e.g. Alesina and Glaeser, 2004) that diversity undermines social solidarity and that this is reflected in reduced public social spending. Using a much larger sample of 52 states including many developing countries, Alesina and Glaeser do find a negative relation between racial diversity and welfare spending controlling for GDP per capita (ibid, 142). Possibly, diversity constitutes a greater threat to solidarity in conditions of scarcity and it is this mechanism that can explain why our findings, which are based on a sample of affluent countries, contrast with those of Alesina and Glaeser (see Janmaat, 2009 for a further discussion of this issue).

Importantly, ethno-racial diversity does not appear to be related to value diversity either (see Figure 12 - discounting Luxembourg the bivariate correlation is a mere .16 and is not anywhere near significant with a $\mathrm{P}$ value of .48). This non-relationship is not consistent with Huntington's (2004) proposition that the influx of immigrants of non-western backgrounds produces such a degree of cultural pluralism that the stability of western democracies is undermined. Evidently, value diversity is a product of other processes and legacies. Apart from a very distinctive east-Asian cluster (Japan and South Korea) combining very low levels of both ethno-racial and value diversity, other clusters are more difficult to identify. Each group of countries appears to have its outlier(s). Thus, in conformity with the plural character of their societies the US and Canada show high levels of value diversity. Britain however has only medium levels of value diversity. Similarly Sweden and Iceland (low on value diversity) contrast strongly with Denmark and Finland (high on value diversity). The cohesion of the otherwise quite tightly clustered social market group (FRA, B, AU and GER all combine medium levels of ethno-racial diversity with high levels of value diversity) is undermined by the very low score of the Netherlands on value diversity. Surprisingly for countries associated with a tradition that appreciates cultural homogeneity (i.e. romantic conservatism), the east European states show medium to very high levels of value diversity. In sum the empirical 
findings only partially support the theory. The east Asian countries cluster and show low value diversity as the theory would predict. The liberal countries are on average quite valuediverse, again in accordance with the theory, but they are not very tightly clustered, with Britain showing only a medium value. The Social Democratic countries on average are not very value diverse, but the wide range of values for the group is too high to say that this really supports the theory. The surprise is that the north-west continental European countries, which are well clustered (with the exception of the Netherlands) appear as value-diverse on average as the liberal countries.

\section{Figure 12. Ethno-racial diversity and value diversity}

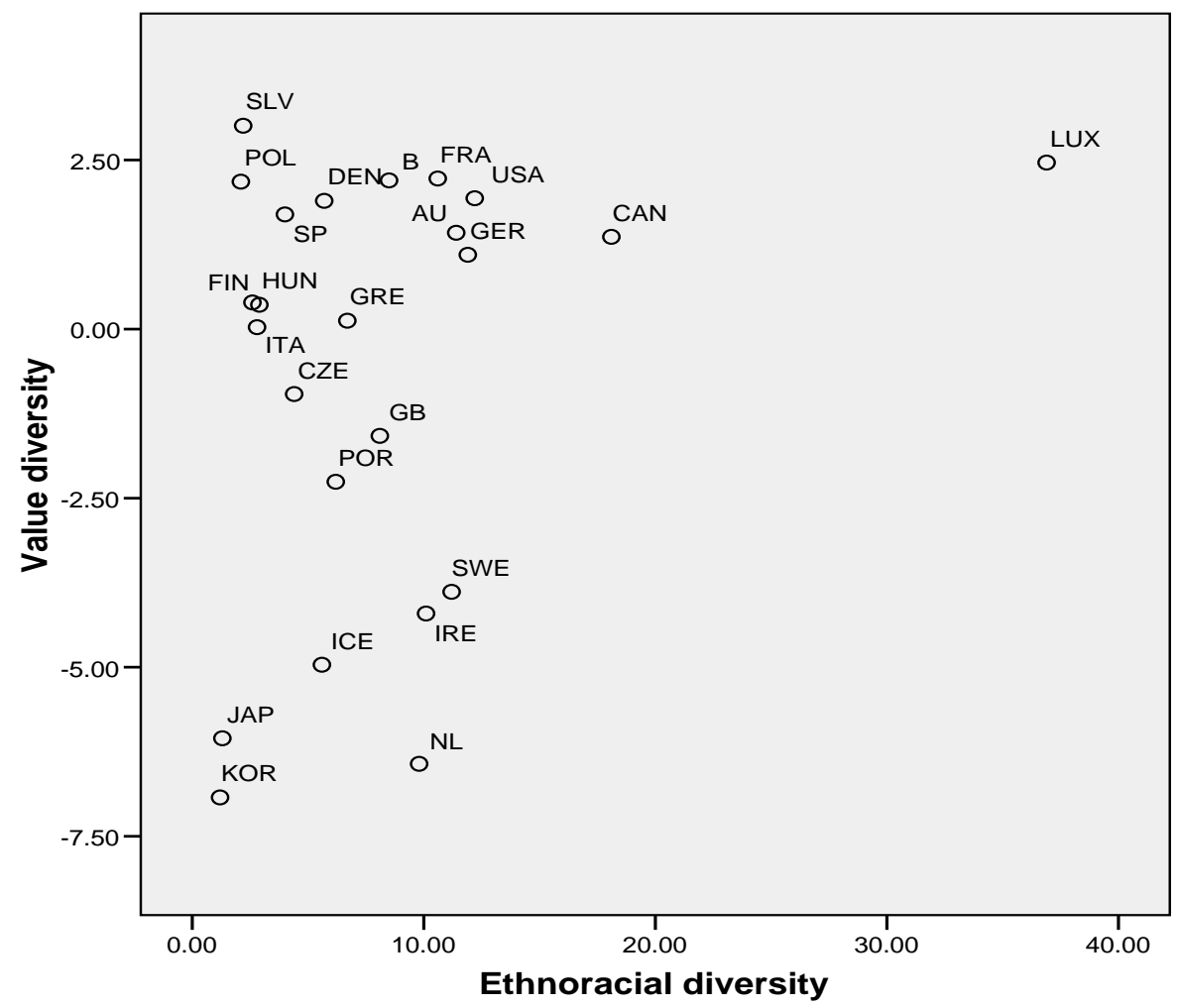




\section{Figure 13. Passive and active civic participation}

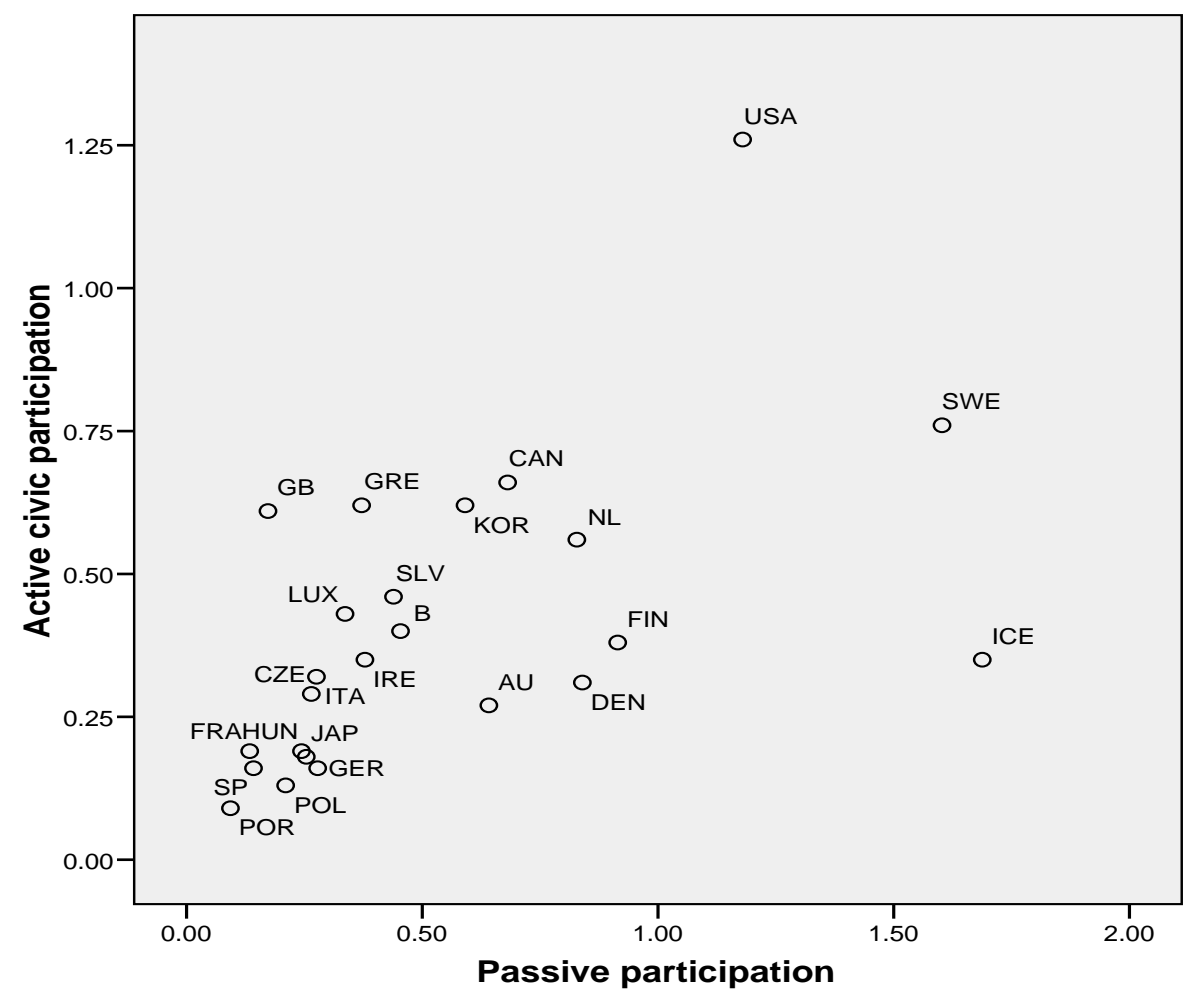

Figure 13 plots passive and active civic participation. We see that the two forms are strongly correlated $(\mathrm{r}=.55 ; \mathrm{p}=.006)$ and show a pattern which is to some extent in conformity with the social cohesion traditions. Civic participation is indeed highest in the English-speaking countries, particularly the active form, whilst all continental European countries, except for the Nordics, record low levels of both passive and active participation. The Nordics show relatively high levels of passive participation. The social market countries do not show high levels of passive participation, however, which is not what we had expected. Japan has low levels of both types of participation, in conformity with expectations, but Korea's moderately high levels of participation do not conform with the theoretical model. However, judging by the Asiabarometer data cited (in section 5) for the larger group of east Asian countries, which mostly show low levels of civic participation, it may be that Korea, with its high levels of unionisation, is something of an exception for east Asia in this respect. The cohesion of the clusters is also somewhat undermined by the extreme values of the US, Sweden and Iceland, suggesting that particular national traditions are equally important in shaping civic participation. 


\section{Figure 14. Freedom versus equality and merit versus equality}

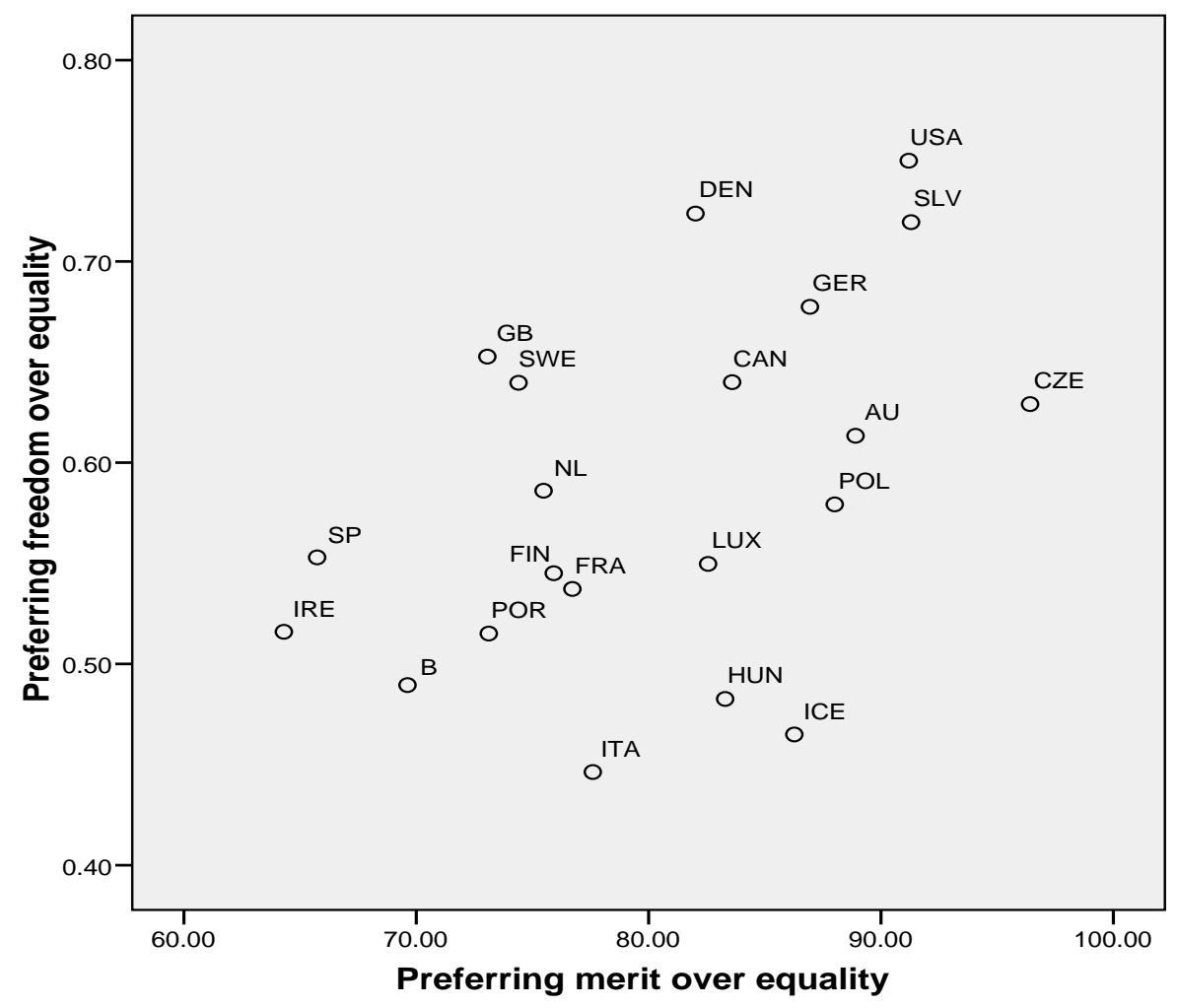

Figure 14 shows the country patterns on the components freedom versus equality and merit versus equality. Do societies which value freedom more than equality also prefer merit over equality as principles governing remuneration, and is it typically the liberal English-speaking societies displaying such opinions, as one would expect in view of their liberal tradition? The answer to both questions is yes, although the 'yes' to the second question is more qualified. Broadly, societies appreciating freedom also support the principle of merit $(r=.65 ; p=.035)$. The United States very much conforms to expectation given its high score on both indicators. Canada and Britain also express a relatively strong preference for freedom but their appreciation of merit is relatively low (particularly that of Britain). A more distinct cluster emerges for Catholic Europe (Belgium, Ireland, France, Spain, Italy and Portugal) which has low values on both indicators. The east European countries show a strong preference for merit over equality, indicating that they have decidedly rejected the egalitarian ethos promoted by the former communist regimes. Their score on freedom over equality is more varied however. The social market countries and Nordics are too spread out for them to be identified as cohesive clusters on this measure. At first sight it seems surprising that the majority in Denmark and Sweden say they value the freedom more than equality. This may 
be because these countries are already relatively egalitarian and respondents are taking this into account in expressing their relative preferences (even though the question is posed in terms of absolutes). On the other hand it may be that this type of question is not well adapted to countries like these where the dominant political discourse does not usually posit a dichotomy between freedom and equality.

Let us now turn to the country patterns on conceptions of nationhood and xenophobia to assess whether any remnants of a romantic-conservative tradition can be identified. As Figure 15 reveals, a preference for cultural markers of nationhood relative to political ones shows a strong positive link with xenophobia cross-nationally $(r=.65 ; p=.023$ in an analysis of just 12 countries). In other words, nations attaching a relatively high importance to cultural markers are also more fearful of foreigners. As suggested in sections four and five, the ethnocultural traditions have continued to leave their mark on central and eastern European countries (with Poland, Czech Republic, and Hungary in particular all showing high values on both the measures) while Germany appears to have severed its link with the romantic conservative tradition which originated there. Canada and the USA have the lowest value on the ethno-cultural measure, which is in conformity with the liberal tradition, and low

\section{Figure 15. Conceptions of nationhood and xenophobia}

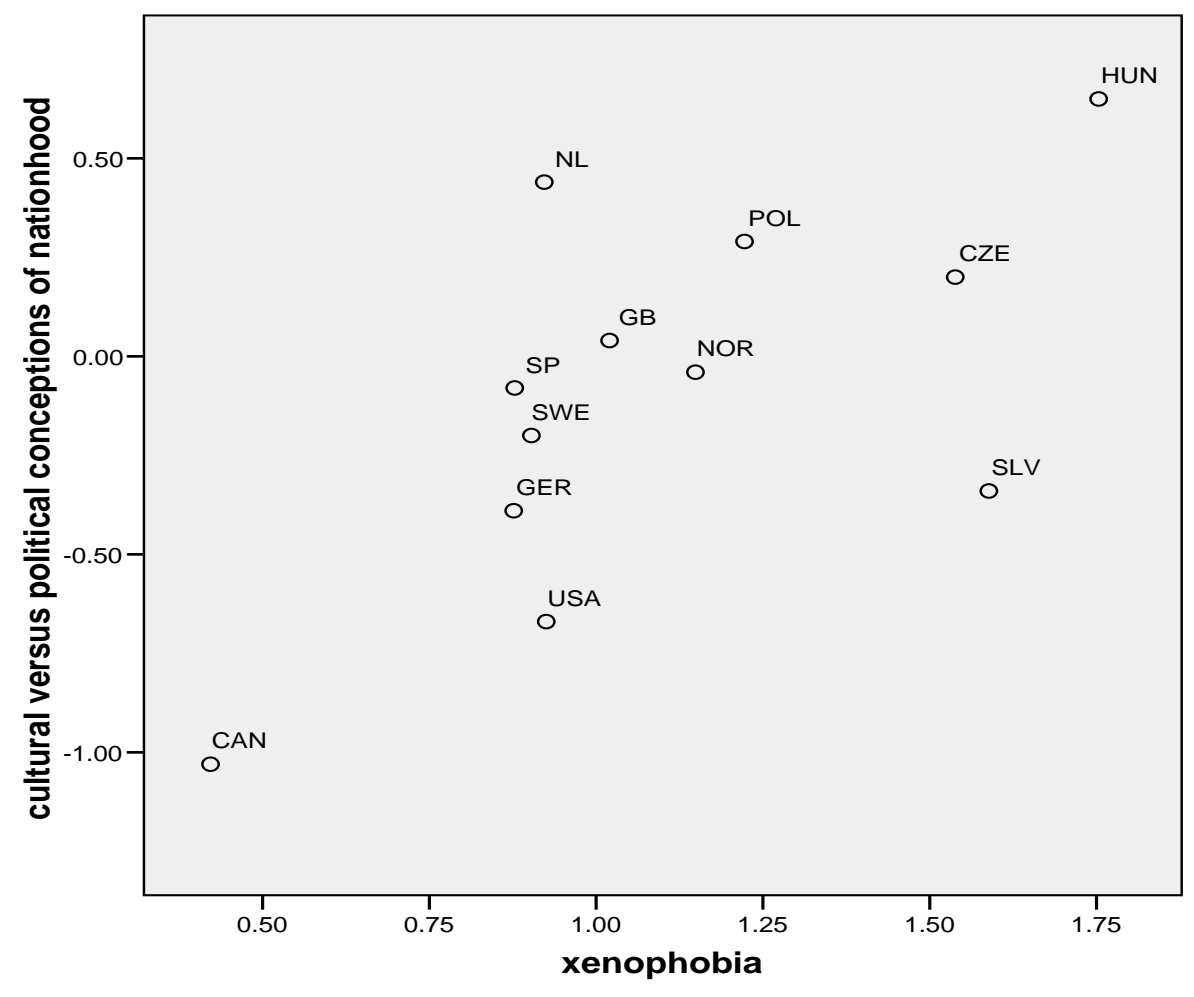


(Canada) to low middling (USA) values on the xenophobia measure, which accords with the how liberal states like to see themselves. Britain, however, has average values on both, which doesn't support the notion of it as an exemplar of liberal nationhood. Since there are no data for France we are not able to put to the test the claims of republicanism to have a dominantly political rather than ethno-cultural view of nationhood. The very high level of identification with cultural markers of citizenship in the Netherlands (combined with middling levels of xenophobia) should also be noted. Hans Kohn associated the Netherlands with the group of states conforming to the civic model of citizenship in the nineteenth century but that association is not apparent from this data for the twenty-first century.

Unsurprisingly, Figure 16 shows a strong negative relation between xenophobia and acceptance of immigrants as neighbours $(r=-.75 ; \mathrm{p}=.001)$. In other words, countries with high levels of xenophobia show low levels of acceptance of immigrants and vice versa. Very much the same patterns can be observed as in Figure 8. The east European countries form a

Figure 16. Ethnic tolerance: xenophobia and acceptance of immigrants as neighbours

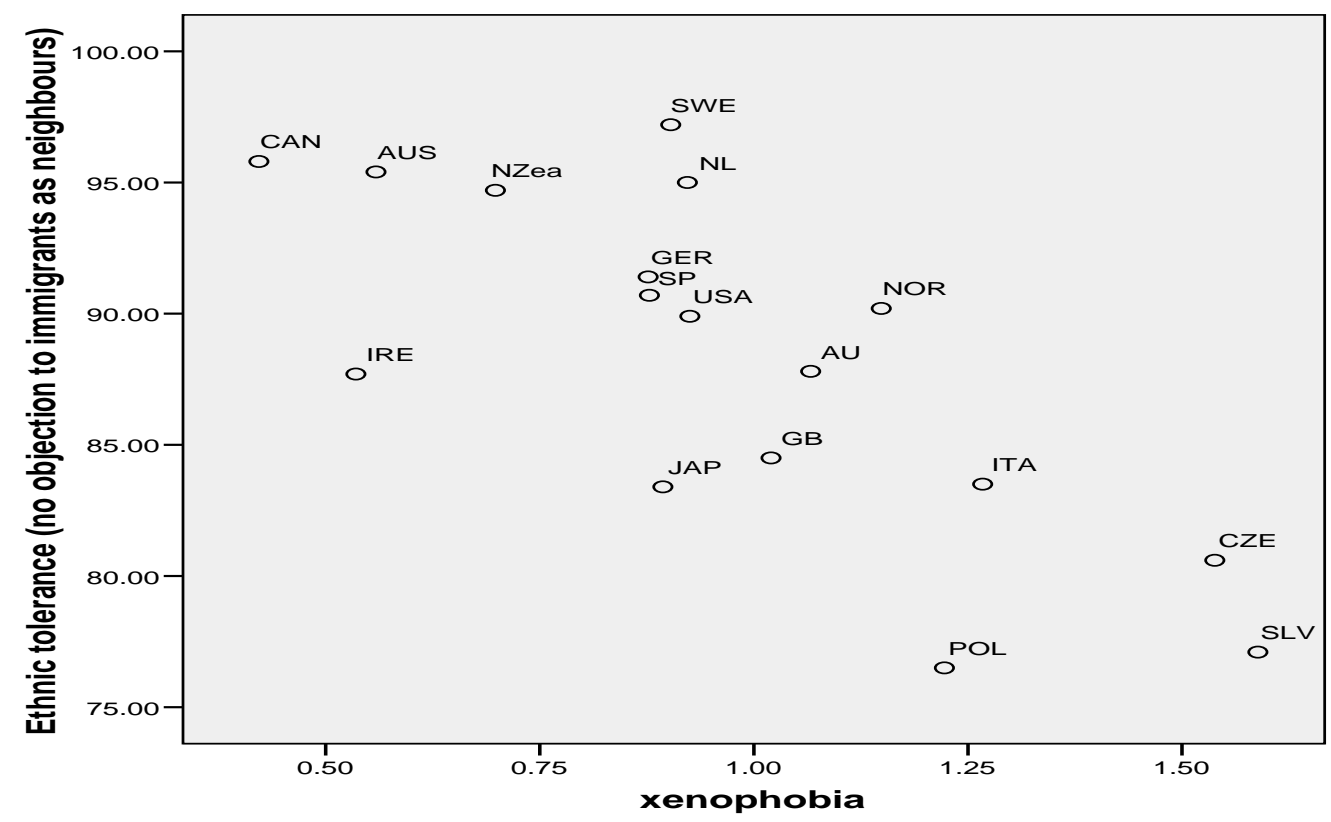

distinct cluster combining high levels of xenophobia with low levels of acceptance of immigrants. In conformity with liberal traditions, Canada, Australia and New Zealand have 
strikingly low levels of xenophobia and high levels of acceptance of immigrants. The US and particularly Britain lag behind on both indicators, however. Germany, Austria, and the Netherlands cluster reasonably closely together, particularly on levels of xenophobia, with middling values on both dimensions. This time, however, the southern European group fails to cluster and overlaps with the core north-western European social market group. Sweden and Norway have middling positions on the Xenophobia dimension but rank higher on acceptance of immigrants as neighbours. However, in the absence of data on Denmark, Norway, Finland and Iceland it is hard to identify a Nordic cluster here.

An equally strong negative correlation characterizes the link between social hierarchy and gender equality ( $\mathrm{r}=-.55 ; \mathrm{p}=$.003) (Figure 17). Generally, countries combine high levels of social hierarchy with low levels of support for gender equality (e.g. Korea and Poland) or vice versa (the Nordics and the Netherlands). There are also exceptions to this regularity. Germany, Austria and Switzerland, for instance, have comparatively low values on both indicators while the US, Canada and Ireland combine strong support for gender equality with high levels of social hierarchy. More broadly, the country scores on both indicators seem to be primarily a reflection of religious heritage, with protestant countries showing the highest levels of support for gender equality and the lowest appreciation for social hierarchy, Catholic countries record average levels on both indicators and Confucian states show quite high levels of respect for hierarchy and particularly low levels of support for gender equality, as would be predicted from the theoretical models. Perhaps because of their religious homogeneity, the Nordic countries and the east Asian countries are the most distinctive of clusters. The countries associated with the liberal and social market traditions do not present themselves as clearly demarcated clusters.

\section{Cluster Analysis}

As noted before, cluster analysis enables an assessment of the similarity of cases in terms of their values on a multitude of variables. For our purposes it can be used to explore the degree to which the countries cluster in the groups as displayed by Table 2 based on all social cohesion indicators together. We did not include union coverage, centralization of wage bargains, violent crime, conceptions of nationhood and xenophobia in the analysis, however, because of the many missing values on these indicators. We used the standardized versions of 
the indicators (i.e. with a mean of 0 and an SD of 1 ) to ensure that each variable has equal weight in the analysis.

Figure 17. Social hierarchy and gender equality

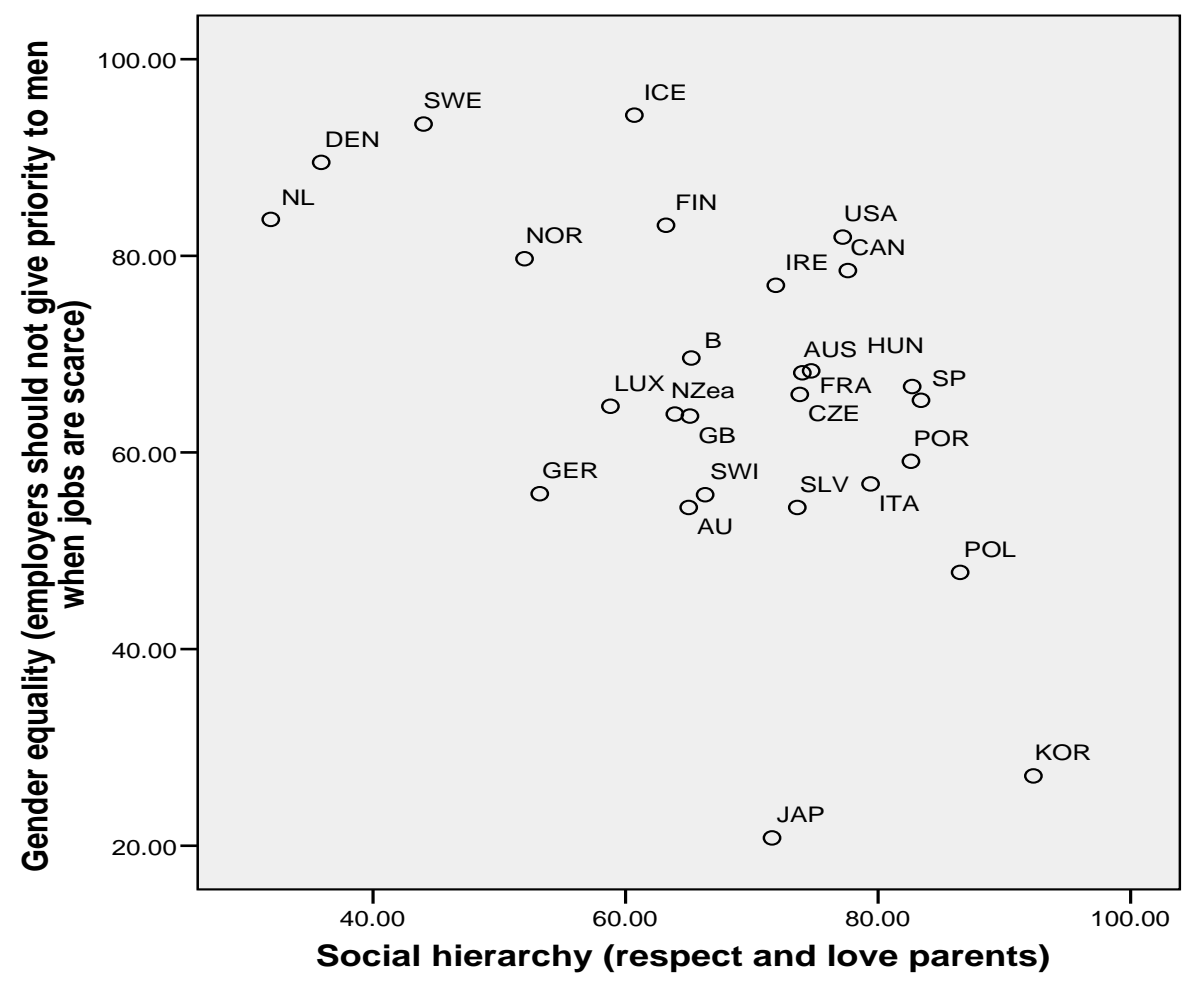

We opted for a hierarchical cluster analysis, meaning that the forming of clusters of cases occurs in a series of stages. The first stage starts with the individual cases and combines the two cases which are most similar in a new cluster. This procedure is repeated in every subsequent stage with two cases, one case and one cluster, or two clusters merging and forming a new cluster. The further the analysis proceeds the fewer clusters remain but the larger the differences between the clusters become and the more heterogeneous the clusters become internally. In other words, in the initial stages it produces many clusters which are relatively homogenous internally and in the final stages just a few highly diversified clusters are left over (Cramer, 2003). The best visual representation of this process is a dendrogram, which displays the different clusters as horizontal lines on the $\mathrm{x}$-axis (see Figure 18). The 
higher the value on this axis, the fewer the number of clusters and thus the more internally diverse each cluster is. The branching points on the axis (i.e. the moments when new clusters are formed) offer good insight into the internal homogeneity of each cluster for a specific cluster solution (by cluster solution we mean the number of clusters produced at a certain stage).

The clusters of countries shown by Figure 18, which presents the output of an analysis using all indicators except for the ones noted above, coincide quite well with the groups of countries associated with a particular regime. Remarkably, and somewhat in contrast to the findings of the scatter plots, a clear Catholic/social market cluster can be identified grouping Belgium, France, Germany, Austria and the Mediterranean countries. At a slightly later stage in the analysis this group is joined by the three eastern European countries which also form a homogenous cluster. Likewise a distinct English-speaking group emerges comprising Great Britain, Canada and Ireland, which joins the European continental group at yet a later stage in the analysis. The US is conspicuously absent from this group, however. It forms a unique country cluster until the final stage in the analysis. A basic Scandinavian cluster can also be identified joined by the Netherlands, although Finland is not part of this group. Thus, the analysis indeed yields the main three traditions in terms of the countries associated with them. The unique position of the United States somewhat undermines the traditions logic however.

Figure 19 shows the results of a cluster analysis using only the administrative indicators, which has the effect of bringing Switzerland, Norway, Australia and New Zealand into the analysis. As we can see, a next to perfect liberal cluster emerges grouping all the Englishspeaking countries, the United States included, and Switzerland, the only odd one out. Clusters representing each of the other traditions also come to the fore: (1) a social democratic group emerges including the Nordic countries and Belgium; (2) a social market cluster appears composed of all the northern and southern states associated with it and Japan (but excluding Netherlands); (3) a separate eastern European group shows up composed of the four Visegrad countries and Netherlands (!), which joins the social democratic group at a later stage in the analysis. In sum, aside from several misfits (Switzerland, Belgium, Netherlands), the analysis based on administrative indicators yields groups of countries which fit the social cohesion traditions almost perfectly. This suggests that the notion of distinct 
Figure 18. Output hierarchical cluster analysis on all indicators

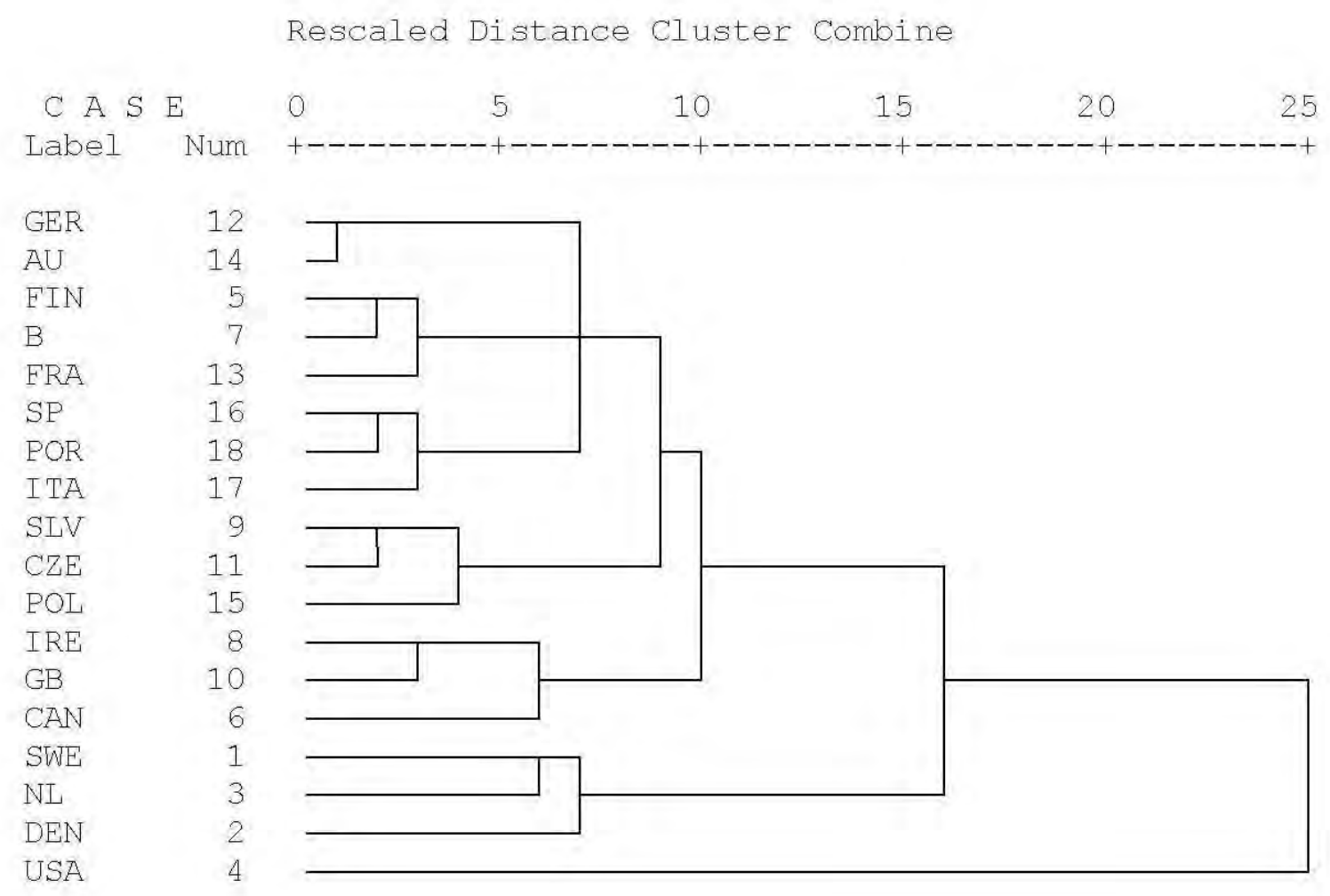

path-dependent traditions particularly applies to material, 'objective' conditions and may be less appropriate for the subjective world of opinions, beliefs and attitudes. Indeed, a recent study on the criteria European native majorities hold to be important for deciding which immigrants can stay in the receiving country found that the cross-national types of such opinions did not conform to the welfare regimes and integration philosophies as highlighted in the political economy and citizenship literature (Bail, 2008). Before exploring this issue further, we first assess whether including the two indicators on wage regulation in the analysis makes a difference.

Figure 20 shows that it indeed does. In fact, adding these two indicators has the effect of breaking up the social market group in two subgroups: a Core Europe group which merges with the Scandinavian group and a Mediterranean group joining the Liberal group at a later stage in the analysis. Thus, with regard to wage regulation, the tripartite division of countries in a liberal, social democratic and social market/catholic cluster does not apply. Clearly, bringing other administrative indicators in could also have the effect of modifying the neat 
clusters of Figure 19. We should therefore not interpret these clusters as fixed, solidly bounded entities.

Figure 19. Cluster analysis based on administrative indicators only

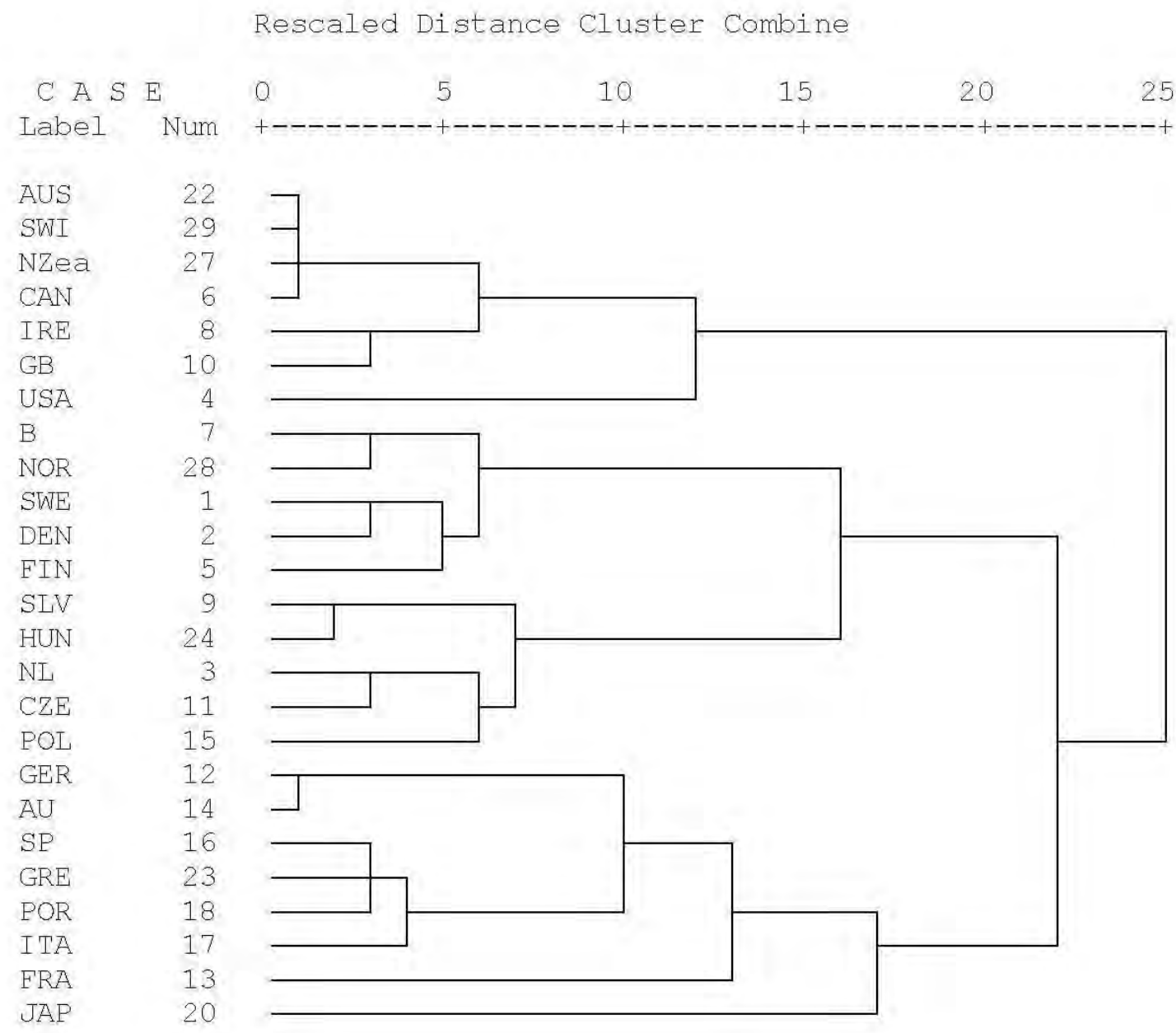

We turn finally to a cluster analysis based on attitudinal indicators only (Figure 21). As suggested above, we indeed see a less perfect clustering of countries by comparison to Figure 19; the US resumes its unique position; the Social Democratic cluster is less cohesive with Finland dropping out and the Netherlands joining; the Social Market cluster once again disintegrates in several sub-groups. Interestingly, two other distinct groups arise: a Catholic European cluster comprising FRA, IRE, POR, SPA, ITA, and BEL, which clearly reflects the influence of Catholicism, and a cluster uniting GER, AU and the four Visegrad nations and thus corresponding almost perfectly with a romantic conservative tradition. Thus, with 
respect to attitudes a somewhat different set of traditions seems to apply which partly crosscuts the liberal, social democratic and social market traditions.

Figure 20. Cluster analysis on all administrative indicators including union coverage and centralization of wage bargains

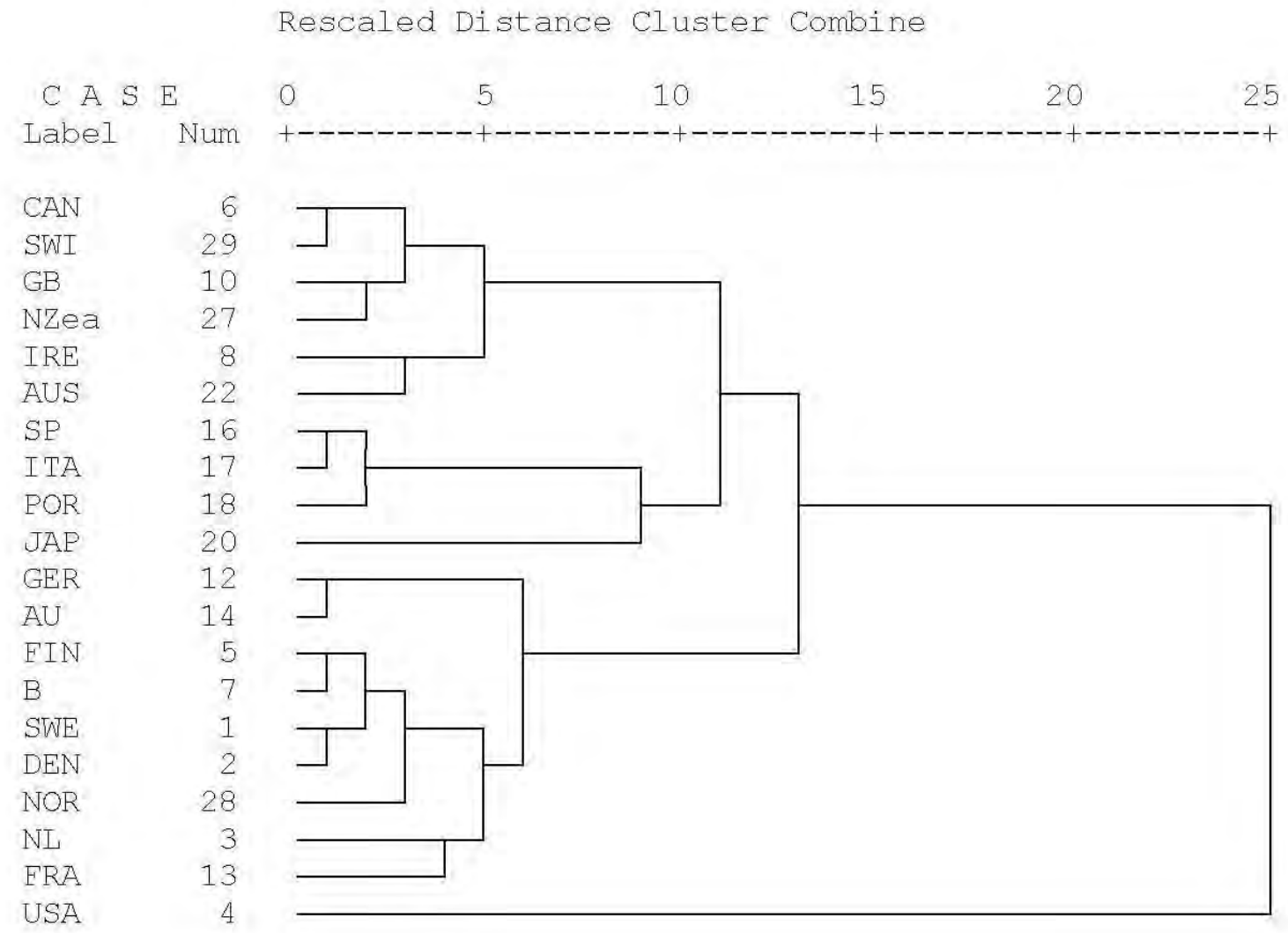




\section{Figure 21. Cluster analysis on indicators drawn from opinion surveys}

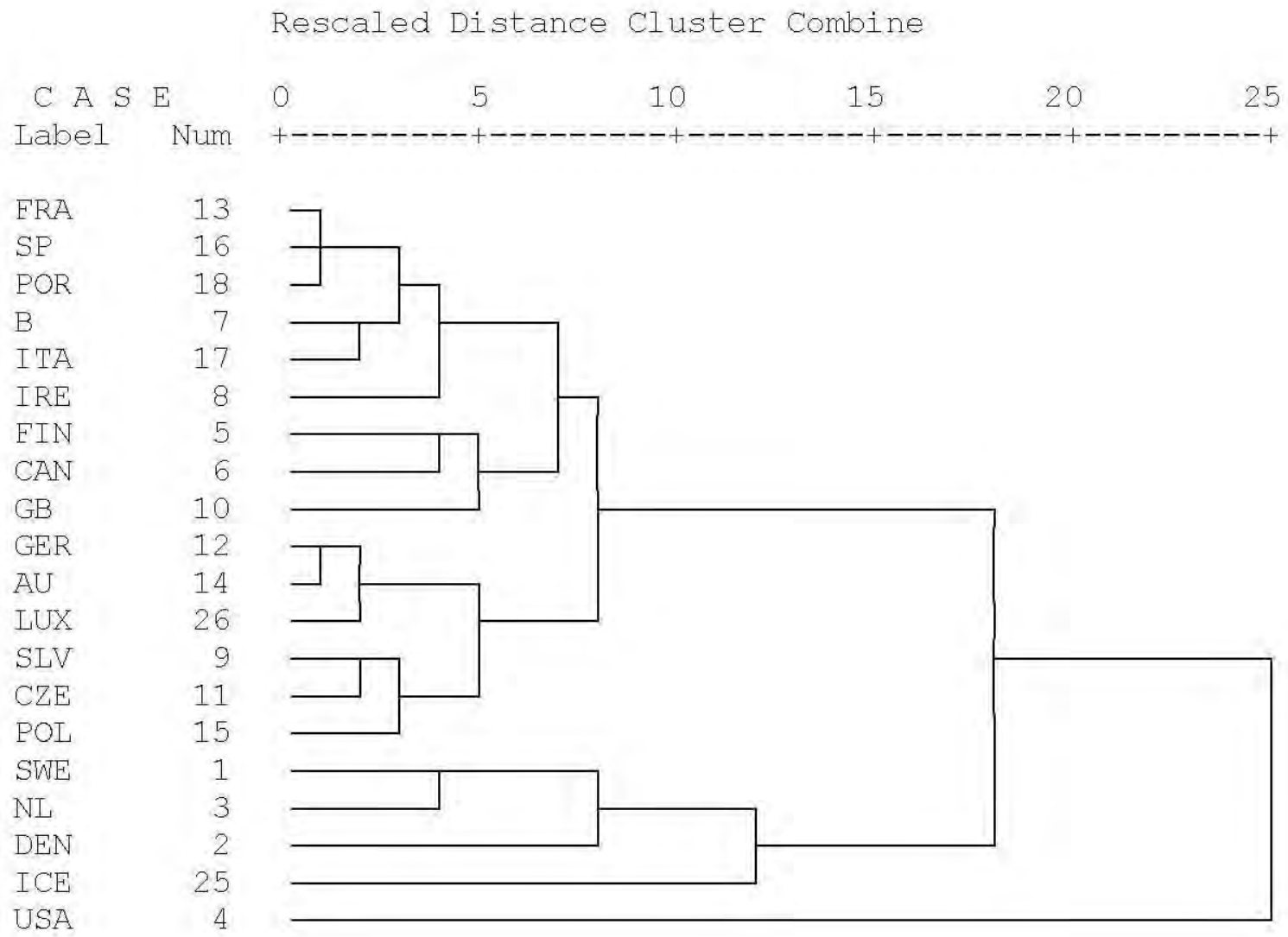

Indexes

As explained above the indexes reflect theoretical constructs corresponding to each of the traditions. We used the social cohesion components and associated traditions of Table 1 as a guideline in the construction of the indexes. The signs placed after the traditions in this table are crucial as they indicate the substantive character of each of the traditions in terms of the social cohesion components (and their corresponding indicators) in relation to other traditions. Thus, the liberal tradition stands for relatively high levels of inequality, low levels of state involvement, low levels of public social expenditure, high levels of active civic participation, and so on. The challenge is thus to construct an index for each of the traditions that captures this relative score on each of the components. The best way to do this, in our view, is to first standardize the indicators and then create an index that combines an addition 
of the standardized indicators on which the corresponding tradition is thought to show relatively high values with a subtraction of the standardized indicators on which that tradition is deemed to have low values. As low values on standardized variables appear as negative scores (remember that standardized variables have a mean of zero), subtracting these scores produces positive values. Consequently, a country with high values on the first-named indicators and low values on the last-named would automatically get a high value on the index. We can illustrate this with the following example. Say we create a liberalism index using standardized versions of the aforementioned four indicators and there is a country with a value of .85 on inequality (i.e. higher than average), -.50 on state involvement (i.e. lower than average), -.90 on social expenditure and .20 on active civic participation. Then the country would have liberalism index score of: $.85+.20-(-.50)-(-.90)=2.45$.

Following this procedure we created four indexes, one for each tradition. Table 3 shows the composition of these indexes in terms of the components (as tapped by their standardized indicators) that were added up (marked by a plus) and those that were subtracted (marked by a minus).

We are now in a position to assess the country rankings on the indexes. Do we see the countries associated with a particular tradition leading the rank order of the corresponding index? Table 4 shows that this is indeed the case. The English-speaking countries have the highest values on the Liberalism Index, the Nordic ones on the Social Democracy Index, the continental European ones on the Social Market Index (Austria and Germany), and South Korea and Japan on the East-Asian Index. The degree of group cohesion, moreover, is remarkable as all the countries associated with a particular tradition form a continuous order in the top positions on the corresponding index. The only exception to this pattern is the Social Market Index where Sweden occupies a third position, interrupting the order of countries linked with this tradition. Broadly, however, the conclusion is warranted that the social cohesion profiles of individual countries very much correspond to the traditions these countries are associated with, both substantively and in terms of group cohesion.

We need to express three reservations though. First, despite countries having continuous sequential rankings in the top positions, there can be large differences between countries within a single group. Thus, the difference between the United States and Great Britain, the number 1 and 3 on the Liberal Index respectively, is slightly larger than that between Great 
Britain and Belgium, the number 14 (before last!) on this index. Similarly, the distance between Finland, the Netherlands and Belgium, numbers 3, 4 and 5 on the Social Democratic

Table 3. Indexes reflecting social cohesion traditions

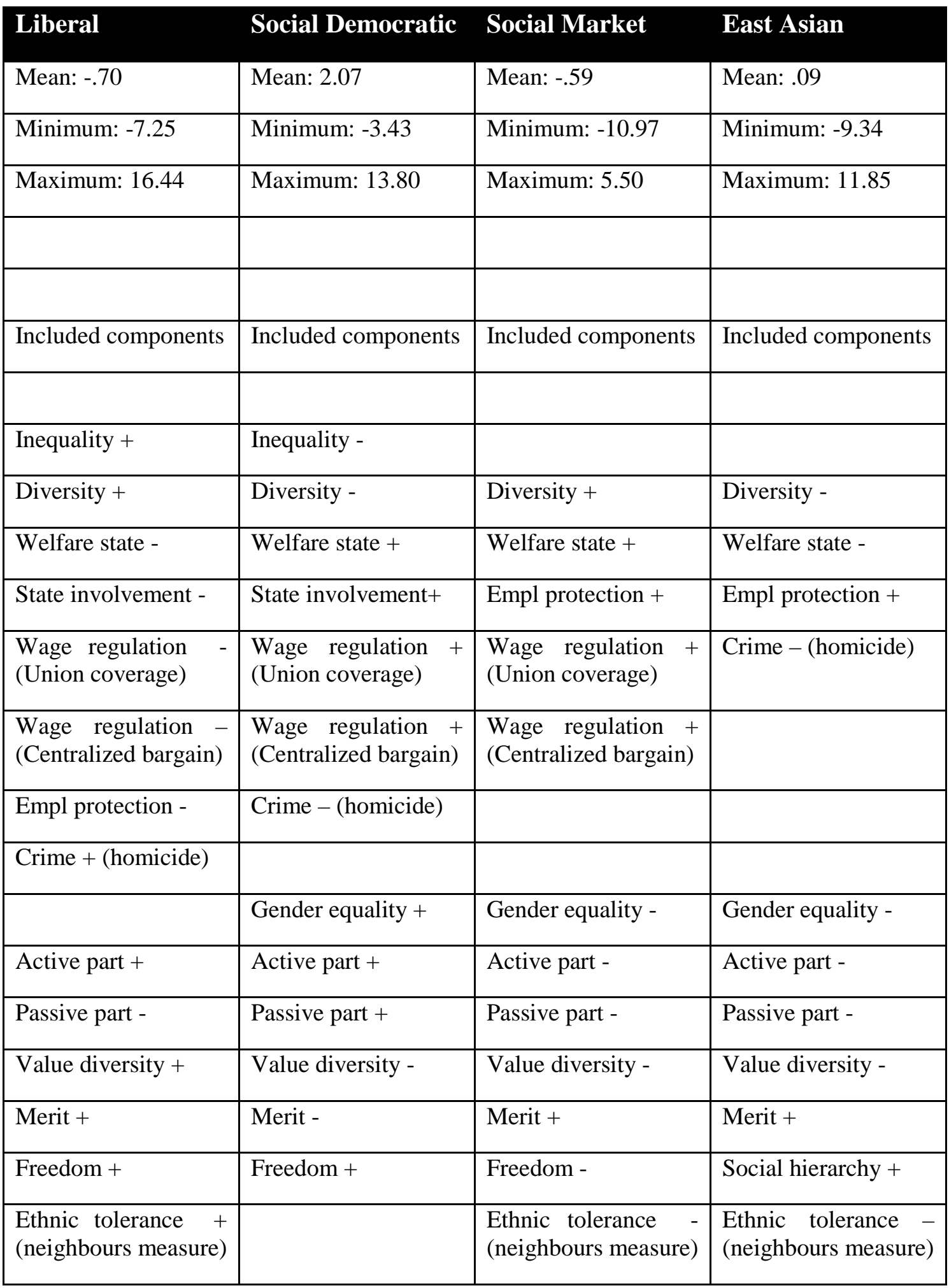


Index respectively, is smaller than that between Finland and Denmark, the number 2 on this index. These substantial internal differences suggest that unique national developments are at least as important in shaping social cohesion profiles as distinct regional/cultural traditions.

Table 4. Rank order of countries on the four indexes

\begin{tabular}{|c|c|c|c|c|c|c|c|}
\hline \multicolumn{2}{|l|}{ Liberal } & \multicolumn{2}{|c|}{ Social Democratic } & \multicolumn{2}{|c|}{ Social Market } & \multicolumn{2}{|c|}{ East Asian } \\
\hline Country & Score & Country & Score & Country & Score & Country & Score \\
\hline USA & 16.44 & SWE & 13.80 & $\mathrm{AU}$ & 5.50 & KOR & 11.85 \\
\hline CAN & 8.89 & DEN & 9.05 & GER & 3.10 & JAP & 8.64 \\
\hline GB & 4.82 & FIN & 6.33 & SWE & 2.21 & CZE & 4.37 \\
\hline IRE & -.30 & NL & 6.30 & FRA & 2.03 & POL & 4.28 \\
\hline GER & -.78 & B & 4.30 & ITA & 2.01 & POR & 3.93 \\
\hline POR & -1.34 & $\mathrm{AU}$ & 1.09 & POR & 1.60 & ITA & 3.07 \\
\hline $\mathrm{AU}$ & -1.97 & GER & .57 & FIN & 1.33 & SLV & 2.88 \\
\hline SP & -2.61 & FRA & .55 & B & 1.24 & SP & 2.12 \\
\hline ITA & -2.68 & IRE & .54 & NL & .57 & FRA & .30 \\
\hline NL & -3.10 & GB & -.28 & DEN & -.68 & GER & .17 \\
\hline FRA & -3.72 & SP & -.31 & SP & -1.40 & $\mathrm{AU}$ & -.24 \\
\hline DEN & -4.30 & ITA & -2.20 & IRE & -2.99 & IRE & -.54 \\
\hline FIN & -6.18 & CAN & -2.54 & GB & -5.93 & GB & -1.50 \\
\hline B & -6.49 & USA & -2.78 & CAN & -6.42 & B & -2.20 \\
\hline \multirow[t]{6}{*}{ SWE } & -7.25 & POR & -3.43 & USA & -10.97 & FIN & -3.08 \\
\hline & & & & & & CAN & -4.16 \\
\hline & & & & & & NL & -4.33 \\
\hline & & & & & & DEN & -5.41 \\
\hline & & & & & & USA & -7.65 \\
\hline & & & & & & SWE & -9.34 \\
\hline
\end{tabular}


Second, the indexes differ in the degree to which they distinguish themselves from the other indexes. The Liberal Index appears most distinctive as the countries leading its rank order trail the ranking order of countries of the other three indexes. Similarly, the Social Democratic Index is fairly distinctive as the countries heading its league have the lowest scores on the Liberal and East Asian indexes. The Social Market Index appears least cohesive and externally distinctive given the high scores of Sweden and Finland on this index. This suggests that there is considerable overlap between the social market regime and the social democratic regime. Correlations between the indexes substantiate these observations. While the Liberal Index shows strong negative links with the Social Democratic Index $(r=-.61 ; p=$ $.015)$, the Social Market Index $(r=-.85 ; \mathrm{p}=.000)$ and the East Asian Index $(\mathrm{r}=-.22 ; \mathrm{p}=$ .44 ), and the Social Democratic Index is negatively correlated with the East Asian Index ( $\mathrm{r}=$ -.62; $\mathrm{p}=.013$ ), the Social Market Index is positively correlated, albeit not significantly, with the Social Democratic $(r=.38 ; p=.16)$ and East Asian indexes $(r=.36 ; p=.19)$ (all correlations are based on 15 observations).

Third, and related to the second point, it is unclear to what extent these indexes, which are purely based on theory, reflect cohesive syndromes of social cohesion. The poor external distinctiveness of the social market index suggests that they may well only represent loose amalgams of sometimes unconnected empirical phenomena. The ensuing factor analyses shed further light on this issue.

\section{Factor analyses}

We performed a Varimax-rotated factor analysis on all the social cohesion indicators based on a sample of 19 countries. ${ }^{11}$ A factor analysis of this type is not trying to produce as small a number of dimensions as possible, but instead attempts to distribute the explained variance in as even a manner across the extracted dimensions, whilst ensuring simultaneously that these dimensions are not correlated to one another. The dimensions are thus maximally distinctive vis-à-vis each other. Table 5 shows the output on this analysis. The first column lists the indicators - as represented by the components they are tapping. Column Two to Five present the loadings of the indicators on the extracted dimensions (loadings of more than .5 or less

\footnotetext{
${ }^{11}$ To minimize the number of missing values we had to remove the indicators of violent crime, freedom versus equality, conceptions of nationhood, xenophobia and the two indicators tapping wage regulation from the analysis.
} 
than -.5 are given in bold). We see that the analysis has produced four dimensions with an Eigen value of more than 1 . While the first three dimensions each explain roughly the same amount of variance (20-21\%), the fourth dimension accounts for just $13 \%$ of the variance in the 13 indicators.

Table 5. Results of factor analysis

\begin{tabular}{|l|l|l|l|l|}
\hline & I & II & III & IV \\
\hline & $\begin{array}{l}\text { Social } \\
\text { democracy }\end{array}$ & $\begin{array}{l}\text { Diversity and } \\
\text { tolerance }\end{array}$ & Liberalism & $\begin{array}{l}\text { Pluralism } \\
\text { and crime }\end{array}$ \\
\hline Inequality & -.761 & .463 & .124 & .249 \\
\hline Ethno-racial diversity & -.014 &. $\mathbf{7 2 8}$ & .255 & .017 \\
\hline Welfare state &. $\mathbf{7 0 0}$ & .156 & -.518 & .170 \\
\hline Employment protection & .075 & .019 &.- .866 & -.005 \\
\hline State involvement & $\mathbf{. 8 2 9}$ & .006 & .070 & .248 \\
\hline Crime & -.207 & -.043 & .512 & $\mathbf{. 6 2 1}$ \\
\hline Value diversity & .181 & -.114 & -.060 & $\mathbf{. 8 8 6}$ \\
\hline Active civic participation & .047 & .412 &. $\mathbf{8 3 8}$ & .082 \\
\hline Passive participation & .529 & .446 & .583 & -.088 \\
\hline Merit versus equality & .092 & -.544 & .437 & .204 \\
\hline Ethnic tolerance & -.030 &. $\mathbf{8 6 5}$ & -.074 & -.266 \\
\hline Gender equality & .457 &. $\mathbf{7 2 8}$ & .288 & .082 \\
\hline Social hierarchy & -.693 & -.294 & -.119 & $\mathbf{. 5 1 7}$ \\
\hline Explained variance (\%) & 21.7 & 21.6 & 20.8 & 13.3 \\
\hline
\end{tabular}

The first dimension is characterised by strong negative loadings of inequality and social hierarchy and strong positive loadings of welfare state, state involvement and passive participation. In other words, countries with strong welfare states also tend to show high rates of state involvement and passive participation and low levels of inequality and social hierarchy. Because of this pattern of loadings we decided to label the first dimension 'social 
democracy'. In a similar vein, the second dimension was labelled 'diversity and tolerance' because of the high positive loadings of ethno-racial diversity and ethnic tolerance on this dimension. The third dimension captures welfare state (-), employment protection (-), crime $(+)$, active civic participation $(+)$, and passive participation $(+)$. Clearly, this dimension can be said to reflect 'liberalism'. The residual dimension, finally, combines components as diverse as value diversity $(+)$, crime $(+)$ and social hierarchy $(+)$, making it difficult to find an appropriate label for it. As it is unclear what this dimension precisely taps and as it captures just 13 percent of the variance, we omitted it in further analyses.

\section{Figure 22. Social democracy and liberalism}

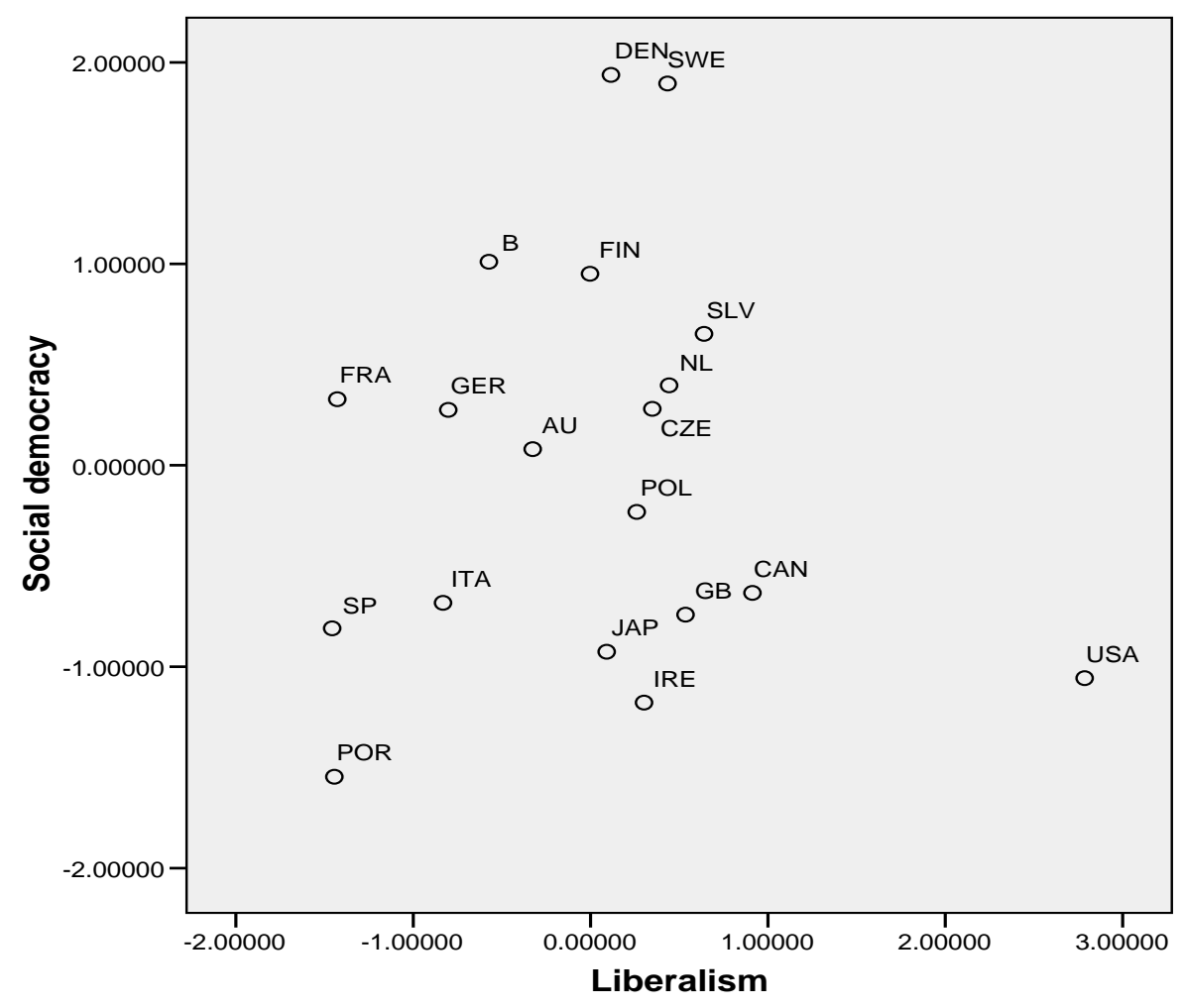

With respect to the social democratic and liberal traditions, the factor analysis thus produces remarkably clear results: there indeed appear to be coherent syndromes of social cohesion characteristics that correspond to these traditions. The two traditions thus represent not only theoretical constructs but also clearly observable empirical phenomena. A social market syndrome could not be identified, however, which further underlines the doubts expressed 
with regard to this tradition previously. Instead, the second dimension produced by the analysis seems to tap into a romantic-conservative tradition, representing as it does the inverse of ethno-cultural homogeneity, intolerance and patriarchy.

An equally clear picture can be obtained by saving the country scores on the dimensions and plotting these in scatter diagrams (Figures 22 and 23). The diagram plotting liberalism against social democracy shows that the English-speaking countries cluster fairly tightly (although the US is somewhat of an outlier), combining medium-high scores of liberalism with low values on social democracy. The Nordics likewise form a coherent group and show, as expected, the highest scores on social democracy (although Finland falls somewhat behind) and medium values on liberalism. A somewhat small but fairly cohesive social market group consisting of France, Germany and Austria can also be identified blending low values on liberalism with medium values on social democracy. Italy, Spain and Portugal, in similar vein, constitute a clearly identifiable cluster showing low values on both dimensions. Lastly, the transition countries form a tight cluster assuming as they do medium positions on liberalism and social democracy, although the Netherlands is an unexpected guest in this cluster.

\section{Figure 23. Diversity \& Tolerance and Liberalism}

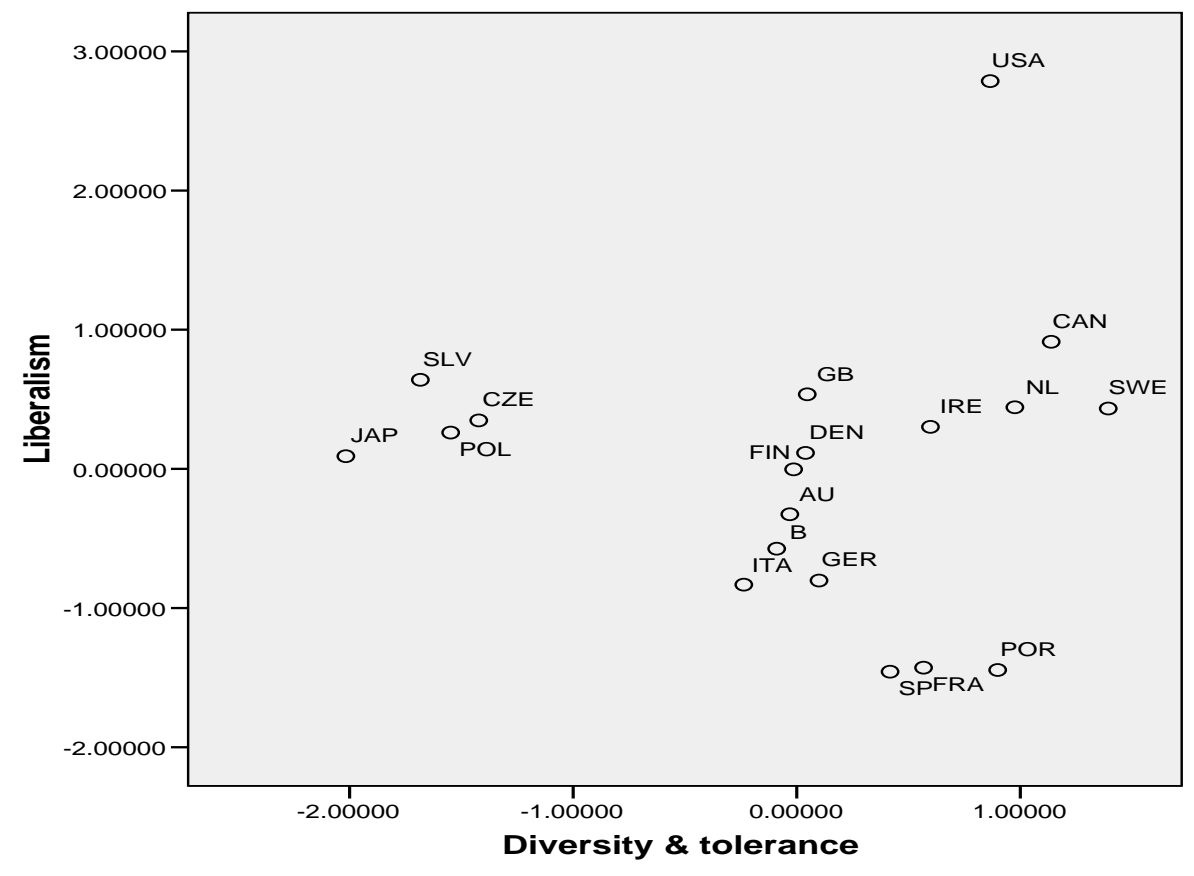


The most conspicuous feature of the diagram plotting liberalism against diversity and tolerance is the tight clustering of the three east European countries along with Japan and their remarkably low values on the diversity and tolerance dimension in relation to the other countries. Clearly this supports the notion that conservative and essentialist ideas (still) frame national identities, opinions on ethnic others and social relations in these countries.

In sum, the country groups and the substantive profiles of the countries are to a large extent in agreement with the social cohesion traditions. Although a social market dimension cannot be so clearly identified, the countries associated with the liberal and social democratic tradition show such a distinct pattern of scores on the corresponding dimensions that they can clearly be said to exhibit a unique social cohesion profile.

\section{Discussion}

The empirical analysis has shown that western countries differ markedly on key indicators of social cohesion. These differences correspond in large measure to the regional types, traditions or regimes identified in the political economy literature. Thus, considerable evidence was found for the existence of a liberal regime as expressed by a distinct group of countries, the English-speaking ones, combining relatively high levels of civic participation and crime with relatively low levels of public welfare spending and employment protection. Similarly, a social democratic tradition could be identified characterized by high levels of equality, state involvement, public social expenditure, and passive participation in nationwide organizations and low levels of social hierarchy. Unsurprisingly, it was the Nordic countries showing this combination of characteristics. Support could also be found for the existence of a complex of beliefs and attitudes corresponding to a romantic-conservative / collectivist tradition. This complex combined little support for gender equality with low levels of ethnic tolerance and high levels of homogeneity, a combination of characteristics exemplified by the transition countries and Japan. The German-speaking countries, which are often associated with the romantic-conservative tradition, were conspicuously absent from this group of countries, however.

Other regimes/traditions highlighted by the aforementioned literature were more difficult to detect. A coherent empirical phenomenon showing the features of a putative social market 
tradition, including northern and southern Europe could, for instance, not be identified. The countries associated with this tradition fell apart in a group comprising Germany, Austria, Belgium and France on the one hand and a group including the Mediterranean states on the other. So the social market regime does seem to be most appropriately identified as a northern continental European one.

\section{Section Seven: Conclusions}

This paper has been principally concerned with two questions: 'what is social cohesion?' and 'what forms does it take different societies?' In the course answering this question we have sought to assess whether one can identify distinctive 'regimes of social cohesion' associated with particular groups of countries and what characteristics they might posses. We find that three distinctive regimes can be identified, each referring to be fairly stable group of core countries: 1) the liberal regime, corresponding to the English-speaking countries; 2) the social democratic regime, corresponding to the Nordic countries and 3) the social market regime, corresponding mainly to a core group of north-western continental countries, including the Germany, Belgium, Austria, and France. Southern Europe is only marginally related to the social market regime and on many characteristics southern European countries form a separate cluster with specific characteristics, as do the new central and eastern European states. East Asia appears in many respects as a distinctive regime, but we have insufficient cases in the statistical analysis to posit this with confidence.

The various statistical tests we have carried out in the last section largely confirm the models that were derived from the analysis of historical traditions in political philosophy and from comparative political economy. The scatter plots for a variety of indicators show that in most instances countries associated with particular regimes do have the characteristics imputed to those regimes by the theory. The cluster analyses, each using different sets of indicators, generally find the same clustering of countries as suggested by the theoretical models, although in two of the four analyses the social market grouping proves to be unstable. The use of composite indicators for the four imputed regimes brings out the country clusters in almost perfect conformity with the models. Subsequent factor analyses shows that the characteristics associated with the countries in each cluster show significant levels of correlation which indicates that the regimes represent coherent syndromes and not merely aggregated but unrelated characteristics. In general the statistical analysis is confirming the 
models generated from the theoretical analysis. However, there are two important caveats. The first is that there is considerable internal variation within each regime. The second is that the boundaries of the social market regime are not sharply defined.

The statistical analysis suggests that the main countries associated with the social market regimes are the north-western continental European countries, including Germany, Austria, Belgium and France. Southern European countries are only marginally related to the social market regime on some of the indicators and more often form their own cluster. On most of the scatter plots the social market clustering appears only for the north-western states and the southern states often form a distinct cluster. The cluster analysis using all the indicators does find a cluster that includes most of the north-western and southern states, and likewise the cluster analysis using only administrative data. However, there is no coherent cluster for the expanded set of countries when you add wage regulation indicators to the analysis and likewise using attitudinal data. The index analysis seems to make the point most clearly. The core north-western European countries do indeed score in top position for the composite indicator for the social market regime (Germany, Austria and France). Southern European countries score lower than these but higher than most other countries. This suggests that they have an association with the social market regime but only a loose one.

The statistical tests also indicate that the boundary between the social market regime and the social democratic regime is sharp only on some indicators - for others there is considerable overlap. This suggests that the comparative political economists who lump together in a single social market group, in respect of their economies, the countries we have distinguished as social market and social democratic have a point. On the other hand, the social democratic regime remains highly distinctive on the social dimensions and hence we feel justified in distinguishing these two regimes of social cohesion.

The fact that many of the characteristics associated with particular contemporary regimes in the statistical analysis could be predicted from the historical analysis of the different political philosophy traditions of social cohesion in the nineteenth and twentieth centuries does suggest that there is a degree of path dependency in how countries and groups of countries deal with issues of social cohesion. This is particularly true in relation to the liberal and social democratic traditions, and possibly also for east Asia, although our data are insufficient to say this with confidence. However, clearly this path dependency is not absolute. Countries go 
through major social, political and economic transformations, even where these are constrained by their prior traditions and inherited institutional structures. The case of Germany and the central and eastern European states illustrates the point very well. Our statistical analysis suggests that the characteristics which we associated with the romantic conservative tradition which were historically highly influential in central and eastern Europe still continue to shape many countries in the region. In particular, the ethno-cultural traditions of nationhood and citizenship which Kohn attributed to the region do still predominate in many states. However, some countries, and most notably Germany, have decisively transformed themselves and moved away from this tradition.

Our theoretical and statistical analyses suggest that the different regimes of social cohesion are constituted both by distinctive sets of attitudes and behaviours and by particular institutional characteristics which underpin these attitudes and behaviours. In some ways the institutional and behavioural characteristics bring out the regime differences more clearly than the attitudinal characteristics. This may be partly because the latter are captured in administrative data which may be more reliable than the survey data which is used to tap attitudes. Certainly it is difficult to find survey questions which tap the relevant attitudinal characteristics very precisely and even then there are problems of the conceptual equivalence of survey items across countries which hampers comparative analysis. ${ }^{12}$ Further work no doubt needs to be done on this.

The use of both institutional and attitudinal indicators also raises some difficult definitional issues. When is an institutional characteristic constitutive of a particular type of social cohesion and when should it be considered a cause? We have not sought to explore this question here but clearly more systematic analysis needs to be performed on the contextual factors which act as preconditions for different types of social cohesion. What is very clear, however, from the analysis here is that institutional forms are integrally related to attitudinal and behavioural characteristics in different social cohesion regimes.

The liberal regime of social cohesion exhibits the classic historical preferences for freedom over equality. Income inequality is high and state welfare expenditure relatively low. Institutional underpinning of social cohesion is relatively weak. Typically there are low levels of employment protection, and union coverage and solidaristic forms of centralised trade

\footnotetext{
${ }^{12}$ The problem of conceptual equivalence arises when a question in a survey uses concepts which may be understood differently in different countries.
} 
union bargaining are limited. Societies associated with this regime tend to be ethnically and culturally diverse, with high levels of values diversity on our measures, and some (Australia, Canada, New Zealand) come out relatively highly on the various measures of tolerance (although core states such as Britain and the US are not necessarily as tolerant as their liberal traditions would like to claim). The relatively high rates of violent crime (although not necessarily homicide) point to limitations in the cohesiveness of these societies. On the other hand, they have high levels of civic participation and quite a high degree of consensus around the core liberal values of freedom and merit which may help to bind the societies together. All the English-speaking countries (except Ireland) seem to be associated with the liberal tradition, but there is considerable variation between countries on many key characteristics. In particular, the US is an outlier on many measures, often at the extreme end of the scale in terms of liberal characteristics.

The social market regime, by contrast, is associated with strong institutional embedding of social cohesion. Public spending on welfare and employment protection tends to be high in most states. Income inequality is moderate and trade union coverage is high but states vary from high to middling on centralisation of trade union bargaining. Civic participation tends to be lower in countries associated with the social market regime than in the liberal states which bears out the theoretical analysis that social cohesion owes relatively more to the state and less to civil society within this regime than in the liberal regime. However, the theory also suggests that shared values constitute an important part of what hold societies in this tradition together. This is not entirely obvious from our statistical analysis. The core countries associated with the social market regime vary considerably on the degree to which on aggregate they value freedom and merit over equality and their populations certainly don't have consensual attitudes on these issues. In fact one of the biggest surprises of the statistical analysis is that values diversity in social market countries is often higher than in liberal societies. In some cases (like Austria, France and Germany) this reflects the fact that their populations are as ethnically diverse as in the liberal states. However, it may also reflect substantial generational differences in values. These maybe greater in some social market states than in a number of liberal states which, according to Inglehart $(1990,1997)$, started the transition to post-materialist values earlier. If correct this would suggest that the social market regime of social cohesion is in a transitional cultural phase in terms of values and attitudes. 
The social democratic regime of social cohesion, like the social market regime, also seems to depend highly on the institutionalisation solidaridarity. High public welfare spending, high levels of centralised union bargaining with wide union coverage, and strongly a redistributive role for the state all contribute to solidaristic labour market behaviour and to relatively low levels of income inequality. The institutional embedding of social cohesion seems to be even stronger in the social democratic regime than in the social market regime. What is more, there appears to be more a more pronounced contribution from social values to social cohesion in these countries than in the social market ones. Levels of trust in the social democracies are exceptionally high, and much higher than in the other regimes. This cannot be attributed solely to greater ethnic homogeneity in these societies, although this may play a part in Norway and Denmark, since Sweden is both ethnically diverse and highly trusting.

The paper has not sought to assess the consequences or outcomes of social cohesion, even though one might consider some of the characteristics we associate with the phenomenon, such as low crime or trust, to be outcomes rather than constituent elements. More distant potential outcomes, such as economic growth, happiness and well-being etc are beyond the scope of the paper.

Nor have we entered into the thorny philosophical and political debate about whether - or under what circumstances - social cohesion is 'a good thing'. The paper has deliberately adopted a non-normative approach which does not assume - in advance of researching the topic - that social cohesion is necessarily always a good thing. We have done this for three reasons. Firstly, so that we can approach the initial question about what constitutes social cohesion in as scientific and comprehensive a manner as possible. Secondly, so that we can analyse comparatively the different types of social cohesion that exist in actual societies, without limiting ourselves to a particular form of social cohesion which may seem to us most desirable. Thirdly, because the authors can think of too many historical circumstances where social cohesion could have only existed as a utopian idea, or in a form not conducive to social progress, to start from a normative assumption about its absolute value as a social state. Because we have not gone into the normative questions about the desirability of social cohesion we have not addressed the literatures which critique the concept of social cohesion tout court (eg those from feminist, post-colonial and Marxist positions), although we do draw on such critiques to provide some of the conceptual tools (such as 'economic and class contradictions' in Marxism) with which to assess the internal coherence of some of the 
dominant theories of social cohesion. This is clearly not because we think them unimportant, but because they belong to a different realm of discourse, and one that hinges essentially on historical and political judgements which are beyond the scope of this initial paper.

The paper, however, does beg the question as to whether some types of social cohesion are in some way 'more cohesive' or, at least, 'more desirable' than others. Using our method of defining social cohesion in the broadest (least specified) manner we cannot assess whether some regimes are more cohesive than others. To do so would require saying that some attributes of social cohesion are more important than others which would contradict our approach. The answer to the second question, whether some are more desirable than others, inevitably, again, depends on political and philosophical judgements. Those who believe that civic participation and some shared core values around freedom and opportunity can provide sufficient cohesion in societies, even when these are highly unequal, will often tend to favour the liberal regime type, since this is also seen to offer more freedom and independence from the state. Those who value a more trusting society with a more profound commitment to social solidarity will tend to favour the social democratic type of social cohesion. When countries associated with this regime demonstrate higher levels of social mobility than many liberal states - and there is some evidence that this is currently the case - this type of regime may become increasingly attractive.

Whatever preferences we may have, however, one thing is clear. Social cohesion regimes are clearly not easily transferred across cultures. They have deep historical roots and their existence depends on a wide range of institutional structures and collective cultural predispositions that have evolved, in most cases, over quite long periods of time. We may wish for a society which is more cohesive in particular ways but it usually requires quite radical and wide-ranging change to bring this about. 


\section{Appendix 1.}

\begin{tabular}{|c|c|c|}
\hline$\overline{\text { Indicator }}$ & Item(s) from survey / database & Source \\
\hline $\begin{array}{l}\text { Gini coefficient } \\
\text { on household } \\
\text { income }\end{array}$ & & $\begin{array}{l}\text { World } \\
\text { Bank } \\
(2005)\end{array}$ \\
\hline Union Coverage & & $\begin{array}{l}\text { Nickell and } \\
\text { Layard } \\
\text { (1998) }\end{array}$ \\
\hline $\begin{array}{l}\text { Centralization of } \\
\text { wage bargaining }\end{array}$ & & $\begin{array}{l}\text { Nickell and } \\
\text { Layard } \\
\text { (1998) }\end{array}$ \\
\hline $\begin{array}{l}\text { Employment } \\
\text { protection } \\
\text { legislation } 1998 \\
\text { (Version 1) }\end{array}$ & $\begin{array}{l}6 \text { point scale synthesizing } 18 \text { items on three main } \\
\text { areas of legislation: (1) individual dismissal of } \\
\text { regular workers; (2) Collective dismissal; (3) } \\
\text { regulation of temporary forms of employment }\end{array}$ & $\begin{array}{l}\text { OECD } \\
\text { (1999) }\end{array}$ \\
\hline $\begin{array}{l}\text { Public } \\
\text { employment as } \\
\text { percentage of } \\
\text { total employment } \\
2000\end{array}$ & & ILO (2009) \\
\hline $\begin{array}{l}\text { Public social } \\
\text { expenditure as } \\
\text { percentage of } \\
\text { GDP } 2000\end{array}$ & & $\begin{array}{l}\text { OECD } \\
\text { (2009) }\end{array}$ \\
\hline $\begin{array}{l}\text { Proportion of the } \\
\text { population born } \\
\text { abroad } 2000\end{array}$ & & UN (2009a) \\
\hline $\begin{array}{l}\text { Homicide rate } \\
\text { (Number of } \\
\text { homicides per } \\
\text { 100.000 people } \\
\text { in 2000) }\end{array}$ & & UN (2009b) \\
\hline $\begin{array}{l}\text { Violent crime } \\
\text { (number of } \\
\text { homicides, rapes }\end{array}$ & & UN (2009b) \\
\hline
\end{tabular}




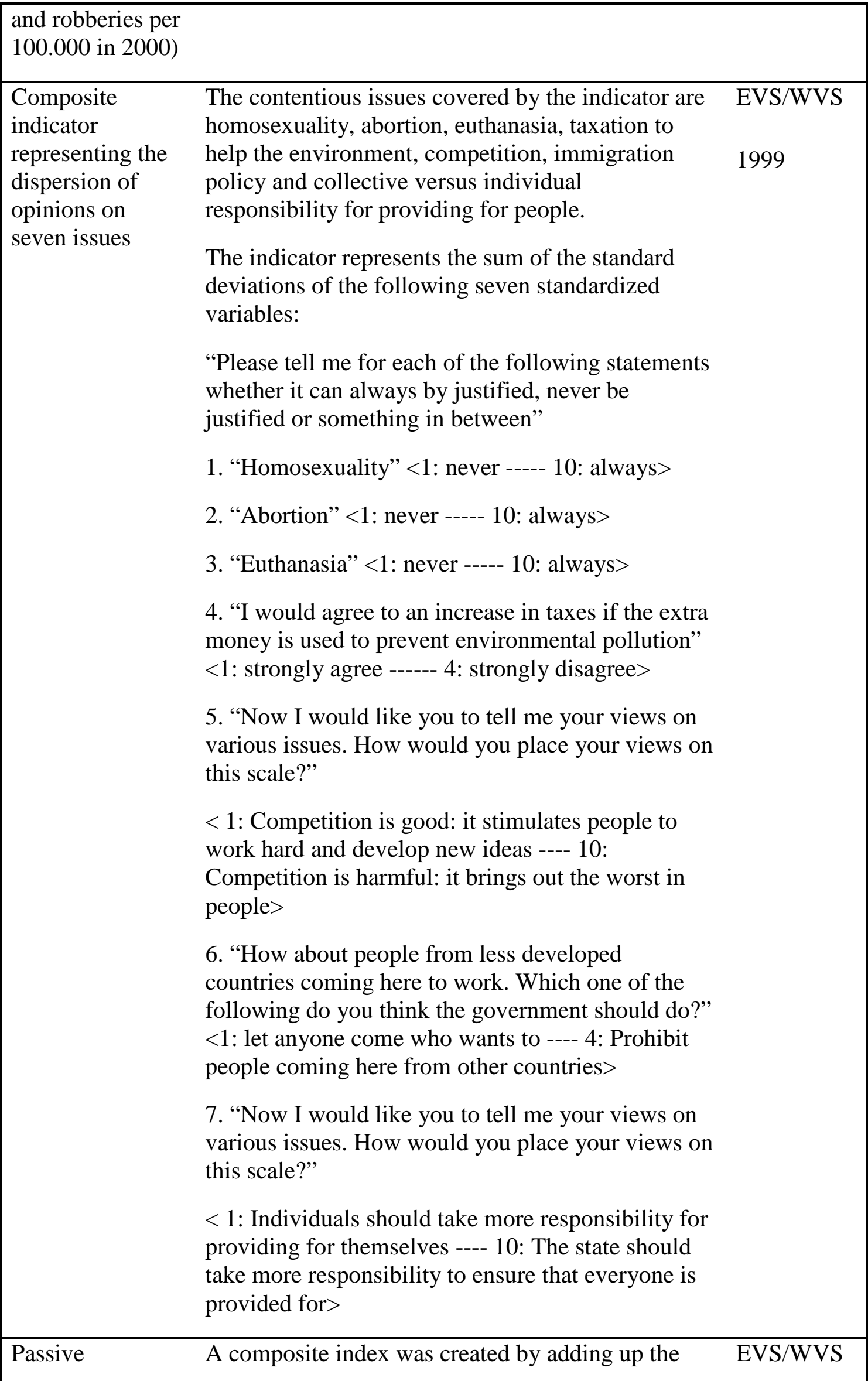




\begin{tabular}{|c|c|c|}
\hline $\begin{array}{l}\text { participation } \\
\text { (number of } \\
\text { different } \\
\text { organizations } \\
\text { respondent } \\
\text { considers } \\
\text { him/herself to } \\
\text { belong to); } \\
\text { average }\end{array}$ & $\begin{array}{l}\text { answers to the nine items listed below. This index } \\
\text { thus represents the number of different } \\
\text { organizations the respondent indicates to belong to. } \\
\text { "Please look carefully at the following list of } \\
\text { voluntary organizations and activities and say (a) } \\
\text { which, if any, you belong to and (b) which, if any, } \\
\text { are you currently doing unpaid voluntary work } \\
\text { for:” } \\
\text { - social welfare for elderly, handicapped or } \\
\text { deprived people; } \\
\text {-religious or church organizations; } \\
\text { - education, arts, music or cultural activities; } \\
\text { - trade unions; } \\
\text { - political parties; } \\
\text { - third world development or human rights; } \\
\text { - conservation, environment, animal rights groups; } \\
\text { - professional associations; } \\
\text { - youth work; } \\
\text { A not mentioned; } \\
\text { B mentioned }\end{array}$ & 1999 \\
\hline $\begin{array}{l}\text { Active } \\
\text { participation } \\
\text { (number of } \\
\text { different } \\
\text { organizations } \\
\text { respondent does } \\
\text { voluntary work } \\
\text { for); average }\end{array}$ & See passive participation & $\begin{array}{l}\text { EVS/WVS } \\
1999\end{array}$ \\
\hline $\begin{array}{l}\text { Freedom or } \\
\text { equality more } \\
\text { important; }\end{array}$ & $\begin{array}{l}\text { "Which of these two statements comes closest to } \\
\text { your own opinion?". } \\
\text { A “I find that both freedom and equality are } \\
\text { important. But if I were to choose one or the other, } \\
\text { I would consider freedom more important, that is, } \\
\text { everyone can live in freedom and develop without } \\
\text { hindrance”. } \\
\text { B “Certainly both freedom and equality are } \\
\text { important. But if I were choose one or the other, I }\end{array}$ & EVS 1999 \\
\hline
\end{tabular}




\begin{tabular}{|c|c|c|}
\hline & $\begin{array}{l}\text { would consider equality more important, that is, } \\
\text { that nobody is underprivileged and that social class } \\
\text { differences are not so strong”. } \\
\text { A Agree with statement A } \\
\text { B Agree with statement B }\end{array}$ & \\
\hline $\begin{array}{l}\text { Pay according to } \\
\text { performance }\end{array}$ & $\begin{array}{l}\text { "Imagine two secretaries, of the same age, doing } \\
\text { practically the same job. One finds that one earns } \\
£ 30 \text { a week more than the other. The better paid } \\
\text { secretary, however, is quicker, more efficient and } \\
\text { more reliable at her job. } \\
\text { In your opinion is it fair or not fair that one } \\
\text { secretary is paid more than the other?” } \\
\text { A Fair } \\
\text { B Unfair }\end{array}$ & $\begin{array}{l}\text { EVS/WVS } \\
1999\end{array}$ \\
\hline $\begin{array}{l}\text { Reasons for } \\
\text { poverty; } \\
\text { percentage } \\
\text { saying “because } \\
\text { of laziness or } \\
\text { lack of } \\
\text { willpower" }\end{array}$ & $\begin{array}{l}\text { "Why are there people in this country who live in } \\
\text { need? Here are four possible reasons. Which one } \\
\text { reason do you consider to be most important?" } \\
\text { A Because they are unlucky } \\
\text { B Because of laziness and lack of willpower } \\
\text { C Because of injustice in our society } \\
\text { D It's an inevitable part of modern progress } \\
\text { E None of these }\end{array}$ & EVS 1999 \\
\hline $\begin{array}{l}\text { Strength of } \\
\text { cultural relative } \\
\text { to political } \\
\text { conceptions of } \\
\text { national identity; } \\
\text { average }\end{array}$ & $\begin{array}{l}\text { This index was created by first inverting the answer } \\
\text { scales of the items below and then subtracting the } \\
\text { answers of the second item from those of the first } \\
\text { item. The index thus represents the importance } \\
\text { attached to cultural markers relative to political } \\
\text { markers of national identity. } \\
\text { 1. "How much do you agree or disagree with the } \\
\text { Following statement : It is impossible for people } \\
\text { who do not share the customs and traditions [of } \\
\text { respondent's country] to become fully [e.g., British, } \\
\text { German, Hungarian, etc.]." } \\
\text { <agree strongly, agree, neither agree nor disagree, } \\
\text { disagree, disagree strongly>; } \\
\text { 2. "Some people say the following }\end{array}$ & ISSP 1995 \\
\hline
\end{tabular}




\begin{tabular}{|c|c|c|}
\hline & $\begin{array}{l}\text { things are important for being [e.g., truly British, } \\
\text { Spanish, Hungarian, etc.]. Others say they are not } \\
\text { important. How important do you think each of the } \\
\text { following is . . ? ?” } \\
\text { - To respect political institutions and laws of } \\
\text { [respondent's country]. } \\
\text { <very important, fairly important, not very } \\
\text { Important, not important at all> }\end{array}$ & \\
\hline $\begin{array}{l}\text { xenophobia } \\
\text { index; average }\end{array}$ & $\begin{array}{l}\text { This index was created by first reversing the answer } \\
\text { scales of items } 1 \text { and } 3 \text { below and then adding up } \\
\text { the answers of the four items. The higher the values } \\
\text { on this index the more negative the opinions on } \\
\text { immigrants. } \\
\text { “ There are different opinions about immigrants } \\
\text { from other countries living in [country]. (By } \\
\text { “immigrants” we mean people who came to settle } \\
\text { in [country]). How much do you agree or disagree } \\
\text { with each of the following statements?” } \\
\text { 1. Immigrants increase crime rates. } \\
\text { 2. Immigrants are generally good for [country’s] } \\
\text { economy. } \\
\text { 3. Immigrants take jobs away from people who } \\
\text { were born in [country]. } \\
\text { 4. Immigrants make [country] more open to new } \\
\text { ideas and } \\
\text { cultures. } \\
\text { <agree strongly, agree, neither agree nor disagree, } \\
\text { disagree, disagree strongly>; }\end{array}$ & ISSP 1995 \\
\hline $\begin{array}{l}\text { Percentage not } \\
\text { mentioning } \\
\text { immigrants }\end{array}$ & $\begin{array}{l}\text { "On this list are various groups of people. Could } \\
\text { you please sort out any that you would not like to } \\
\text { have as neighbours?" } \\
\text { "Immigrants / foreign workers <1: mentioned; 0: } \\
\text { not mentioned> }\end{array}$ & $\begin{array}{l}\text { EVS/WVS } \\
1999\end{array}$ \\
\hline $\begin{array}{l}\text { Percentage } \\
\text { saying one } \\
\text { should always }\end{array}$ & $\begin{array}{l}\text { "Which of these statements do you tend to agree } \\
\text { with" }\end{array}$ & EVS/WVS \\
\hline
\end{tabular}




\begin{tabular}{|lll|}
\hline $\begin{array}{l}\text { love and respect } \\
\text { one’s parents }\end{array}$ & $\begin{array}{l}\text { A “Regardless of what the qualities and faults of } \\
\text { one’s parents are, one must always love and respect } \\
\text { them” }\end{array}$ & 1999 \\
& $\begin{array}{l}\text { B "One does not have the duty to love and respect } \\
\text { parents who have not earned it by their behaviour } \\
\text { and attitudes" }\end{array}$ & \\
\hline $\begin{array}{l}\text { Percentage } \\
\text { disagreeing with } \\
\text { the opinion that } \\
\text { in times of } \\
\text { scarcity men } \\
\text { have more right } \\
\text { to a job than } \\
\text { women }\end{array}$ & $\begin{array}{l}\text { "Do you agree or disagree with the following } \\
\text { "When jobs are scarce men have more right to a job }\end{array}$ & EVS/WVS \\
\hline
\end{tabular}




\section{Appendix 2. Dataset used for Statistical Analyses}

\begin{tabular}{|c|c|c|c|c|c|c|c|c|c|c|c|c|c|c|}
\hline Country & Gini & $\begin{array}{l}\text { Union } \\
\text { coverage }\end{array}$ & $\begin{array}{l}\text { Centrali } \\
\text { zation }\end{array}$ & $\begin{array}{l}\text { Employment } \\
\text { protection }\end{array}$ & $\begin{array}{l}\text { Public } \\
\text { employment }\end{array}$ & $\begin{array}{l}\text { Public } \\
\text { social } \\
\text { expenditure }\end{array}$ & $\begin{array}{l}\text { Migrant } \\
\text { stock }\end{array}$ & Homicide & $\begin{array}{l}\text { Violent } \\
\text { crime }\end{array}$ & $\begin{array}{l}\text { Value } \\
\text { diversity }\end{array}$ & $\begin{array}{l}\text { Passive } \\
\text { participation }\end{array}$ & $\begin{array}{l}\text { Active } \\
\text { participation }\end{array}$ & $\begin{array}{l}\text { Freedom } \\
\text { over } \\
\text { equality }\end{array}$ & $\begin{array}{l}\text { Merit } \\
\text { over } \\
\text { equality }\end{array}$ \\
\hline Austria & 30 & 3 & 17 & 2.21 & 13.7 & 26.4 & 11.4 & 1.8 & & 1.42 & 0.64 & 0.27 & 61.34 & 88.9 \\
\hline Australia & 35.2 & 3 & 8 & 1.19 & 20.1 & 17.8 & 21.4 & 1.8 & 206.45 & & & & & 81.84 \\
\hline Belgium & 25 & 3 & 10 & 2.15 & 31.2 & 25.3 & 8.5 & 1.4 & & 2.2 & 0.45 & 0.4 & 48.95 & 69.62 \\
\hline Canada & 33.1 & 2 & 1 & 0.78 & 18.9 & 16.5 & 18.1 & 1.6 & 169.89 & 1.36 & 0.68 & 0.66 & 64 & 83.59 \\
\hline Czech Republic & 25.4 & & & 1.9 & 22.8 & 19.8 & 4.4 & 1.7 & 47.32 & -0.96 & 0.26 & 0.29 & 62.91 & 96.42 \\
\hline Denmark & 24.7 & 3 & 14 & 1.42 & 34.3 & 25.6 & 5.7 & 1 & 72.41 & 1.9 & 0.84 & 0.31 & 72.38 & 82.02 \\
\hline Finland & 26.9 & 3 & 13 & 2.09 & 27.3 & 24.3 & 2.6 & 2.8 & 64.26 & 0.39 & 0.91 & 0.38 & 54.51 & 75.92 \\
\hline France & 32.7 & 3 & 7 & 2.98 & 29.5 & 27.9 & 10.6 & 1.6 & 59.29 & 2.23 & 0.13 & 0.19 & 53.73 & 76.72 \\
\hline Great Britain & 36 & 2 & 6 & 0.6 & 19.2 & 26.2 & 8.1 & 1.5 & 198.91 & -1.58 & 0.17 & 0.61 & 65.27 & 73.06 \\
\hline Germany & 28.3 & 3 & 12 & 2.46 & 16.7 & 19.2 & 11.9 & 1.2 & 84.77 & 1.1 & 0.28 & 0.16 & 67.74 & 86.94 \\
\hline Greece & 35.4 & & & 3.54 & 21.1 & 19.2 & 6.7 & 1.5 & 10.35 & 0.12 & 0.37 & 0.62 & & 87.93 \\
\hline Hungary & 24.4 & & & 1.27 & 36.7 & 20 & 2.9 & 2.5 & 44.4 & 0.36 & 0.24 & 0.19 & 48.26 & 83.29 \\
\hline Iceland & & & & & & 15.3 & 5.6 & 0.7 & 39.86 & -4.96 & 1.69 & 0.35 & 46.49 & 86.27 \\
\hline Ireland & 35.9 & 3 & 6 & 0.93 & 18 & 13.6 & 10.1 & 1 & 71.32 & -4.21 & 0.38 & 0.35 & 51.59 & 64.3 \\
\hline Italy & 36 & 3 & 5 & 2.7 & 15.6 & 23.3 & 2.8 & 1.4 & 73.14 & 0.03 & 0.28 & 0.32 & 44.63 & 77.6 \\
\hline Japan & 24.9 & 2 & 4 & 2.03 & 8.7 & 16.5 & 1.3 & 1 & 6.94 & -6.05 & 0.25 & 0.18 & & 87.54 \\
\hline South Korea & 31.6 & & & 2.03 & & 19.7 & 1.2 & 2.1 & 32.46 & -6.93 & 0.59 & 0.62 & & 87.07 \\
\hline Luxembourg & & & & & & 19.8 & 36.9 & & & 2.46 & 0.34 & 0.43 & 54.97 & 82.56 \\
\hline Netherlands & 32.6 & 3 & 11 & 2.12 & 25.1 & 19.4 & 9.8 & 1.5 & 138.03 & -6.43 & 0.83 & 0.56 & 58.61 & 75.48 \\
\hline Norway & 25.8 & 3 & 16 & 2.69 & 36 & 21.3 & 6.6 & 0.8 & 54.62 & & & 0.34 & & 54.43 \\
\hline New Zealand & 36.2 & 2 & 9 & 0.86 & 19.7 & 20.5 & 18.5 & 1.1 & 70.79 & & & & & 91.45 \\
\hline Poland & 31.6 & & & 1.49 & 27.9 & 19.6 & 2.1 & 4.7 & 151.33 & 2.18 & 0.21 & 0.13 & 57.93 & 88.01 \\
\hline Portugal & 38.5 & 3 & 7 & 3.67 & 13.9 & 17.9 & 6.2 & 3 & 177.88 & -2.26 & 0.09 & 0.09 & 51.51 & 73.12 \\
\hline Slovakia & 25.8 & & & 1.8 & 33.2 & 5 & 2.2 & 2.6 & 29.04 & 3.01 & 0.44 & 0.46 & 71.95 & 91.29 \\
\hline Spain & 32.5 & 3 & 7 & 2.93 & 15.7 & 20.3 & 4 & 1.2 & & 1.7 & 0.14 & 0.16 & 55.29 & 65.74 \\
\hline Sweden & 25 & 3 & 15 & 2.24 & 33.7 & 28.5 & 11.2 & 1.8 & 18.79 & -3.89 & 1.6 & 0.76 & 63.97 & 74.4 \\
\hline Switzerland & 33.1 & 2 & 3 & 1.14 & 16 & 17.9 & 21.8 & 1.3 & 38.22 & & & & & 84.75 \\
\hline United States & 40.8 & 1 & 2 & 0.21 & 15.8 & 14.5 & 12.2 & 5.7 & 183.96 & 1.94 & 1.18 & 1.26 & 75 & 91.19 \\
\hline
\end{tabular}




\begin{tabular}{|c|c|c|c|c|c|c|c|c|c|c|c|c|}
\hline Country & $\begin{array}{l}\text { Cultural } \\
\text { versus } \\
\text { political }\end{array}$ & Xenophobia & $\begin{array}{l}\text { No objection } \\
\text { to immigrants } \\
\text { as neighbours }\end{array}$ & $\begin{array}{l}\text { Respect } \\
\text { parents }\end{array}$ & $\begin{array}{l}\text { Men not more } \\
\text { right to job than } \\
\text { women }\end{array}$ & $\begin{array}{l}\text { Liberalis } \\
\mathrm{m} \\
\text { index }\end{array}$ & $\begin{array}{l}\text { Social } \\
\text { market } \\
\text { index }\end{array}$ & $\begin{array}{l}\text { Social } \\
\text { Democracy } \\
\text { index }\end{array}$ & $\begin{array}{l}\text { East } \\
\text { Asia } \\
\text { index }\end{array}$ & $\begin{array}{l}\text { Social } \\
\text { democracy } \\
\text { factor }\end{array}$ & $\begin{array}{l}\text { Diversity and } \\
\text { tolerance } \\
\text { factor }\end{array}$ & $\begin{array}{l}\text { Liberalism } \\
\text { factor }\end{array}$ \\
\hline Austria & & 1.07 & 87.8 & 65 & 54.4 & -1.97 & 5.5 & 1.09 & -0.24 & 0.07996 & -0.03104 & -0.32603 \\
\hline Australia & & 0.56 & 95.4 & 74 & 68.1 & & & & & & & \\
\hline Belgium & & & 81.8 & 65.2 & 69.6 & -6.49 & 1.24 & 4.3 & -2.2 & 1.01029 & -0.08982 & -0.57337 \\
\hline Canada & -1.03 & 0.42 & 95.8 & 77.6 & 78.5 & 8.89 & -6.42 & -2.54 & -4.16 & -0.63364 & 1.13844 & 0.91314 \\
\hline Czech Republic & 0.2 & 1.54 & 80.6 & 73.8 & 65.9 & & & & 4.37 & 0.28033 & -1.42228 & 0.34841 \\
\hline Denmark & & & 89.4 & 35.9 & 89.5 & -4.3 & -0.68 & 9.05 & -5.41 & 1.93767 & 0.03937 & 0.115 \\
\hline Finland & & & 87 & 63.2 & 83.1 & -6.18 & 1.33 & 6.33 & -3.08 & 0.95034 & -0.01363 & -0.00343 \\
\hline France & & & 88 & 74.7 & 68.3 & -3.72 & 2.03 & 0.55 & 0.3 & 0.32812 & 0.56721 & -1.42827 \\
\hline Great Britain & 0.04 & 1.02 & 84.5 & 65.1 & 63.7 & 4.82 & -5.93 & -0.28 & -1.5 & -0.7417 & 0.04702 & 0.53556 \\
\hline Germany & -0.39 & 0.88 & 91.4 & 53.2 & 55.8 & -0.78 & 3.1 & 0.57 & 0.17 & 0.2751 & 0.09973 & -0.80226 \\
\hline Greece & & & 86.3 & & 72.6 & & & & & & & \\
\hline Hungary & 0.65 & 1.75 & & 82.7 & 66.7 & & & & & & & \\
\hline Iceland & & & 97 & 60.7 & 94.3 & & & & & & & \\
\hline Ireland & & 0.54 & 87.7 & 71.9 & 77 & -0.3 & -2.99 & 0.54 & -0.54 & -1.17818 & 0.59806 & 0.30159 \\
\hline Italy & & 1.27 & 83.5 & 79.4 & 56.8 & -2.68 & 2.01 & -2.2 & 3.07 & -0.68286 & -0.23666 & -0.83184 \\
\hline Japan & & 0.89 & 83.4 & 71.6 & 20.8 & & & & 8.64 & -0.92588 & -2.01661 & 0.09082 \\
\hline South Korea & & & 53.2 & 92.3 & 27.1 & & & & 11.85 & & & \\
\hline Luxembourg & & & 91.6 & 58.8 & 64.7 & & & & & & & \\
\hline Netherlands & 0.44 & 0.92 & 95 & 31.9 & 83.7 & -3.1 & 0.57 & 6.3 & -4.33 & 0.39684 & 0.97583 & 0.44271 \\
\hline Norway & -0.04 & 1.15 & 90.2 & 52 & 79.7 & & & & & & & \\
\hline New Zealand & & 0.7 & 94.7 & 63.9 & 63.9 & & & & & & & \\
\hline Poland & 0.29 & 1.22 & 76.5 & 86.5 & 47.8 & & & & 4.28 & -0.23156 & -1.54777 & 0.26068 \\
\hline Portugal & & & 97.5 & 82.6 & 59.1 & -1.34 & 1.6 & -3.43 & 3.93 & -1.54606 & 0.89873 & -1.44491 \\
\hline Slovakia & -0.34 & 1.59 & 77.1 & 73.6 & 54.4 & & & & 2.88 & 0.65215 & -1.68351 & 0.63982 \\
\hline Spain & -0.08 & 0.88 & 90.7 & 83.4 & 65.3 & -2.61 & -1.4 & -0.31 & 2.12 & -0.80957 & 0.41747 & -1.4573 \\
\hline Sweden & -0.2 & 0.9 & 97.2 & 44 & 93.4 & -7.25 & 2.21 & 13.8 & -9.34 & 1.89517 & 1.39378 & 0.43366 \\
\hline Switzerland & & & 90 & 66.3 & 55.7 & & & & & & & \\
\hline United States & -0.67 & 0.93 & 89.9 & 77.2 & 81.9 & 16.44 & -10.97 & -2.78 & -7.65 & -1.05652 & 0.86567 & 2.78604 \\
\hline
\end{tabular}




\section{References}

Ajegbo, K. (2007) Curriculum Review: Diversity and Citizenship. Department for Education and Skills, London.

Addison, P. (1977) The Road to 1944. Cape, London.

Albert, M. (1993) Capitalism against Capitalism. Whurr publishers, London.

Alesina, A., Baqir, R. and Easterly, W. (1997) Public Goods and Ethnic Divisions, NBER Working Paper No 6009. National Bureau of Economic Research, Cambridge, Mass.

Alesina, A. and Glaeser, E.L. (2004) Fighting Poverty in the US and Europe: A World of Difference. Oxford University Press, Oxford.

Alesina, A. and La Ferrara, E. (2002) 'Who Trusts Others?' Journal of Public Economics, 85, pp.207-234.

Beauvais, C. and Jenson, J. (2002) Social Cohesion: Updating the State of Research.' CPRN Discussion Paper No. F/22, Canadian Policy Research Network, Ottawa.

Allport, G. (1954) The Nature of Prejudice. Addison-Wesley Publishing Company, Cambridge, Mass.

Amsden, A. (1989) Asia's Next Giant, South Korea and Late Industrialisation, Oxford University Press, Oxford.

Anderson, P. (1974) Lineages of the Absolutist State. Verso, London.

Arnold, M. (1932) Culture and Anarchy, Cambridge University Press, Cambridge.

Bail, C. (2008). 'The Configuration of Symbolic Boundaries against Immigrants in Europe', American Sociological Review, 73, February, pp 37-59.

Bailyn, B. (1977) The Ideological Origins of the American Revolution. Cambridge, Mass.

Banfield, E. (1958) The Moral Basis of a Backward Society. Free Press, New York.

Berger-Schmitt, R. (2000) Social Cohesion as an Aspect of the Quality of Societies: Concept and Measurement. EuReporting Working Paper No. 14, Centre for Survey Research and Methodology, Manheim.

Bernard, P. (1999) 'Social Cohesion: A Critique.' CPRN Discussion Paper No. F/09, Canadian Policy Research Networks, Ottawa.

Blandon, J., Gregg, P. and Machin, S. (2005) Intergenerational Mobility in Europe and North America: A Report Supported by the Sutton Trust. Centre for Economic Performance, London School of Economics, London.

Bourdieu, P. (1996) 'The Forms of Capital' in J. Richardson (ed) Handbook of Theory and Research for the Sociology of Education. Greenwood Press, Westport, CT.

Bowen, J. (1981) A History of Western Education, Vol 3. Methuen, London.

Bowles, S. and Gintis, H. (1976) Schooling in Capitalist America. Routledge and Kegan Paul, London

Braudel, F. (1981) Civilization and Capitalism, 15th-18th Century, Harper and Row, New York. 
Bredgaard, T., Larsen, F. and Masden, P. (2005) The Flexible Danish Labour Market: A Review, Unpublished Paper, CARMA, Aalborg University, Allborg.

Brown, P., Green, A. and Lauder, H. (2001) High Skills: Globalisation, Competitiveness and Skill Formation. Oxford University Press, Oxford.

Brubaker, R. (1992) Citizenship and Nationhood in France and Germany. Harvard University Press, Boston.

Brubaker, R. (1996) Nationalism Reframed: Nationhood and the National Question in the New Europe. Cambridge University Press, Cambridge.

Butterfield, H. (1959) The Whig Interpretation of History. Bell and Sons, London.

Burke, E. (1986) Reflections on the Revolution in France. Penguin, Harmondsworth.

Calder, A. (1969) The People's War. Cape, London.

Canovan, M. (1996) Nationalism and Political Theory. Edward Elgar, Cheltenham.

Castells, M. (1997) The Power of Identity. The Information Age: Economy, Society and Culture, Vol 11. Blackwell, Oxford.

Castells, M. (1992) 'Four Asian Tigers with a Dragon's Head: A Comparative Analysis of the State, Economy and Society in the Asian Pacific Rim.’ In R. Applebaum and J. Henderson (eds) States and Development in the Asia Pacific Rim, Sage, London.

Chan, H. C. (1993) 'Democracy: Evolution and Implementation: an Asian Perspective’ in: R. Bartley, H. C.

Chan, S. Huntington and S. Ogata (eds) Democracy and Capitalism: Asian and American Perspectives. Institute of SouthEast Asian Studies, Singapore, pp. 1-26.

Chan, J., To, H-P and Chan, E. (2006) 'Reconsidering Social Cohesion: Developing a Definition and Analytical Framework for Empirical Research,' Social Indicators Research, 75, pp. $273-3-2$.

Chang, H-J. (2007) Bad Samaritans: Rich Nations, Poor Policies and the Threat to the Developing World. Random House, London.

Coleman, J. (1988) 'Social Capital and the Creation of Human Capital', American Journal of Sociology, 94, Supplement, pp. S95-S120.

Commission on Integration and Cohesion (Chair: Darra Singh) (2007) Our Shared Future. Online:

http://collections.europarchive.org/tna/20080726153624/http://www.integrationandcohesion. org.uk/ /media/assets/www.integrationandcohesion.org.uk/our_shared_future\%20pdf.ashx, accessed 24 Aug 2009.

Confucius Publishing (n.d.) $\square$ 与全文 (Full Text of the Lun Yu) (rendered in modern Chinese with simplified characters). Online: http://www.confucius.org/lunyu/langz.htm, accessed 19 Nov 2008.

Conservative Party Group on National and International Security (CPGNIS) (2007) Uniting the Country: Interim Report on National Cohesion. Conservative Party, London.

Council of Europe (2004) A New Strategy for Social Cohesion. European Committee for Social Cohesion. Approved by Committee of Ministers of Council of Europe on $31^{\text {st }}$ March 2004. Council of Europe. 
Cramer, D. (2003) Advanced Quantitative Data Analysis. Open University Press, Maidenhead.

Crouch, C., Finegold, D. And Sato, M. (1999) Are Skills the Answer? Oxford University Press, Oxford.

Crouch, C. and Streeck, W. (2006) The Diversity of Democracy: Corporatism, Social Order and Political Conflict. Edward Elgar, Cheltenham.

Delanty, G. 2000 Citizenship in the Global Age: Culture, Society and Politics. Open University Press, Buckingham.

Delhy, J. and Newton, K. (2005) 'Predicting Cross-National Levels of Social Trust: Global Pattern or Nordic Exceptionalism?’ European Sociological Review, pp. 331-327

Denham, J. (2001) Building Cohesive Communities: A Report of the Ministerial Group on Public Order and Community Cohesion. Home Office, London.

Dore, R. (2002) Stock Market Capitalism Versus Welfare Capitalism. Oxford University Press, Oxford.

Dubet, F. (2007) Integration et Cohesion Sociale. Unpublished paper.

Durkheim, E. (1956) Education and Sociology, trans. S. D. Fox. The Free Press, New York.

Durkheim, E. (1964) The Division of Labour in Society. Translated by G. Simpson. The Free Press, New York.

Durkheim, E. (1982) The Rules of Sociological Method. Macmillan, London.

Eagleton., T. (1975) ‘Ideology and Literary Form,’ New Left Review, I, 90, pp. 81-109.

Esping-Andersen, G. (1985) Politics against Markets: The Social Democratic Road to Power, Princeton University Press, Princeton.

Esping-Andersen, G. (1990) The Three Worlds of Welfare Capitalism. Princeton University Press, New Jersey.

Esping-Andersen (1997) 'Hybrid or Unique: the Japanese Welfare State between Europe and America, Journal of European Social Policy, 7, pp. 179-189.

Esping-Andersen, G. (1999) Social Foundations of Post-Industrial Economies, Oxford University Press, Oxford.

Esping-Andersen, G. (2005) 'Inequality of Incomes and Opportunities' in A. Giddens and P. Diamond (eds) The New Egalitarianism. Polity Press, Cambridge.

Etzioni, A. (1993) The Spirit of Community. Crown Books, New York.

European Committee for Social Cohesion (2004) New Strategy for Social Cohesion Fukuyama. European Commission, Brussels.

F. (1999) The Great Disruption: Human Nature and the Reconstitution of Social Order. Profile Books, London.

Fraser, D. (1985) The Evolution of the British Welfare State. Macmillan, London.

Furoka, F. (2005) 'Japan and the 'Flying Geese' Pattern of East Asian Integration,' eastasia.at, 4(1). 
Gamble, A. (1981) Britain in Decline: Economic Policy, Political Strategy and the Modern State. Macmillan, Basingstoke.

Giddens, A. and Diamond, P. (2005) Introduction in A. Giddens and P. Diamond (eds) The New Egalitarianism. Polity Press, Cambridge.

Glazer, N. (1997) 'Diffusion of Values and the Pacific Rim' in J. D. Montgomery (ed.) Values in Education: Social Capital Formation in Asia and the Pacific, Hollis, Pacific Basin Research Centre, Soka University of America, pp. 49-69.

Glyn, A. (2007) Capitalism Unleashed: Finance, Globalisation and Welfare. Oxford University Press, Oxford.

Gough, I. and Olofsson, G. (1999) 'Introduction: New Thinking on Exclusion and Integration' in I. Gough and G. Oloffson (eds) (1999) Capitalism and Social Cohesion: Essays on Exclusion and Integration. Macmillan, Basingstoke.

Green, A. (1990) Education and State Formation: The Rise of Education Systems in England, France and the USA. Macmillan, London.

Green, A. (1999) 'East Asian Skills Formation Systems and the Challenge of Globalization,' Journal of Education and Work, 21 (3), pp.253-279.

Green, A. Preston, J. and Janmaat, G. (2006) Education, Equality and Social Cohesion. Palgrave, Basingstoke.

Greenfeld, L. (2003a) Nationalism: Five Roads to Modernity. Harvard University Press, Boston.

Greenfeld, L. (2003b) The Spirit of Capitalism: Nationalism and Economic Growth. Harvard University Press, Cambridge, Mass.

Gray, J. (2007) Black Mass: Apocalyptic Religion and the Death of Utopia. Allen Lane, London.

Hall, P. (1999) 'Social Capital in Britain.’ British Journal of Policy, 29, pp.417-461.

Hall, P. and Soskice, D. (eds) (2001) Varieties of Capitalism: The Institutional Foundations of Comparative Advantage, Oxford University Press, Oxford.

Halpern, D. (2005) Social Capital. Polity, Cambridge.

Hansen, C. (1991) 'Classical Chinese Ethics.' In P. Singer (ed) A Companion to Ethics. Basil Blackwell, Oxford, pp. 69-81.

Held, D. (1983) 'Introduction: Central Perspectives on the Modern State' in States and Societies' in D. Held et al. (eds) States and Societies. Oxford: Basil Blackwell.

Held, D. (1993) Political Theory and the Modern State. Polity Press, Cambridge.

Heydt, J.-M. (2003) Education for Democratic Citizenship and Social Cohesion: Background Study. Council of Europe, Strasbourg.

Hobsbawm, E. (1990) Nations and Nationalism since 1780: Programme, Myth and Reality. Cambridge University Press, Cambridge.

Hobsbawm, E. (1987) Age of Empire, 1875-1914, Weidenfeld and Nicholson, London. Huntington, S. (2004) Who Are We? America's Great Debate. Simon and Schuster, London. Hutton, W. (1995) The State We're In. Jonathan Cape, London. 
Hutton, W. (2002) The World We're In. Little, Brown, London.

ILO (2009). Laborsta Online Statistics. http://laborsta.ilo.org/STP/guest (accessed 25 April 2009)

Inglehart, R. (1990). Culture Shift in Advanced Industrial Society. Princeton University Press, Princeton, N.J.

Inglehart, R. (1997). Modernization and Postmodernization. Princeton University Press, Princeton, N.J.

Janmaat, J.G. and Braun, R. (2009) 'Diversity and Postmaterialism as Rival Perspectives in Accounting for Social Solidarity: Evidence from International Surveys', International Journal of Comparative Sociology, 50, pp 39-68.

Jenson, J. (1988) Mapping Social Cohesion: The State of Canadian Research. Canadian Policy Research Networks inc., Ottawa.

Jessop, B. (2002) The Future of the Capitalist State. Polity Press, Cambridge.

Johnson, C. (1982) MITI and the Japanese Miracle: The Growth of Industrial Policy, 19251975, Stanford University Press.

Johnson, R and Soroka, S (1999) 'Social Capital in a Multicultural Society: the Case of Canada', paper presented at the Annual Meeting of the Political Science Association, Sherbrooke QC.

Judt, T. (2005) Postwar: A History of Europe Since 1945. Heinemann, London.

Khan, Habibullah (2001) 'Social Policy in Singapore: A Confucian Model?' World Bank Institute, Washington. Online:

http://siteresources.worldbank.org/WBI/Resources/wbi37165.pdf [accessed 26 Nov 2008].

Kohn, H. (1976) The Age of Nationalism: The First Era of Global History. Greenwood Press, Connecticut.

Kohn, H. (2008) The Idea of Nationalism: A Study in its Origins and Background. Transaction Publishers, New Brunswick.

Knack, S. and Keefer, P. (1997) 'Does Social Capital Have an Economic Pay-off? A CrossCountry Investigation.' Quarterly Journal of Economics, CX11, pp.1251-1288.

Kuzio, T. (2002) 'The Myth of the Civic State: A Critical Survey of Hans Kohn's Framework for Understanding Nationalism,’ Ethnic and Racial Studies, 25, pp. 20-39.

Kwan, C. H. (2002) The Rise of China and Asia's Flying-Geese Pattern of Economic Development: An Empirical Analysis Based on US Import Statistics. RIETI Discussion Paper Series, 02-E-009, July 2002

Layard, R. (2005) Happiness: Lessons from a New Science. Penguin Books, London.

Leibfried, S. (1992) 'Towards a European Welfare State: On Integrating Poverty Regimes in the European Community', in Z. Ferge and J. E. Kolberg (eds.), Social Policy in a Changing Europe. Frankfurt: Campus Verlag, pp. 245-80.

Letki, N. (2006) 'Does Diversity Erode Social Cohesion? Social Capital and Race in British Neighbourhoods.' Unpublished paper, Nuffield College, Oxford.

List, F. (1885) The National System of Political Economy, trans Sampson Lloyd. Longmans, Green and Company, London. 
Locke, J. (1963) Two Treatises on Government. Cambridge University Press, Cambridge.

Lukes, S. (1973) Emile Durkheim. His Life and Work: A Historical and Critical Study. Penguin, Harmondsworth.

Macfarlane, A. (1978) The Origins of English Individualism. Springer, London.

Mann, M. (2005) The Dark side of Democracy: Explaining Ethnic Cleansing. Cambridge University Press, Cambridge.

Mason, G., Mayhew, K. and Osborne, M. (2008) 'Low-Paid Work in the United Kingdom.' In C. Lloyd, G. Mason and K. Mayhew (eds) Low-Wage Work in the United Kingdom. Russell Sage, London.

Marquand, D. (1988) The Unprincipled Society: New Demands and Old Politics. Jonathan Cape, London.

Marx, K. (1973) 'Contribution to the Critique of Hegel's Philosophy of Right' in Marx and Engels, Selected Works. Lawrence and Wishart, London.

Marx, K. and Engels, F. (1973) Selected Works, Lawrence and Wishart, London.

Max Plank Institut (1998) Bericht der Kommission Mittestimmung at www.mpi-fgkoeln.mpq.de/bericht/endbricht/anheng.htm

Mazower, D. (1999) Dark Continent: Europe’s Twentieth Century. Penguin Books, London.

Mill, J. S. (1985) 'Bentham' in Mill, J. S., Utilitarianism, edited by Warnock. M. Fontana, Glasgow, pp. 78-125.

Milliband, R. (1975) Parliamentary Socialism: A Study in the Politics of Labour. Merlin Press, London.

Miller, D. (1995) On Nationality. Clarendon Press, Oxford..

Ministerial Group on Public Order and Community Cohesion (2001) Building Cohesive Communities. Home Office, HMSO, London.

Montgomery, J. D. (1997) 'Are Asian Values Different?’ in J. D. Montgomery (ed) Values in Education:

Social Capital Formation in Asia and the Pacific, Hollis, Pacific Basin Research Centre, Soka University of America, pp. 29-47.

Moore, B. (1973) Social Origins of Dictatorship and Democracy. Penguin Books, Harmondsworth.

Nelson, R. (ed) (1993) National Innovation Systems: A Comparative Analysis. Oxford University Press, Oxford.

Nerthrong, J. H. and Berthrong, E. N. (2000) Confucianism: a Short Introduction. Oneworld, Oxford.

Newton, K. And Norris, P. (2000) 'Confidence in Public Institution: Faith Culture or Performance? In Pharr, S. J. and Putnam, R. (eds) Disaffected Democracies: What's Troubling the Trilateral Countries? Princeton University Press, Princeton.

Nickel, S. and Layard, R. (1998) Labour Market Institutions and Economic Performance. Centre for Economic Performance, LSE, London. 
Norris, P. (2001) Making Democracies work: Social Capital and Civic Engagement in 47 Societies.' KSG Faculty Working Paper, Harvard University, Boston.

Oakeshott, M. (1991) Rationalism in Politics and Other Essays and other Essays. Liberty Press, Indianapolis.

OECD (1997) Employment Outlook. OECD, Paris.

OECD (1999) Employment Outlook. OECD, Paris.

OECD (2007) Science Competences for Tomorrow's World, Volumes I and 2. OECD, Paris.

OECD (2009) StatExtracts. http://stats.oecd.org/Index.aspx\# (Accessed 25 April 2009)

Olson, M. (1971) The Logic of Collective Action. Harvard University Press, Cambridge Mass.

Osberg, L. (ed) (2003) The Economic Implications of Social Cohesion. Toronto University Press, Toronto.

Park, C.-M. and Lee, S. G. (2007) Are Associations the Schools of Democracy across Asia? Asian Barometer Project Office National Taiwan University and Academia Sinica. Available at $\quad$ http://www.asianbarometer.org/newenglish/publications/workingpapers/no.38.pdf, accessed on 17 Aug 2009.

Parsons, T. (1968) The Structure of Social Action. Free Press,

Perkin, H. (1996) Third Revolution: Professional Elites in the Modern World. Routledge, London.

Perkin, H. (1985) The Origins of Modern English Society. Routledge, London.

Polanyi, K. (1957) The Great Transformation. Beacon Press, Boston.

Putnam, R. (2000) Bowling Alone: The Collapse and Revival of American Community. Simon and Schuster, New York

Putnam, R (2007) 'E Pluribus Unum: Diversity and Community in the Twenty-First Century.’ Scandinavian Political Studies, 20, pp.139-174.

Regini, M. (1995) 'Firms and Institution: The Demand for Skills and their Social Production in Europe.’ European Journal of Industrial Relations, 1, 2, pp. 199-202.

Reich, R. (1991) The Work of Nations: A Blueprint for the Future. Simon and Schuster, London.

Reich, R. (2001) The Future of Success. Alfred A. Knopf, New York.

Rothstein, B. (2001) 'Social Capital in the Social Democratic Welfare State', Politics and Society, 29, p. 207.

Rousseau, J-J. (1983) The Social Contract and other Discourses. J. M. Dent and Sons, London.

Schuller, T., Baron, S. and Field, J. (2000) 'Social Capital: A Review and Critique' in S. Baron, J. Field and T. Schuller (eds), Social Capital: Critical Perspectives. Oxford University Press, Oxford, pp. 226-242.

Siddique, S. (2001) 'Social Cohesion and Social Conflict in SouthEast Asia' in Colletta, N. J., Lim, T. G., and Kelles-Viitanen, A. (eds) Social Conflict and Conflict Prevention in Asia, The World Bank, Washington, pp. $17-42$. 
Skocpol, T. (1979) States and Social Revolutions. Cambridge University Press, Cambridge, Mass.

Showronek, S. (1982) Building a New American Nation: The Expansion of American Administrative Capacities, 1877-1920. Cambridge University Press, Cambridge.

Smelser, N. (1976) Comparative Methods in the Social Sciences. Prentice Hall, New Jersey.

Smith, A. (1904) The Wealth of Nations, E. Cannan (ed). Book 1. Methuen, London.

Smith, A. D. (1995) Nations and Nationalism in the Global Era, Polity Press, Cambridge.

Sombart, W. (1976) Why is There No Socialism in the USA? Macmillan, London.

Wilkinson, R. and Pickett, K. (2009) The Spirit Level: Why More Equal Societies Always Do Much Better. Allen Lane, London.

Stiglitz, J. (2002) Globalisation and its Discontents. Norton, New York.

Stiglitz, J. (2004) The Roaring Nineties. Penguin Books, London.

Streeck, W. (1989) 'Skills and the Limits of Neo-Liberalism: The Enterprise of the Future as a Place of Learning,' Work, Employment and Society, 3, 1, pp.89-104.

Streeck, W. (1997) 'German Capitalism: Does it Exist? Can it Survive?' in New Political Economy, 2, 2, pp.237-256.

Taylor, A. J. (1972) Laissez-Faire and State Intervention in Nineteenth-Century Britain. Macmillan, London.

Taylor, A. J. P. (1978) The Course of German History. Methuen, London.

Taylor, C. (2005) Modern Social Imaginaries. Public Planet Books.

Thelen, K. (2004) How Institution Evolve: The Political Economy of Skills in Germany, Britain, the US and Japan. Cambridge University Press, Cambridge.

Tocqueville, A. de (1955) The Old Regime and the French Revolution, trans. Stuart Gilbert. Doubleday, New York.

Tocqueville, A. de (1956) Democracy in America. Signet, New York.

Touraine, A. (2000) Can We Live Together? Polity Press, Cambridge.

Tyack, D. (1974) The One Best System: A History of American Urban Education, Harvard University Press, Cambridge, Mass.

Tu, Wei-Ming (2000) 'Multiple Modernities: A Preliminary Inquiry into the Implication of East Asian Modernity’ in L. Harrison, and S. Huntington (eds) Culture Matters: How Values Shape Human Progress. Basic Books, New York, pp. 256- 267.

Ulsaner, E. (2002) The Moral Foundations of Trust. Paper for the Symposium, "Trust in the Knowledge Society,” University of Jyvaskyla, Jyvaskala, Finland, 20 September, 2002, Department of Government and Politics, University of Maryland.

Ulsaner, E. (2003) 'Trust, Democracy and Governance: Can Government Policies Influence Generalised Trust?' in M. Hooghe and D. Stolle (eds) Generating Social Capital: Civil Society and Institutions in Comparative Perspective, Palgrave, Basingstoke.

UN (2009a) Online Data on Population of Migrant Stock. http://esa.un.org/migration/index.asp?panel=2 (Accessed 26 April 2009). 
UN (2009b) United Nations Survey of Crime Trends and Operations of Criminal Justice System. http://www.unodc.org/pdf/crime/seventh_survey/7sc.pdf (Accessed 27 April 2009).

Wade, R. (1990) Governing the Market: Economic Theory and the Role of Government in East Asian Industrialisation, Princeton University Press, Princeton.

Waley, A. (2005a) The Analects of Confucius, translated and annotated by Arthur Waley. Allen and Unwin, London.

Waley, Arthur (2005b) 'Terms: The Analects of Confucius, translated and annotated by Arthur Waley. George Allen and Unwin, London, pp. 27-50.

Walker, A. and Wong, C. (2005) 'Introduction: East Asian Welfare Regimes.' In A. Walker and C. Wong (eds) East Asian Welfare Regimes in Transition: from Confucianism to Globalisation. Polity Press, Bristol, pp. 3 - 20.

Walzer, M. (1997) On Toleration. Yale University Press, London.

Wiborg, S. (2009) Education and Social Integration. Macmillan, Basingstoke.

White, G. and Goodman, R. (1998) 'Welfare Orientalism and the Search for an East Asian Welfare Model.' In R. Goodman, G. White and H-J Kwon (eds) The East Asian Welfare Model: Welfare Orientalism and the State. Routledge, London, pp. 4-24.

Wilkinson, R. (1996) Unhealthy Society: The Affluence of Inequality. Routledge, London.

Williams, R. (1961) The Long Revolution. Penguin, Harmondsworth.

Woo-Cumings, M. (1999) The Developmental State. Cornell University Press, London

World Bank (2005) World Development Report. Washington, DC: World Bank / Oxford University Press. 
For more information, please contact Jeremy Tayler: J.Tayler@ioe.ac.uk

LLAKES Centre Institute of Education 20 Bedford Way WC1H OAL London UK 
$\mathrm{E} \cdot \mathrm{S} \cdot \mathrm{R} \cdot \mathrm{C}$ ECONOMIC \& SOCIA L RESEARCH C OUNCIL 